SERVIÇO DE PÓS-GRADUAÇĀO DO ICMC-USP Data de Depósito: 20.02.2003

Assinatura: Whna rawe lamiraw ire/one-

\title{
Ambiente para exploração de regras
}

\author{
Marcos Ferreira de Paula \\ Orientadora: Prof $^{\mathrm{a}} \mathrm{Dr}^{\mathrm{a}}$ Solange Oliveira Rezende
}

Dissertação apresentada ao Instituto de Ciências Matemáticas e de Computação - ICMC/USP, como parte dos requisitos para obtenção do titulo de Mestre em Ciências de Computação e Matemática Computacional.

\author{
USP - São Carlos \\ Fevereiro de 2003
}

Trabalho realizado com apoio financeiro da CAPES 
A Comissão Julgadora:

Profa. Dra. Solange Oliveira Rezende Solounge Ohuarc Kejede

Profa. Dra. Maria Carolina Monard

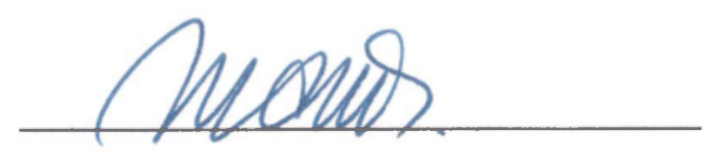

Prof. Dr Geber Lisboa Ramalho Glen h Kandho 
Este documento foi preparado com o formatador de textos LTYX. O sistema de citaçoes de referèncias bibliográficas utilizado foi o $\mathrm{BrBT}_{\mathrm{E}} \mathrm{X}$ padrāo Chicago. 


\section{Dedicatória}




\section{Agradecimentos}

A meus pais, Geraldo e Ana Rosa, e minha irmã Ligia pelo amor, carinho e respeito tão importantes para que pudesse realizar tudo que sempre desejei.

A professora Solange que foi mais que uma orientadora desde os trabalhos de Iniciaçào Cientifica, mas uma grande amiga que ofereceu incentivo, apoio. dedicaçāo c comprecnsão, tendo contribuido nāo somente nesse trabalho de mestrado mas também para meu crescimento pessoal.

À Talita por ser tão especial e por todo carinho, comprometimento, dedicação e ajuda em todos os momentos desde a época da graduaçāo.

A todos os meus "irmāos", Luis Carlos, Alex, Tereza, Luiz, Fernando, Léa, Walter, Robson. Cristiane, Jaqueline, Edson, Valmir, Daniel, Marcos Aurélio, Roberta, Camila, entre outros alunos e ex-alunos da "mamāe" Solange, que contribuiram na minha formaçāo desde a Iniciaçāo Cientificá, na elaboração deste trabalho, na redação final desta dissertaçāo e por todos os bons moneritos que passamos jumlos.

À professora Maria Carolina Monard e aos seus alunos Ronaldo e Gustavo por todas as discussōes, dicas e contribuiçōes para a realizaçāo deste trabalho.

A todos do IABIC pelos bons momentos e por fazer do laboratório um ambiente agradável, propicio para a realização de qualquer trabalho.

A todos os funcionários do 1CMC pelo respeito, dedicaçāo e educaçào.

À CAPES pelo apoio financeiro.

Por fim, a Deus por ter me dado condiçōes para cumprir mais uma etapa da minha vida. 


\section{Resumo}

Recentemente, o desenvolvimento das tecnologias de coleta e armazenamento de dados, a popularizaçāo da Internet, e a evoluçāo das necessidades de informaçāo fazem com que qualquer esforço para facilitar a manipulação e o entendimento humano em relação a esse grande leque de informaçōes ganhe grande importância. Nesse sentido, as organizaçōes tèm visto com crescente interesse o desenvolvimento de tecnologias automatizadas para extraçāo de conhecimento de grandes volumes de dados. Estas tecnologias têm sido referenciada na literatura como Extraçào de Conhecimento de Bases de Dados ou Mineração de Dados (MD)

Um dos objetivos do processo de Extração de Conhecimento de Bases de Dados ć que seus usuários finais possam analisar, compreender e utilizar o conhecimento extraído em um processo de tomada de decisão. Entretanto, do ponto de vista desses usuários, um problema encontrado no final do processo de Extração de Conhecimento é que muitos dos algoritmos utilizados geram uma cnorme quantidade de padrōes, dificultando consideravelmente sua anảlise. Outro problema freqüentemente identificado é a dificuldade na compreensāo dos modelos extraídos dos dados. Nesse sentido, diversos trabalhos têm sido descnvolvidos para apoiar os usuários na avaliaçāo e interpretação do conhecimento extraido a partir dos dados.

A existência de um Ambiente para Exploração de Regras em que as regras encontradas em um processo de Extração de Conhecimento estejam armazenadas, disponibilizadas aos usuários e que apresente diversos tipos de métodos para sua avaliação pode representar um auxílio efetivo para os usuários na compreensão, identificação das regras interessante e utilizaçāo das mesmas. Nesta dissertação, sāo apresentadas algumas caracteristicas importantes de um Ambiente para Exploraçào de Regras, uma arquitetura geral e a implementação de um ambiente deste tipo, o Ambiente RulEE. É também apresentado um estudo de caso realizado com objetivo de mostrar essas características na análise e disponibilização de regras extraidas a partir de um conjunto de dados financeiros. 


\section{Abstract}

Recently, the development of the data collection and storage technologies. the popularization of the Internet, and the evolution of the necessities of information give great importance to any effort to facilitate the manipulation and the human comprehension of this great amount of information. In this way, the organizations have seen, with increasing interest, the development of automatized technologies for knowledge extraction from great volumes of data. These technologies have been referenced in literature as Knowledge Discovery in Databases or Data Mining (DM).

One of the objectives of the Knowledge Discovery in Database process is to make its final users able to analyze. understand and use the knowledge in a decision making process. However, from the point of view of these users, a problem found in the end of the Knowledge Discovery process is that many of the used algorithms generate an enormous amount of pattcrns, making difficult its analysis. Another problem frequently identified is the difficulty to understand the models extracted from the data. In this way, several works have been developed to help the users in the evaluation and interpretation of the knowledge extracted from the data.

The existence of a Rule Exploration Environment where the rules found in a Knowledge Discovery in Databases process are stored, made available to the users and that presents several types of methods for its evaluation can represent an effective aid for the uscrs in the understanding, identification and use of the interesting rules. In this work, it is presented some important characteristics of a Rule Exploration Environment, a general architecture. and an implementation of an environment of this type, the RulEE environment. A case study is also presented showing these characteristics in the exploration of rules extracted from a financial data set. 


\section{Sumário}

Lista de Figuras $\quad$ v

Lista de Tabelas

1 Introduçāo 1

2 Visão Geral do Processo de Extraçāo de Conhecimento de Bases de Dados 5

2.1 Consideraçòes Iniciais . . . . . . . . . . . . . . . . 5

2.2 O Processo de Extraçào de Conhecimento de Bases de Dados . . . . . . 6

2.2.1 Conhecimento do Dominio e Identificação do Problema . . . . . . 7

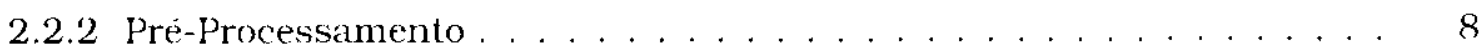

2.2 .3 Extração de Padrōes . . . . . . . . . . . . . . . . . 12

2.2 .4 Pós-Processamento . . . . . . . . . . . . . . . . . 15

2.3 Ferramentas de Mineração de Dados . . . . . . . . . . . . . . . . 16

2.3 .1 Protótipos de Pesquisa $\ldots \ldots \ldots \ldots \ldots$

2.3.2 Produtos Comerciais . . . . . . . . . . . . . . . . . 17

2.4 Consideraçōes finais $\ldots \ldots \ldots \ldots \ldots . \ldots \ldots$

3 Avaliaçāo de Regras

3.1 Consideraçooses Iniciais . . . . . . . . . . . . . . . . . . . . . 23

3.2 Interessabilidade de Regras . . . . . . . . . . . . . . . 24

3.3 Aspectos Objetivos para Avaliação de Regras . . . . . . . . . . . . 26

3.3 .1 Medidas de Surpresa . . . . . . . . . . . . . . . . . . . . 26

3.3 .2 Seleção de Regras não Redundantes . . . . . . . . . . . . . . 29

3.3.3 Medidas Derivadas da Tabela de Contingencia . . . . . . . . 30

3.3.4 Medida $R I$ (Rule-Interest) . . . . . . . . . . . . . . . . . 34 
3.4 Aspectos Subjetivos para Avaliaçào de Regras . . . . . . . . . . . . . . . . . . 34

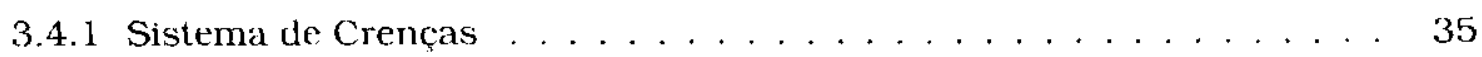

3.4 .2 Modelos de Regras . . . . . . . . . . . . . . . 36

$3.4 .3 \wedge$ plicativo $\Lambda \mathrm{I} \Lambda \mathrm{S} \ldots \ldots \ldots \ldots \ldots \ldots$

3.5 Sumário das Medidas Apresentadas . . . . . . . . . . . . . . . . 40

3.6 Consideracoos Finais $\ldots \ldots \ldots \ldots$. . . . . . . . . . . . . . . . 41

4 Ambiente para Exploração de Regras $\quad 43$

4.1 Consideraçòes Iniciais . . . . . . . . . . . . . . . . . . . . . . 43

4.2 O Ambiente Discover . . . . . . . . . . . . . . . . . 44

4.2.l Sintaxe Padrão para Representação de Dados . . . . . . . . . . . . 46

4.2.2 Sintaxe I’adrāo para Representaçāo de Regras de Classificação . . . . . 47

4.2.3 Sintaxe Padrão para Representaçāo de Regras de Regressāo . . . . . . 48

4.2.4 Sintaxe Padrão para Representação de Regras de Associação . . . . . . 48

4.3 Requisitos de um $\Lambda$ mbiente para Exploraçāo de Regras . . . . . . . . . . . . 49

4.4 O Ambiente RulEE . . . . . . . . . . . . . . . . . . . . . . . . . . . 54

4.4 .1 Descrição Geral ..................... 54

4.4 .2 Funcionalidades do Ambiente RulEE . . . . . . . . . . . . . . . 57

4.5 Consideraçōes Finais $\ldots \ldots \ldots$. . . . . . . . . . . . . . . . . . 57

5 Implementação do Ambiente RulEE

5.1 Consideraçoes Iniciais . . . . . . . . . . . . . . . . . . 61

5.2 Implementação . . . . . . . . . . . . . . . . . 61

5.2 .1 Informacoes Gerais . . . . . . . . . . . . . . . 66

5.2 .2 Implementaçāo da Base de Dados . . . . . . . . . . . . . 68

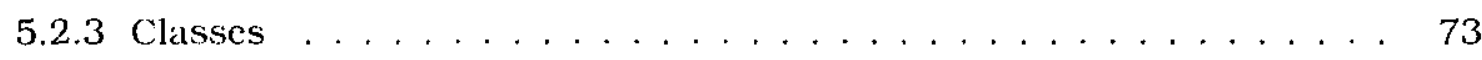

5.2 .4 Obtenção e Cálculo de Valores de Medidas . . . . . . . . . . . . . . 74

5.2 .5 Descriçāo da Interface . . . . . . . . . . . . . . . . . 78

5.2 .6 Utilizaçào de Consultas . . . . . . . . . . . . . . . . 89

5.3 Medidas Disponiveis . . . . . . . . . . . . . . . . . . . . . . . 92

5.4 Consideraçós Finais $\ldots \ldots \ldots \ldots$ 
6.1 Consideraçōes Iniciais . . . . . . . . . . . . . . . . . . . . . . . 95

6.2 A Extração de Regras em Dados Financeiros . . . . . . . . . . . . . . . . . . 95

6.2.1 Conhecimento do Dominio e Identificaçāo do Problema . . . . . . . . . 96

6.2 .2 Pré-Processamento . . . . . . . . . . . . . . . . 98

6.2 .3 Extração de Padrōes . . . . . . . . . . . . . . . . . 100

6.2 .4 Pôs-Processamento . . . . . . . . . . . . . . . . 101

6.3 Exploração das Regras Utilizando o RulEE . . . . . . . . . . . . . . . . . 101

6.3.1 Utilizaçào do Ambiente por Scripts . . . . . . . . . . . . . 101

6.3 .2 Utilizaçāo do Ambiente pela Interface . . . . . . . . . . . 104

6.4 Consideraçōes Finais . . . . . . . . . . . . . . . . . . . 109

7 Conclusões e Trabalhos Futuros $\quad 111$

Referências Bibliográficas 


\section{Lista de Figuras}

2.1 Etapas do Processo de Extraçāo de Conhecimento . . . . . . . . . . . . 7

4.1 Estrutura do Ambiente Discover . . . . . . . . . . . . . . . . . . . 44

4.2 Exemplo de Arquivo names na Sintaxe Padrāo . . . . . . . . . . . . . 46

4.3 Exemplo de Arquivo data na Sintaxe Padrão . . . . . . . . . . . . . . . 47

4.4 Exemplo de Arquivo de Regras de Classificação na Sintaxe Padrăo . . . . . . . 47

4.5 Exemplo de Arquivo de Regras de Regressão na Sintaxe Padrāo . . . . . . . 49

4.6 Exemplo de Arquivo de Regras de Associação na Sintaxe Padrāo . . . . . . . . 49

4.7 Metodologia para Obtenção de Regras nas Sintaxes Padrão . . . . . . . . . . 55

5.1 Arquitetura Geral do Ambiente RulEE . . . . . . . . . . . . . . . . . . 62

5.2 Diagrama Físico da Base de Dados do Ambiente RulEE . . . . . . . . . . . 72

5.3 Relacionamentos entre as Classes do Módulo de Gerenciamento . . . . . . . 74

5.4 Herança, Atributos e Métodos das Classes do Módulo de Gerenciamento . . . 75

5.5 Login no Ambiente . . . . . . . . . . . . . . . . . . . . . . . . 80

5.6 Meru Principal do Ambiente . . . . . . . . . . . . . . . . . . . . 80

5.7 Inserção de Conjuntos de Regras . . . . . . . . . . . . . . . . . 81

5.8 Listagem de Conjuntos de Regras . . . . . . . . . . . . . . . . . . . 81

5.9 Visualização de um Conjunto de Regras . . . . . . . . . . . . . . . . 83

5.10 Download ou Visualizaçāo do Arquivo de Regras Original . . . . . . . . . . 83

5.11 Inserção de um Novo Comentârio . . . . . . . . . . . . . . . . . . 84

5.12 Visualizaçāo de Informaçōes sobre uma Regra . . . . . . . . . . . . . . . . 84

5.13 Listagem de Consultas . . . . . . . . . . . . . . . . . . . . 85

5.14 Visualização de Consulta . . . . . . . . . . . . . . . . . . . 85

5.15 Arquivos de Descrição e de Dados Referentes à Consulta . . . . . . . . . 86

5.16 Ediçāo de Consultas - Modo Simples . . . . . . . . . . . . . . . . . . 87 
5.17 Edição de Consultas - Modo Avançado . . . . . . . . . . . . . . . . . 88

5.18 Listagem de Medidas . . . . . . . . . . . . . . . . . . 90

5.19 Informaçōes sobre Medidas . . . . . . . . . . . . . . . . . . . 90

6.1 Diagrama da Base de Dados Financeira . . . . . . . . . . . . . . 96

6.2 Exemplo de Script para Criação de Sessōes no Ambiente RulEE . . . . . . . 102

6.3 Execução do Script de Exemplo para Criação de Sessōes . . . . . . . . . . . 102

6.4 Exemplo de Script para Inserçào do Conjunto de Regras Extraido de Financi-

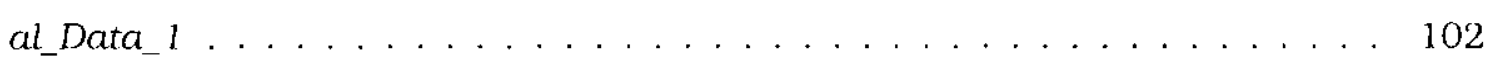

6.5 Resultado da Execução do Script de Exemplo para Inserção do Conjunto de

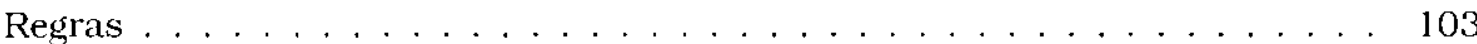

6.6 Exemplo de Script para Execuçāo de Consulta . . . . . . . . . . . 103

6.7 Resultado do Script de Exemplo para Execuçāo de Consulta . . . . . . . . . . 104

6.8 Tela para Inserção do Conjunto de Regras Extraido de Financial_Data_2 . . . 104

6.9 Regras que Classificam os Clientes como BAD ou GOOD . . . . . . . . . 106

6.10 Quantidade de Regras que Classificam como BAD e GOOD . . . . . . . . 106

6.11 Precisão das Regras . . . . . . . . . . . . . . . . . . . . . . 107

6.12 Precisāo Relativa . . . . . . . . . . . . . . . . . . . 107

6.13 Soma da Cobertura das 4 Regras com Maior Cobertura . . . . . . . . . . . 108

6.14 Valor da Medida Novidade para as Regras . . . . . . . . . . . . . . 109

6.15 Valor da Medida Especificidade para as Regras . . . . . . . . . . . . . . . . . 109 


\section{Lista de Tabelas}

2.1 Conjunto de Dados no Formato Atributo-Valor . . . . . . . . . . . . . . 9

3.1 Tabela de Contingència . . . . . . . . . . . . . . . . 31

3.2 Tabela de Contingència com Freqüências Relativas . . . . . . . . . . . . . . . . 31

3.3 Classificação das Medidas de Avaliaçào de Conhecimento . . . . . . . . . 40

4.1 Sintese de Funcionalidades de Ambientes para Análise de Regras . . . . . . 58

5. 1 Subdiretórios do Ambiente RulEE . . . . . . . . . . . . . . . . . . . . . 67

5.2 Descrição das Tabelas da Base de Dados do Ambiente RulEE . . . . . . . . . . 71

5.3 Descriçāo das Classes do Módulo de Gerenciamento . . . . . . . . . . . . 73

6.1 Descrição das Tabelas da Base de Dados Financeira . . . . . . . . . . . . . . . 97

6.2 Transformação de Valores de Atributos da Base de Dados Financeira . . . . 99

6.3 Novos Atributos da Base de Dados Financeira . . . . . . . . . . . . . . . . 99 


\section{Capítulo 1}

\section{Introdução}

O desenvolvimento da tecnologia para armazenamento de dados possibilitou às organizaçōes coletarcm e armazenarem informaçòes de diversas fontes a uma taxa alguns anos atrás considerada inimaginável. Em (7uffo 2002) é feita uma estimativa de quanta informa ção é produzida anualmente. Nesse trabalho, os pesquisadores estimaram que o volume de dados produzido anualmente está em torno de 1,5 exabyte (1,5 bilhāo de gigabytes), incluindo mídia impressa, filme c meios óptico e magnético. Desse total, 99,997\% está disponivel em meio digital. Em (Lyman \& Varian 2000) é destacado que a capacidade de armazenamento em meio magnético tem dobrado a cadá ano, permitindo que um volume de dados cada vez maior esteja disponivel.

Em uma economia cada vez mais competitiva, as organizaçōes têm tido uma maior preocupação em adquirir novas tecnologias para apoiar o entendimento das informaçōes e do conhecimento embutido em suas bases de dados. Os dados são vistos pelas organizaçōes como uma fonte potencial de informação valiosa que pode prover vantagem competitiva. Esses dados podem conter, por exemplo, um conhecimento extremamente importante com relação ao comportamento de seus clientes, fornecedores e mesmo dos concorrentes que. possivelmente, não poderia ser descoberto sem uma análise mais profunda dos mesmos.

O método tradicional de transformar dados em conhecimento é baseado em análise e interpretaçāo manual. Para muitas aplicaçōes, essa busca manual é cara, lenta e altamente subjetiva. Além disso, a busca manual tem se tornado impraticável nos domínios em que a quantidade de dados tem crescido exponencialmente (Monard, Caulkins, Baranauskas, Oliveira, \& Rezende 1999). Sem a existencia de ferramentas para explorar o volume crescente de dados. o armazenamento desses dados, apesar de sua potencial utilidade, pode se tornar inútil (Keim 2001). 
Tècnicas de análise de dados normalmente não extrapolam a realização de consultas SQL (Structured Query Language) simples, utilização de ferramentas OLAP (Online Analytical Processing) ou mecanismos de visualização de dados. Com essa forma de análise de dados, algumas questões importantes para tomada de decisão não podem ser expressas, como:

- Quais são os usuários potenciais para praticar fraude?

- Quais clientes gostariam de comprar o novo produto X?

Diante da deficiencia para analisar e compreender grandes volumes de dados, diversos estudos tèm sido direcionados ao desenvolvimento de tecnologias de extração automática de conhecimento de bases de dados. Este campo de pesquisa é chamado de Extraçāo de Conhecimento de Bases de Dados, normalmente referenciado na literatura como Mincração de Dados (MD).

O processo de Extraçāo de Conhecimento tem o objetivo de encontrar conhecimento a partir de um conjunto de dados para ser utilizado em um processo de tomada de decisão. Portanto, um requisito importante é que esse conhecimento descobcrto scja compreensivel, além de útil c interessante para os usuários finais do processo. fornecendo a esses usuários apoio no processo de tomada de decisão.

Inicialmente. muitos estudos sobre o processo de Extraçāo de Conhecimento estiveram focados na etapa de Extração de Padrões. Entretanto, o desenvolvimento da tecnologia e sua utilização para resolver problemas reais tornou claro que a Extraçāo de Padrões não c o ponto final do processo. Desta mancira. diversos trabalhos têm sido desenvolvidos no sentido de analisar ou processar o conhecimento extraido com objetivo de auxiliar o usuário na sua interpretação e utilização.

Do ponto de vista do usuário, um dos problemas encontrados no final do processo de Extração de Conhecimento é que muitos dos algoritmos de extração geram uma enorme quantidade de padrōes (Padmanabhan \& Tuzhilin 2000). Por exemplo, algoritmos de extração de regras de associação geralmente produzem milhares ou dezenas de milhares de regras, especialmente quando os atributos da base de dados são altamente correlacionados. Assim. maior atenção têm sido direcionada a apoiar os usuários na identificação do conhecimento interessante (Liu, Isu, \& Ma 2001: Liu, Hsu, \& Ma 1999; Javrac, Flach, \& Zupan 1999: Klemettinen, Mannila. \& Toivonen 1997; Silberschat \& Tuzhilin 1996; Piatetsky-Shapiro \& Matheus 1994). 
Um outro problema identificado é a dificuldade na compreensāo dos modelos extraídos dos dados. Muitas vezes. esses modelos podem ser muito complexos ou nāo fazerem sentido para os usuários especialistas no dominio da aplicaçāo em que processo de Extraçào de Conhecimento está sendo aplicado (Pazzani. Mani, \& Shankle 1997).

Dada a necessidade de se pesquisar técnicas para auxiliar o usuário na compreensão e utilização do conhecimento descobcrto em um processo de Extração de Conhecimento, o objetivo principal deste projeto de mestrado é a proposta e implementaçāo de um Ambiente para Exploração de Regras (RulEE - Rule Exploration Environment) que apresente caracteristicas de apoio ao usuário ná compreensâo e identificaçào do conhecimento interessante.

Uma caracteristica importante para o Ambiente RulEE é facilitar o acesso ao conhecimento descoberto. Isto é feito por uma interface de disponibilizaçāo do conhecimento baseada na WWW (World Wide Web). Dessa maneira, algumas características importantes da WWW são incorporadas ao ambiente, como a independência de plataforma, facilidade de utilização pelos usuários independente de sua localização fisica e da ferramenta de extraçāo, além da utilizaçāo de toda uma infra-estrutura de rede existente.

Uma vez que o conhecimento descoberto tenha sido armazenado no ambiente, pode-se disponibilizar ao usuário não somente as regras. mas também métodos para que cle possa avaliá-las. O Ambiente RulEE apresenta um conjunto de medidas de avaliaçāo que pode ser utilizado pelo usuário para ordenaçāo e seleçāo de regras para auxiliā-lo na identificação do conhecimento mais interessante. O Ambiente RulEE apresenta também uma modelagem que visa facilitar a incorporaçăo de novas medidas de avaliação pelos pesquisadores, sem necessidade de alteraçāo do código fonte do ambiente. Desta maneira, o ambiente auxilia os pesquisadores na realização de cxperimentos com relação a novas medidas de avaliação.

A arquitetura proposta e implementada do Ambiente para Exploração de Regras é composta por: um Repositôrio de Regras e Medidas, em que são armazenadas as regras e os respectivos valores das medidas disponibilizadas; um Repositório de Dados, em que sāo armazenados os dados utilizados na extração e teste dos conjuntos de regras; um Repositório de Informação de Usuários, contendo os dados referentes aos usuários do ambiente: um Módulo de Gerenciamento, no qual estāo implementadas todas as funçōes disponiveis no ambiente; um conjunto de Módulos de Pós-Processamento. que possui os métodos in dependentes do ambiente para o cálculo dos valores de algumas medidas; e a Interface, baseada na WWW, para disponibilização do conhecimento. 
l’ara apresentar a revisāo bibliográfica e o $\Lambda$ mbiente RulEE, esta dissertaçāo está organixada como segue:

No Capitulo 2 é descrito de forma geral o processo de Extraçāo de Conhecimento de Bases de Dados, apresentando as etapas que o compoem e algumas ferramentas disponiveis no mercado para descoberta de conhecimento.

No Capítulo 3 são apresentados alguns aspectos sobre avaliação de regras no processo de Extração de Conhecimento, detalhando algumas medidas objetivas e subjetivas de avaliaçào.

No Capitulo 4 são apresentados de maneira geral os requisitos de um Ambiente para Exploração de Regras c o Ambiente Discover, que é um projeto de maior porte ao qual o Ambiente RulEE está integrado.

No Capitulo 5 é detalhada a implementação do Ambiente RulEE, apresentando sua arquitetura geral, a base de dados que contćm o conhecimento, a biblioteca de classes e a interface.

No Capítulo 6 é apresentado um estudo de caso desenvolvido no domínio de dados financeiros cujo objetivo foi mostrar a viabilidade do Ambiente RulEE na análise das regras descobertas em um processo de Mineraçāo de Dados.

No Capitulo 7 sāo apresentadas as conclusões deste trabalho e. finalizando, as Referēncias Bibliogräficas. 


\section{Capitulo 2}

\section{Visão Geral do Processo de Extração de Conhecimento de Bases de Dados}

\subsection{Considerações Iniciais}

Os métodos tradicionais de análise de dados têm se tornado impraticáveis com o aumento do volume de dados disponiveis. O processo de Extração de Conhecimento de Bases de Dados se apresenta como uma tecnologia que automatiza a análise de grandes volumes de dados buscando conhecimento e tem sido visto com elevado interesse pelas organizaçōes.

Apesar de automatizar a análise de dados, o processo de Extração de Conhecimento de Bases de Dados é bastante complexo, envolvendo a execução de diversas etapas, iteração entre cssas etapas e interação com os usuários. Além disso, o processo de Extração de Conhecimento é uma área multidisciplinar, envolvendo campos de pesquisa como Base de Dados, Aprendizado de Máquina (AM), Reconhecimento de Padrōes, Estatística, Visualizaçāo de Dados. Dessa mancira, nảo se pode esperar a descoberta de conhecimcnto útil apenas submetendo um conjunto de dados a uma caixa preta.

Neste capítulo ć apresentado de maneira geral o processo de Extraçāo de Conhecimento de Bases de Dados, descrevendo suas etapas e algumas ferramentas disponiveis no mer cado para apoio a este processo. 


\subsection{O Processo de Extração de Conhecimento de Bases de Dados}

O processo de Extraçāo de Conhecimento de Bases de Dados foi definido em (Fayyad, Piatetsky-Shapiro, \& Smyth 1996) como: "Processo de identificar padröes nos dados que sejam válidos, novos, potencialmente úteis e compreensíveis a seres humanos". A Extraçāo de Conhecimento é definida como sendo um processo pois cnvolve a exccuçào de diversas etapas. O conhecimento extraído dos dados deve ser válido para um novo conjunto de dados com um ccrto grau de certeza, além de ser compreensivel, pelo menos após algum Pós-processamento, para que possa ser utilizado por seres humanos, e trazer algo de novo para cles, sendo portanto, potencialmente uitil.

Existem diversas abordagens para a divisão das etapas do processo de Extração de Conhecimento. Inicialmente, foi proposta em (Fayyad, Piatetsky-Shapiro, \& Smyth 1996) uma divisão do processo em nove etapas. Já em (Weiss \& Indurkhya 1998), essa divisāo é composta por apenas quatro ctapas. No cntanto. neste trabalho, assim como delinido cm (Baranauskas 2001), considera-se a divisão do processo em três grandes etapas: Préprocessamento, Extração de Padrōes e Pós-processamento. Nesta divisão, foram incluídas uma ctapa anterior à execução do processo, correspondente ao conhecimento do domínio e identificaçāo do problema, c uma ctapa posterior, correspondente à utilização do conhecimento obtido. Essas etapas estāo ilustradas na Figura 2.1.

Um aspecto importante a ser observado na figura é que a Extração de Conhecimento de Bases de Dados è um processo iterativo, envolvendo experimentação, iteraçāo entre suas fases c muitas decisōes $\mathrm{c}$ adaptaçōes, de forma a ajustar o processo para o melhor desempenho ou outras caracteristicas desejáveis, como, por exemplo, simplicidade da solução. Além disso, a Extraçāo de Conhecimento é um processo centrado na interação entre usuários, c o sucesso do mesmo depende, cm parte, da interação entre as diversas classes de usuários. Os usuários do processo são normalmente divididos em três classes (Rocha 1999):

Especialista do dominio Usuário que deve possuir amplo conhecimento do domínio da aplicaçào e deve fornecer apoio para a execução do processo:

Analista Usuário especialista no processo de Extraçāo de Conhecimento e responsável por sua exccução. Este usuário deve conhecer profundamente as etapas que compõem o processo: 


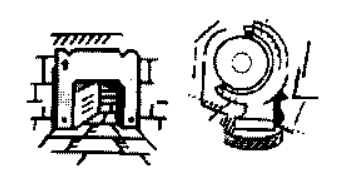

Pré-processamento

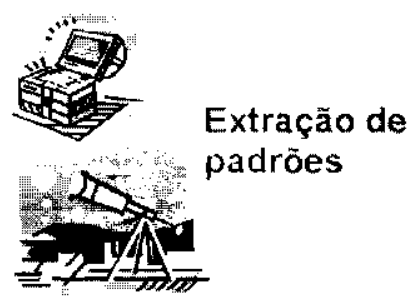

Identificação

do problema

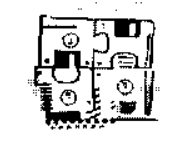

Pós-processamento

Figura 2. 1: Etapas do Processo de Extração de Conhecimento (Rezende, Pugliesi, Melanda. \& Paula 2003)

Usuário final Representa a classe de usuário que utiliza o conhecimento extraído no processo para auxiliá-lo em um processo de tomada de decisão. Não é necessário que esse usuário possua confecimento profundo do dominio da aplicação.

Vale ressaltar que pode haver situaçōes em que o especialista do domínio também é o usuário final. ou que este auxilie ou execute funçōes pertinentes ao analista. Entretanto, é pouco provável que o analista encontre conhecimento útil a partir dos dados sem o aval do especialista sobre o que seria interessante para um dominio especifico (Rocha 1999).

Nas próximas seçōes sāo descritas as etapas que compōem o processo de Extração de Conhecimento.

\subsubsection{Conhecimento do Dominio e Identificação do Problema}

O sucesso do processo de Extraçāo de Conhecimento depende, em parte, da participação dos especialistas do dominio da aplicaçào em fornecerem um conhecimento sobre o domi- 
nio e apoiar os analistas em sua tarefa de encontrar os padrões. Dessa maneira, antes do inicio das tarefas do processo é importante a realização de um estudo a fim de se adquirir um conhecimento inicial do dominio.

Algumas questōes importantes devem ser respondidas nesta fase de aquisição de conhecimento do dominio (Fayyad 1996), como:

- Quais sāo as principais metas do processo?

- Quais critérios de performance são importantes?

- O conhecimento extraido deve ser compreensivel a seres humanos ou um modelo do tipo caixa preta é apropriado?

- Qual deve ser a relaçāo entre simplicidade e precisāo do conhecimento extraido?

Além dessa análise inicial para definição das principais metas e restriçócs, o conhecimento sobre o dominio fornece um subsidio para todas as etapas do processo de Extração de Conhecimento (Baranauskas \& Monard 2000: Baranauskas 2001). Mais especificamente, na etapa de Pré-processamento. esse conhecimento pode ajudar os analistas na escolha do melhor conjunto de dados para se realizar a Extraçào de Padrōes, saber quais valores são válidos para os atributos, critérios de preferência entre os possiveis atributos, restriçòes de relacionamento ou informaçôes para geração de novos atributos.

Na etapa de Extração de Padrões. o conhecimento sobre o domínio pode ajudar os analistas na escolha de um critério de preferencia entre os modelos gerados, no ajuste dos parâmetros do processo de indução, ou mesmo na geraçào de um conhecimento inicial a ser fornecido como cntrada do algoritmo de Mineraçāo de Dados para aumentar a eficiència no aprendizado dos conceitos, melhorar a precisão ou compreensibilidade do modclo final.

Na etapa de Pós-processamento, o conhecimento extraído pelos algoritmos de extração de padrōes deve ser avaliado. Alguns critérios de avaliaçāo utilizam o conhecimento do especialista para saber. por exemplo, se o conhecimento extraido é interessante ao usuário (Liu \& Hsu 1996: Piatetsky-Shapiro \& Matheus 1994).

\subsubsection{Pré-Processamento}

Normalmente. os dados disponiveis para análise nāo estāo em um formato adequado para a Exxtração de Conhecimento. Além disso, devido a limitaçóes de memória ou tempo de processamento, muitas vezes não é possivel a aplicação direta dos algoritmos de extração de padrōes sobre os dados. Desta maneira, torna-se necessária a aplicação de métodos 
para tratamento, limpeza e redução do volume de dados antes de se iniciar a etapa de Extração de Padrōes. É importante salientar que a execuçāo das transformaçōes deve ser guiada pelos objetivos do processo de extração a fin de que o conjunto de dados gerado apresente as caracteristicas necessárias para que eles sejam cumpridos.

Diversas transformaçōes nos dados podem ser executadas na etapa de Pré-processamento, dentre elas:

Extração e Integração Os dados disponiveis podem ser encontrados em diferentes fontes, como arquivos texto, arquivos no formato MS EXCEL, base de dados ou Data Warehouse. Dessa maneira, é necessária a extraçāo desses dados e sua integraçāo. formando uma única fonte de dados no formato atributo-valor, como ilustrado na Tabela 2.1. Esses dados no formato atributo-valor serāo utilizados como entrada do algoritmo de extraçāo de padröes.

A Tabela 2.1 representa um conjunto de dados com $n$ exemplos de $k$ atributos. Uma linha $E_{i}$ representa o $i$-ésimo exemplo $(i=1,2, \ldots, n)$ e uma coluna $A_{j}$ representa o $j$-ésimo atributo $(j=1,2, \ldots, k)$. Um valor $n_{i, j}$ corresponde ao valor do atributo $A_{j}$ do exemplo $E_{i}$. A coluna $C$ é um atributo especial, denominado classe ou meta. $O$ valor desse atributo deve ser predito para novos exemplos pelo modelo encontrado, caso se esteja realizando uma tarefa de predição. Dependendo da funçāo escolhida no processo de extraçāo, nāo é necessária a existência desse atributo mela. Mais detalhes sobre a função desejada pela solução a ser encontrada e sobre o atributo especial $C$ são encontrados na Seção 2.2.3.

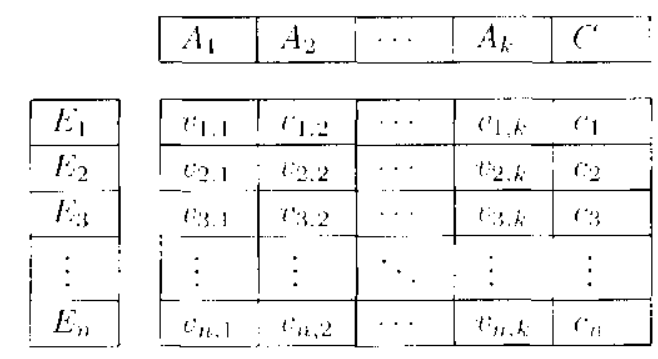

Tabela 2.1: Conjunto de Dados no Formato Atributo-Valor

Transformação Após a extraçāo e integração dos dados, estes devem ser adequados para serem utilizados pelos algoritmos de extraçāo de padrōes. Algumas transformaçōes comuns que podem ser aplicadas aos dados são resumo, por exemplo quando dados sobre vendas sāo agrupados para formar resumos diários, transformação de tipo, por exemplo quando um atributo do tipo data é transformado em um outro tipo para 
que o algoritmo de extraçāo de padrōes possa utilizá-lo de forma mais adequada, e normalização de atributos continuos, colocando seus valores em intervalos definidos como, por exemplo, entre o e 1 .

Limpeza Os dados disponiveis para aplicação dos algoritmos de extração de padrōes podem apresentar problemas advindos do processo de colcta. Estes problemas podem corresponder a erros de digitação ou erros na leitura dos dados por sensores. Como o resultado do processo de extração possivclmentc será utilizado em um processo de tomada de decisão, a qualidade dos dados é um fator extremamente importante. Desta maneira. técnicas de limpeza devem ser aplicadas aos dados a lim de garantir sua qualidade.

$\Lambda$ limpeza dos dados pode ser realizada utilizando o conhecimento do dominio. Por exemplo, pode-se encontrar registros com valor inválido em algum atributo. Podese também efetuar limpeza independente de dominio, como decisão da estratégia de tratamento de atributos incompletos, remoçāo de ruido ou tratamento de conjunto de cxemplos nāo balanceados (Batista, Carvalho, \& Monard 2000).

Redução de Dados Devido a restrições de espaço em memória ou tempo de processamento, o número de exemplos e de atributos disponiveis para anàlise pode inviabilizar a utilizaçāo de algoritmos de extração de padrões. Como solução para esse problema. pode ser necessária a aplicaçāo de métodos para reduçào dos dados antes de sc iniciar a busca pelos padrōes. Esta reduçāo pode ser feita de três maneiras (Weiss \& Indurkhya 1998):

- Redução do número de exemplos:

- Redução do número de atributos;

- Redução do número de valores de um atributo.

$\Lambda$ reduçào do numero de exemplos deve ser feita de forma a manter as caracteristicas do conjunto de dados original, isto é, através da geração de amostras representativas dos dados (Glymour, Madigan, Pregibon. \& Smyth 1997). $\Lambda$ principal abordagem para rcduçāo do número de exemplos é realizar amostragem aleatória (Weiss \& lndurkhya 1998), pois este método tende a produzir amostras representativas.

É importante salientar que se a amostra nâo for representativa. ou sc a quantidade de excmplos for insuliciente para caracterizar os padroes embutidos nos dados, os 
modelos encontrados podem não representar o comportamento dos dados originais, nào tendo, portanto, valor

A redução do número de atributos também pode ser utilizada como forma de se reduzir o espaço de busca pela soluçào. O objetivo é selecionar um subconjunto dos atributos existentes de forma que isto não tenha grande impacto na qualidade da so. luçāo final. Essta redução pode ser realizada com o apoio do especialista do domínio. uma vez que ao se remover um atributo potencialmente útil para o modelo final, a qualidade do conhecimento extraído pode diminuir consideravelmente. Além disso, por nāo se saber inicialmente quais atributos serāo importantes para atingir os objetivos, deve-se remover somente aqueles atributos que sabe-sc com certeza nāo ter nenhuma importância para o modelo final.

Também conı forma de reduçào do número de atributos, pode-se utilizar indução construtiva, em que um novo atributo é criado a partir do valor de outros. Caso os atributos originais utilizados na construçāo do novo atributo nāo estejam presentes em um novo modelo, eles podem ser descartados, reduzindo assim o número de atributos. A utilizaçāo de indução construtiva pode aumentar consideravelmente a qualidade do conhecimento extraído (Lee 2000)

A terceira forma de reduçāo dos dados consiste na redução do número de valores de um atributo. Isso é feito, normalmente, por discretizaçāo ou suavização dos valores de um atributo continuo.

Discretização de um atributo consiste na substituição de um atributo continuo (inteiro ou real) por um atributo discreto pelo agrupamento de seus valores. Em essência, um algoritmo de discretização aceita como entrada os valores de um atributo continuo e gera como saida uma pequena lista de intervalos ordenados. Cada intervalo é repre-

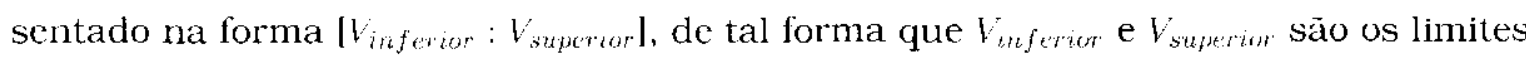
inferiores e superiores do intervalo. Os métodos de discretização podem ser classificados em supcrvisionados ou nāo supervisionados, locais ou globais, e parametrizados ou não parametrizados (Félix, Rezende, Monard, \& Caulkins 2000).

Na suavização dos valores de um atributo. o objctivo é diminuir o número de valores do mesmo sem discretizá-lo. Nesse método. os valores de um determinado atributo são agrupados, mas ao contrário da discretização, cada grupo de valores è substituido por um valor numérico que o represente. Esse novo valor pode ser a média, a mediana ou mesmo os valores de borda de cada grupo (Weiss \& Indurkhya 1998). 
A aplicação das transformações apresentadas nesta seção deve ser realizada de forma bastante cuidadosa. E importante garantir que as informaçōes presentes nos dados brutos continuem presentes nas amostras geradas de forma que os modelos finais representem a realidade expressa nos dados brutos.

A etapa de Pré-processamento é realizada antes da Extração de Padrōes. Mas, como o processo de Extração de Conhecimento é iterativo, algumas atividades de Pré-processamento podem ser realizadas novamente ao se analisar os padrōes encontrados na etapa de Extração de Padrōes. Por exemplo, pode-se desejar acrescentar algum atributo, reduzir ou aumentar o volume de dados. fazer uma outra transformação no tipo de algum atributo. a fim de que o indutor possa utilizá-lo de forma mais eficiente e melhorar a qualidade do conhecimento extraido.

\subsubsection{Extração de Padrōes}

O processo de Extraçāo de Conhecimento è direcionado a cumprir um determinado objetivo. A definição desse objetivo depende das necessidades dos usuários finais do processo e da disponibilidade de dados. Com esses objetivos e os dados preparados, a etapa de Extraçāo de Padrōes trata da escolha. configuraçāo e execução de um ou mais algoritmos visando cumprir os objetivos determinados.

Por ser um processo iterativo, esta etapa do processo de Extraçāo de Conhecimento pode ser executada diversas vezes para ajustar todos os parâmetros a fim de se obter um resultado mais adequado aos objetivos, como por exemplo, quanto à precisão ou compreensibilidade do conhecimento extraido.

Esta etapa pode ser subdividida em três sub-etapas (Fayyad. Piatetsky-Shapiro, \& Smyth 1996; Félix 1998):

Escolha da função A escolha da funçāo é feita de acordo com os objetivos desejáveis para a solução a ser encontrada pelo algoritmo. As funções possiveis de um algoritmo de extração de padrōes podem ser agrupadas em duas grandes categorias: predição e descriçào.

Funçōes relacionadas à predição, ou Mineraçāo de Dados preditivo, consistem na gencralizaçāo de cxemplos com suas respectivas classes conhecidas em uma linguagem capaz de reconhecer a classe de um novo exemplo. Os dois principais tipos de problemas de predição são classificação e regressão. I’roblemas de classificação consistem na predicão de um valor categórico como. por exemplo, predizer se o cliente é bom ou mau pagador. Nos problemas de regressão, o atributo a ser predito consistc em 
um valor contínuo como, por exemplo, predizer o lucro em um empréstimo (Weiss \& Indurkhya 1998).

Funçōes relacionadas à descrição, ou Mineração de Dados descritivo, consistem na identificação de comportamentos no conjunto de dados, sendo que estes dados nāo possuem um atributo-meta cspecificado, como acontcce na prediçāo. Alguns dos problemas de descrição sāo a geração de clusters, geraçāo de regras de associaçāo e sumarização.

Escolha do Algoritmo Com a função desejada escolhida, existe uma variedade de algoritmos para realizá-la. Nesta etapa deve ser escolhido o algoritmo a ser utilizado. bem como a configuraçà̃o de seus paràmetros.

A escolha do algoritmo está relacionada com a linguagem de representaçāo dos padrōes encontrados. Por exemplo, se o objetivo é realizar uma classificação, tem-se a possibilidade de utilizar algoritmos indutores de árvores de decisão, regras de produção, entre outros. Tipos de representaçōes comuns sāo: árvores de decisāo. regras. modelos lineares. modelos não lineares (Redes Neurais), modelos baseados cm exemplos (KNN - K-Nearest Neighbour, Raciocinio Baseado em Casos) e modelos de dependência probabilistica (Redes Bayesianas).

Um aspccto que merece atenção é a complexidade da solução encontrada pelo algoritmo de extração. A complexidade da solução está diretamente relacionada com a capacidade de representaçāo do conceito embutido nos dados. O problema é que quando os parâmetros do algoritmo estāo ajustados para cncontrar soluçōes mais complexas que o conceito efetivamente existente nos dados, o modelo resultante poderá ter uma precisāo boa para o conjunto de treinamento, mas um desempenho ruim para novos exemplos. Diz-se entào que o modclo é específico para o conjunto de treinamento, ou seja, é pouco genérico. Neste caso, ocorreu overfitting.

Por outro lado, se a complexidade da solução que está sendo buscada não for suliciente para adequar o conceito representado nos dados, por exemplo, ao se definir um número insuficiente de neurônios para uma Rede Neural ou um fator de poda muito alto na geraçāo de uma Árvore de Decisāo, pode-se não conseguir induzir um modelo representativo (Baranauskas \& Monard 2000). Isto é o que se chama de underfitting. Neste caso, o modelo encontrado pode nāo ter uma boa performance lanto nos exemplos disponíveis para o treinamento quanto para novos exemplos. 
Desta maneira. a configuração dos parâmetros do algoritmo deve ser feita de forma bastante cuidadosa. Em (Kearns \& Vazirani 1994) é sugerido que, na escolha de uma determinada solução, o modelo mais apropriado é aquele mais simples que scja consistente com todas as observaçōes.

Em (Kohavi, Sommerfield, \& Dougherty 1997) é mostrado experimentalmente que não existe um único bom algoritmo para todas as tarefas. Dessa maneira, a escolha de vários algoritmos para realizar a tarefa desejada pode ser feita. Isto levaria à obtençāo de diversos modelos que, na etapa de Pós-processamento, seriam tratados a fim de fornecer o conjunto de padrōes mais adequado para o usuário final.

Extração de Padrões A etapa de Extração de Padrōes do processo de Extração de Conhecimento de Bases de Dados consiste na aplicação dos algoritmos de mineraçào escolhidos para a extraçāo dos padrōes embutidos nos dados. É importante ressaltar que, geralmente, essa etapa consiste de diversas execuçōes dos algoritmos de cxtraçāo de padrōes.

Técnicas de combinaçāo de preditores têm sido pesquisadas com o objetivo de construir um preditor mais preciso pela combinação de vários outros. O resultado dessa combinação é chamado de ensemble. A utilização de ensembles tem obtido melhores resultados que a utilização de um único preditor (Dietterich 2000: Breiman 2000).

Um outro aspecto importante é o fato de que. com o objetivo de se fazer uma avaliação mais precisa da taxa de erro de um classificador, métodos de resampling têm sido normalmente utilizados na Extração de Padrões. Resampling consiste na realizaçāo de vários expcrimentos cm que o classificador é trcinado c testado com diferentes conjuntos de treinamento e teste disjuntos. Como resultado de cada um desses experimentos. é obtida uma taxa de erro. A média dessas taxas de crro é considerada uma boa aproximaçào para a taxa de erro do classificador para exemplos futuros.

Em um dos métodos de resampling, $k$-fold cross-validation, o conjunto de exemplos é dividido em $k$ partiçōes mutuamente exclusivas. Em cada iteração do método, $k-1$ partiçōes sāo fornecidas ao algoritmo de aprendizado e a restante è utilizada para calcular a laxa de erro da iteração. $\Lambda$ taxa de erro final estimada pelo método é a média das taxas de erro de cada uma das $k$ iteraçōes.

Após a etapa de Extraçāo de Padrões. o conjunto de padrões descoberto deve ser analisado ou processado na etapa de Pós-processamento para ser entāo fornecido ao usuário. 


\subsubsection{Pós-Processamento}

O processo de Extração de Conhecimento de Bases de Dados não termina após a descoberta dos padrōes existentes nos dados. Uma vez que o conhecimento extraido tem sido utilizado para resolver problemas da vida real, sendo utilizado $\mathrm{em}$ um sistema inteligente ou por um ser humano em um processo de tomada de decisão, concorda-se que a obtenção do conhecimento não é o passo final do processo. Além disso, o fato de se utilizar técnicas de Extração de Conhecimento de Bases de Dados não significa que os usuários náo possuem nenhum conhecimento prévio sobre os dados. Portanto, é importante que algumas questōes sejam respondidas aos usuários (Liu \& Hsu 1996):

- O conhecimento extraido representa o conhecimento do especialista?

- De que maneira o conhecimento do especialista difere do conhecimento extraido?

- Em que parte o conhecimento do especialista está correto?

Outro aspecto importante é que os algoritmos de extração de padrōes podem gerar uma quantidade enorme de padrōes, muitos dos quais podem näo ser importantes, relevantes ou interessantes para o usuário, o que pode tornar inviável a tarefa realizada pelos usuá rios de encontrar o conhecimento interessante. Dessa maneira, muitos estudos têm sido direcionados ao desenvolvimento de técnicas para apoiar os usuários na selecão dos padrōes mais interessantes (Silberschatz \& Tuzhilin 1995). Uma descriçāo mais detalhada do problema da interessabilidade do conhecimento extraido é apresentada na Seçào 3.2.

Um dos objetivos principais do processo de Extração de Conhecimento é que o usuário possa compreender e utilizar o conhecimento descoberto. Entretanto, podem ocorrer casos em que os modelos são muito complexos ou nảo fazem sentido para os especialistas (Pazzani 2000; Pazzani. Mani, \& Shankle 1997). Assim, a compreensibilidade do conhecimento extraido é um outro aspecto bastante importante para o processo de Extraçāo de Conhecimento de Bases de Dados.

$\Lambda$ compreensibilidade de um dado conjunto de regras está relacionada com a facilidade de interpretação dessas regras por um ser humano. A compreensibilidade de um modelo pode ser estimada, por exemplo. pelo número de regras e o número de condiçoes por regra Nesse caso, quanto menor a quantidade de regras de um dado modelo e menor o número de condiçōes por regra, maior será a compreensibilidade das regras descobertas (Fertig. Freitas, Arruda, \& Kaestner 1999). Em (Pazzani 2000; Pazzani, Mani, \& Shankle 1997) é discutido que outros fatores, além do tamanho do modelo, são importantes na determi- 
nação da compreensibilidade de um conhecimento. Um fator citado ć que os especialistas possuem tendência a compreender melhor modelos que nảo contradizem scu conhecimento prévio.

Apôs a análise do conhecimento nessa etapa de Pôs-processamento, caso o conhecimento não seja de interesse do ısuário final ou não cumpra com os objetivos propostos, o pro. cesso de extração pode scr repctido ajustando seus parámetros ou melhorando o processo de escolha dos dados para a obtenção de resultados melhores numa próxima iteração.

No final do processo de Extração de Conhecimento, é interessante que todo o conhecimento adquirido seja disponibilizado em um ambiente adequado de forma a facilitar sua validaçāo, interpretaçāo e utilização pelo usuảrio final. Uma descrição geral de um Ambiente para Exploração de Regras é apresentada no Capítulo 4.

\subsection{Ferramentas de Mineração de Dados}

O desenvolvimento da tecnologia de Extraçāo de Conhecimento e sua utilizaçāo nos mais variados domínios e pelas mais diversas organizações tem motivado o desenvolvimento de várias ferramentas para apoiar o processo e a elaboração de muitos protótipos de pesquisa. Esta seção apresenta uma visão geral de alguns protótipos de pesquisa de ferramentas de Mineraçāo de Dados que possuem funcionalidades inovadoras c de alguns produtos comerciais disponiveis no mercado.

\subsubsection{Protótipos de Pesquisa}

Nos últimos anos, diversos protótipos de ferramentas de Mineraçāo de Dados têm sido desenvolvidos em inúmeras universidades e laboratórios de pesquisa. Com o objetivo de ilustrar as principais ảreas que tèm recebido maior atenção dos pesquisadores do processo de Extração de Conhecimento. os protótipos apresentados nesta secão foram agrupados nas seguintes categorias (Thuraisingham 1999):

Novos Modelos Funcionais As ferramentas pertencentes a esta categoria são aquelas que visam desenvolver novos modelos funcionais para Mineração de Dados. Essencialmente. na maioria destes projetos. o objetivo é integrar métodos de Mineração de Dados com o gerenciamento de base de dados. A idéia principal desses trabalhos é desenvolver novas técnicas para otimizar as consultas e permitir um melhor suporte aos métodos de Mineração de Dados. Um exemplo de protótipo pertencente a esta categoria ć o projeto Gueryflocks, desenvolvido em conjunto pela Universida- 
de de Stanford e as organizaçōes MITRE e Hitachi (Tsur, Ullman, Abiteboul, Clifton, Motwani. Nestorov, \& A. 1998).

Tratamento de Novos Tipos de Dados O tratamento de diferentes tipos de dados, como dados multimidia, é o objetivo dos protótipos pertencentes a esta categoria. Tambén pertencem a esta categoria as ferramentas que apóiam o processo de Text Mining. O protótipo Queruflocks pode ser utilizado para encontrar associaçôes em basces textuais, pertencendo também a esta categoria.

Alguns protótipos são voltados à extração de conhecimento a partir de imagens (Image Mining). O protótipo SKICAT (Sky Image Cataloging and Analysis Tool). desenvolvido pelo JPL (Jet Propulsion Laboratory). visa detectar objetos desconhecidos a partir de imagens espaciais (Fayyad, Haussler, \& Stolors 1996).

Escalabilidade Um problema identificado ao se utilizar muitos dos métodos de extração de conhecimento é que estes não foram projetados para tratar grandes volumes de dados. Por outro lado. com o desenvolvimento da tecnologia de armazenamento, o volume de dados disponivel para anàlise tem crescido exponencialmente. Desta maneira. diversos projetos de pesquisa têm sido desenvolvidos com objetivo de tratar grandes bases de dados. Alguns trabalhos que tratam da escalabilidade dos algoritmos de extraçāo de conhecimento têm sido desenvolvidos pela Thinking Machines Corporation e pela Silicon Crraphics.

Compreensibilidade dos Resultados Um outro problema identificado no final do processo de Extraçâo de Conhecimento de Bases de Dados è a compreensibilidade do resultado obtido. Os padrões extraidos pelos algoritmos podem ser muito complexos ou nāo fazerem sentido para os usuários do processo de lixtração de Conhecimento, dificul tando sua compreensão e possivel utilização (Pazzani 2000: Pazzani. Mani, \& Shankle 1997). Assim. muitos projetos têm sido voltados a tratar este aspecto. A visualização dos padrỏes extraidos tem sido utilizada nesses projetos como principal técnica para auxiliar a compreensão dos mesmos (Thearling, Becker, DeCoste, Mawby, Pilote, \& Sommer(ield 2002)

\subsubsection{Produtos Comerciais}

O desenvolvimento de ferramentas comerciais de Mineração de Dados tem como objetivo principal fornecer aos tomadores de decisāo das organizaçōes, usuários normalmente não especialistas em Mineração de Dados, ferramentas intuitivas e amigáveis (Freitas \& 
Lavington 1998). Nesta secão é fornecida uma visão geral de alguns produtos comerciais de Mineraçāo de Dados disponiveis no mercado.

\section{Clementine}

Clementine $^{l}$ é uma ferramenta integrada que implementa basicamente indução de árvores de decisāo (C5.0). algoritmos de Redes Neurais (Multi-layer Perceptron MI.P e redes Kohonen), k-means, regras de associação e regressāo lincar (Freitas \& Lavington 1998).

Clementine oferece uma interface gráfica bascada cm programação visual. Isto permite: ao usuário especificar operações de Mineração de Dados, incluindo de Pré-processamento, Extraçāo de Padrões e Pós-processamento, para serem executadas "arrastando" ícones e objetos relacionados facilitando a criação de uma seqüência de operaçōes.

Uma outra caracteristica da ferramenta Clementine é que cla pode fazer uma confguração automática dos parâmetros dos algoritmos de AM. A ferramenta apresenta três niveis de configuraçāo dos parâmetros. No nivel mais autônomo, todos os parâmetros são determinados automaticamente, baseando-se nos dados a serem minerados. No nivel intermediário, a ferramenta permite ao usuário especificar os parámetros de mais alto nível, como por exemplo o fator de generalidade das regras descobertas. No nivel menos autônomo, a ferramenta permite ao usuário a configuração de todos os parametros (Freitas \& Lavington 1998).

\section{DARWIN}

A ferramenta DARWIN'2 foi projetada para minerar grandes bases de dados utilizando paralclismo. A ferramenta é constituída de vários módulos (Freitas \& Lavington 1998; Tamayo, Berlin, Dayanand, Drescher, Mani, \& Wang 1997).

StarData Módulo que provè todas as funcionalidades de manipulação e transformação de dados utilizadas pelos outros módulos da ferramenta IDARWIN:

StarTree Módulo baseado no algoritmo CAR'T (Classification and Regression Tree) (Breiman. Friedman. Olshen. \& Stone 1984). podendo realizar tanto tarefas de classificação quanto de regressão. O algoritmo CART paralelo implementado nessa ferramenta constrói árvores de decisào idênticas às construidas pelo algoritmo seqüencial;

StarNet Módulo baseado em algoritmos de Redes Neurais. Esse módulo oferece várias funçōes de ativação para serem utilizadas nas redes, além de um procedimento espe-

${ }^{1}$ http: //www spss.com/Clementine (ultimo acesso: 21/01/2003)

${ }^{2}$ http://otn.oracle.com/products/datamining/content.htnul (último acesso: 21/01/2003) 
cial para seleção automática do tamanho da rede. Esse módulo permite a adição de novas funçōes de ativaçāo, medidas de erro e algoritmos de treinamento da rede:

StarMatch Módulo baseado no algoritmo $K$-nearest neighbor com atributos ponderados. Esse módulo permite a especificaçāo manual ou automática dos pesos dos atributos e utiliza estruturas de dados do tipo KDTrees para aumentar a velocidade de busca dos exemplos armazenados mais similares a um novo exemplo fornecido:

StarGene Módulo baseado em Algoritmos Genéticos cuja funçào principal é otimizar os parâmetros usados por outros módulos da ferramenta. Por exemplo, o módulo StarGene pode ser usado para otimizar os pesos de interconexão de uma rede neural no módulo StarNet.

Mineset

$\mathrm{O}_{\text {Mineset }}{ }^{T H}$ (Motroni \& Vanderberg 2000) consiste de um software produzido pela Silicon Graphics para mineração de dados. O Mineset ${ }^{T M}$ possui algumas ferramentas de Pré-processamento dos dados, um conjunto de ferramentas para Extração de Padrōes e ferramentas de visualizaçāo de dados e dos modelos encontrados pelos algoritmos de Mi neraçào de Dados.

O Mineset ${ }^{T M}$ utiliza umá Biblioteca de $\Lambda$ goritmos de Aprendizado de Máquina implementada em $\mathrm{C}^{++}$, chamada de $\mathrm{MLC}^{-+}$, em que estão implementados os algoritmos de Aprendizado de Máquina utilizados pela ferramenta. Essa biblioteca possui um papel duplo por apresentar os principais algoritmos de aprendizado de máquina implementados e prontos para serem utilizados e por fornecer um conjunto de classes para auxiliar os desenvolvedores na construçào de novos algoritmos (Félix. Rezende, Doi, Paula, \& Romanato $1998)$.

A ferramenta Mineset ${ }^{7 / y}$ está dividida nos seguintes módulos:

Módulo de Controle Centralizado Módulo constituido de uma interface grálica chamada Tool Manager e de um processo chamado Data Mover. A Tool Manager deve ser executada em uma estação cliente e é responsável pela maioria das interaçōes com os componentes do Mineset ${ }^{I M}$. O Data Mover é executado no servidor do Mineset ${ }^{I M}$ e é responsável principalmente pelo acesso e pela transformação dos dados utilizados na ferramenta:

Módulo de Ferramentas de Mineração de Dados Módulo constituído de um conjunto de algoritmos para extração de modelos e padrōes dos dados. Os algoritmos implemen 
tados são Indutores de Árvores de Decisāo e de Regressão, Cálculo da Importância de Colunas, Gerador de Regras de Associaçāo, Gerador de Clusters, Indutor de Evidência, Discretizador Automático e Indutor de Tabelas de Decisāo.

Módulo de Visualização Módulo constituido de um conjunto de ferramentas para visualizaçāo de dados e dos modelos ou padrōes extraídos pelos algoritmos existentes no módulo de Ferramentas de Mineraçāo de Dados. As ferramentas de visualizaçāo sāo Visualizador de Ärvores, Visualizador de Mapas, Visualizador de Regras, Visualizador de Evidência, Visualizador de Registros, Visualizador de Estatísticas, Visualizador de Clusters. Visualizador de Tabelas de Decisão, Scatter Visualizer e Splat Visualizer.

Intelligent Miner

A Ferramenta Intelligent Miner ${ }^{3}$ incorpora algumas pesquisas que tem sido desenvolvidas pela IBM. Intelligent Miner é uma ferramenta de Mineraçāo de Dados que pode executar muitas tarefas, incluindo descoberta de regras de associação e padrões seqüenciais. classificação, clusterizaçăo e modelagem de dependencia. A ferramenta também trata o problema de dados incompletos, detecção de ruídos e categorização de dados contínuos (Freitas \& Lavington 1998; Thuraisingham 1999).

Com relação à classificaçāo, o sistema inclui algoritmos de indução de àrvores de decisão e de Redes Neurais. Dentre os algoritmos utilizados em Redes Neurais, encontram-se: backpropagation, radial basis functions, adaptive resonance networks e mapas de kohonen (Freitas \& Lavington 1998). Alguns desses algoritmos podem ser utilizados para realizar clustering.

\section{DataMind}

Em um projeto conjunto entre a corporaçào Red Brick, especializada em Data Warehousing, e a corporaçāo DataMind foi desenvolvido um produto chamado DataMind que integra produtos de Data Warehousing e Mineraçāo de Dados (Thuraisingham 1999).

A ferramenta de Data Warehouse da Red Brick é uma base de dados relacional especialmente projetado para atender o mercado de Data Warehouse. apresentando algumas características importantes para este tipo de aplicaçāo. As funcionalidades de Mineração de Dados do produto da Red Brick é integrada ao produto de Data Warehousing como uma extensão dos comandos SQL

${ }^{3} \mathrm{http} / /$ www-3.ibml.com/software/data/iminer (ultimo acesso: 21/01/2003) 
WEKA (Waikato Environment for Knowledge Analysis)

WEKA ${ }^{4}$ (Witten \& Frank 1999) consiste de uma biblioteca contendo implementaçōes na linguagem Java de alguns algoritmos de $\mathrm{AM}$. Como na $\mathrm{MLC}^{++}$, os algoritmos implementados na WEKA podem ser utilizados diretamente pelos usuários ou tem-se a possibilidade de utilizar as classes existentes na elaboração de variantes dos algoritmos já implementados ou na construçảo de novos algoritmos. Alguns dos algoritmos atualmente implementados sào J48 (versão Java do C4.5), ID3, Naive Bayes. Regressão Linear e M5.

A WEKA tambem possui algumas ferramentas que executam tarefas de preparação de dados, como normalização, discretização, redução do número de valores e redução do nümero de exemplos.

\subsection{Considerações Finais}

Recentemente, com o desenvolvimento da tecnologia de armazenamento, a quantidade de dados disponivel nas bases de dados das organizaçōes tem crescido demasiadamente. Este crescimento inviabilizou a utilização de técnicas manuais para anâlise desses dados. Ao mesmo tempo, as organizações têm visto a possibilidade de utilizar seus dados a fim de obter conhecimento sobre seus clientes, produtos e parceiros, e assim adquirir vantagem competitiva perante seus concorrentes.

Nesse contexto, os pesquisadores da área de Inteligência Artificial têm direcionado estudos para o processo de Extração de Conhecimento de Bases de Dados, que visa automatizar a tarefa de extrair conhecimento útil a partir de grandes volumes de dados.

Este capitulo teve o objetivo de apresentar o processo de Extraçào de Conhecimento de Bases de Dados, detalhando as atividades que devem ser realizadas desde a compreensào do dominio, preparação dos dados. até a avaliação do conhecimento extraído para verificar se este é de interesse do usuário final. alćm de apresentar algumas ferramentas disponivcis no mercado para apoiar o processo de Extração de Conhecimento.

Conforme apresentado, pode-se observar que o processo de Extraçāo de Conhecimento é bastante complexo e trabalhoso, pois envolve a execuçēo de muitas tarefas, configuraçāo de diversos parâmetros e grande interação com os usuários. Contudo, o sucesso do processo pode trazer uma recompensa valiosa para as organizaçooes.

${ }^{4}$ http://www.cs.waikato.ac.nz/^ $\mathrm{ml} /$ welka/index.html (último acesso: 21/01/2003) 
O próximo capitulo é focado em alguns aspectos relativos ao P’ós-processamento de conhecimento, mais especificamente sobre a avaliação de regras, apresentando algumas medidas objetivas e subjetivas para avaliaçāo de regras. 


\section{Capítulo 3}

\section{Avaliação de Regras}

\subsection{Considerações Iniciais}

A Extração de Conhecimento de Bases de Dados è um processo voltado a atender às necessidades de seus usuários finais. O objetivo final do processo é que esses usuários obtenham algum tipo de vantagem ao utilizar o conhecimento encontrado a partir dos dados. Contudo, a utilização efetiva desse conhecimento depende de fatores como a identificação do conhecimento mais interessante ou relevante e a facilidade de sua interpretação.

No contexto da disponibilizaçāo de conhecimento, sāo tratados modelos que possam ser compreendidos, interpretados e utilizados pelos usuários do processo, ou seja, são considerados principalmente os modelos simbólicos de Aprendizado de Máquina que utilizam regras como linguagem para represcntação das hipóteses. O objetivo é que os usuários possam olhar "dentro" desses modelos, isto é. os usuários podem analisar as regras existentes dentro de um modelo e utilizar esse conhecimento para apoiar um processo de tomada de decisão. Além de modelos simbólicos de classificação, também são considerados modelos simbólicos para regressảo e conjuntos de regras de associação.

Análises mais detalhadas dos conjuntos de regras são necessárias para efetivamente apoiar os usuários na avaliação do conhecimento, sendo necessária a utilização de métodos mais sofisticados do que simplesmente utilizar a precisão de um modelo. Assim. maior atençāo tem sido dada pelos pesquisadores do processo de Mineração de Dados a problemas relacionados à utilizaçāo c compreensāo do conhecimento, e diversos trabalhos têm sido desenvolvidos. tendo sido propostas diversas medidas para avaliaçāo de regras. Essas medidas permitem avaliar tanto o desempenho quanto a qualidade das regras. 
O desempenho de uma regra está associado à fidelidade com que esta representa os dados. Por exemplo, uma medida de desempenho é a precisāo da regra. Quanto à avaliaçāo de qualidade. conceitos como compreensibilidade e interessabilidade são utilizados. A compreensibilidadc de um dado conjunto de regras está relacionada à sua facilidade de interpretação pelos usuários, podendo ser estimada, por exemplo, pelo número de regras c o número de condiçōes por regra, conforme apresentado no Capitulo 2. A interessabilidade, por sua vez, é uma avaliação realizada a partir de estimativas da quantidade de conhecimento interessante ao usuário está presente no conjunto de regras. Medidas de interessabilidade podem estar relacionadas, por exemplo, à utilidade ou novidade do conjunto de regras.

Nesse sentido, esse capitulo trata de alguns desses problemas, apresentando em mais detalhes o problema da interessabilidade do conhecimento extraido, assim como algumas medidas de avaliação quanto a desempenho e qualidade das regras.

\subsection{Interessabilidade de Regras}

Un problema que tem sido identificado no processo de Extração de Conhecimento é que, normalmente, o número de padrōes encontrados a partir dos dados é muito grande. Devido a esse grande número de padrōes, sua análise é certamente bastante difícil de ser cxecutada manualmente. Normalmente, os usuários esperam receber somente uma pequena coleçāo de padrōes que sejam úteis, novos e interessantes (Liu, Hsu, \& Ma 2001; Liu, Hsu, \& Ma 1999; Klemettinen, Mannila, \& Toivonen 1997: Liu, Hsu, Mun, \& Lee 1996). Alguns fatores que levam um conhecimento a não ser de interesse do usuário sāo (Padmanabhan \& Tuzhilin 2000; Klemettinen, Mannila, Ronkainen, Toivonen, \& Verkamo 1994):

- Uma regra pode corresponder a um conhecimento prévio;

- Uma regra pode referenciar atributos ou uma combinação de atributos não interessantes;

- Regras podem ser redundantes.

Desta maneira, é extremamente importante para o processo de Extraçāo de Conhecimento o desenvolvimento de técnicas para seleção de regras interessantes. Essas técnicas são freqüentemente referenciadas na literatura como Interessabilidade de Regras.

Muitas pesquisas têm mostrado que a identificação e remoção dos padrōes redundantes ou nào interessantes para os usuários pode ser realizada por um processo automático. 
Como resultado dessas pesquisas, diversas medidas de interessabilidade e ferramentas de apoio à seleção de padrōes interessantes têm sido desenvolvidas pelos pesquisadores do processo de Extraçào de Conhecimento para auxiliar os usuários nessa tarefa de identificaçăo dos padróes interessantes (Liu, Hsu, \& Ma 2001; Liu. Hsu, \& Ma 1999; Lavrac. Flach, \& Zupan 1999; Klemettinen, Mannila, \& Toivonen 1997; Silberschatz \& Tuzhilin 1996; Piatetsky-Shapiro \& Matheus 1994).

A interessabilidade se refere ao grau que um dado padrāo descoberto é de interesse para um usuário firal do processo de Extração de Conhecimento de Bases de Dados e está relacionada a fatores como novidade, utilidade, relevância e significancia estatística. Um sistema automático de descoberta de conhecimento que seja interessante para o usuário requer que fatores de interesse sejam especificados e combinados numa medida que reflita como o especialista no domínio julga os padrões, para que scja possivel a análise automática da interessabilidade dos padrōes descobertos (Piatetsky-Shapiro \& Matheus 1994). A identificaçāo desses aspectos que permitem a determinação do conhecimento interessante nāo é simples e é extremamente dependente do dominio e do usuârio.

Em (Liu, Hsu, Mun, \& Lec 1996), a interessabilidade foi definida como: Seja $B$ o conjunto de todos os padrões descobertos a partir de uma base de dados $D$ pela aplicação de uma técnica $Q$. o problema da interessabilidade consiste em determinar o conjunto $I$ de padrōes interessantes e ordenar esses padrōes de acordo com o grau de interesse do usuário em um determinado instante de tempo.

Alguns aspectos importantes sobre essa definição devem ser ressaltados:

- O conjunto I pode não ser o conjunto completo de todos os padrōes que foram descobertos a partir de $D$. Geralmente, $I$ é apenas um subconjunto dos padrões contidos en $B$;

- Nem todos os padrōes de $I$ são igualmente interessantes. Dois padróes diferentes pertencentes ao conjunto $I$ podem ter diferentes graus de interesse para o usuário;

- I é um conjunto dinâmico, pois é dependente do usuário e do tempo. Diferentes usuários podem possuir interesse em diferentes subconjuntos do conjunto $I$, ou aindà, um único usuário pode ter interesse em diferentes subconjuntos em diferentes momentos.

É extremamente importante que seja possivel projetar técnicas gerais de seleçāo e ordenação de padrōes de acordo com sua interessabilidade. Diversas pesquisas têm sido 
realizadas no sentido de desenvolver medidas para avaliação de interessabilidade independentes do usuário e do domínio (Freitas 1998b). Essas medidas mais gerais são chamadas de medidas objetivas para avaliaçāo de conhecimento.

As medidas objetivas para avaliaçāo de padrōes dependem somente da estrutura dos padrōes e dos dados que os originaram. Algumas dessas medidas estão detalhadas na Seção 3.3. Essas medidas são úteis em muitos aspectos, mas, por nāo levarem em consideração fatores específicos do usuário. elas são insuficientes para selecionar precisamente o foco de interesse do usuário, devido às características do problema de interessabilidade.

Dessa maneira, foram desenvolvidas medidas que levam em consideracão aspectos re lacionados ao usuário e ao domínio da aplicação. Por essc motivo. essas medidas são normalmente chamadas de medidas subjetivas para avaliaçào de conhecimento. Na Seção 3.4 algumas dessas medidas são detalhadas.

\subsection{Aspectos Objetivos para Avaliação de Regras}

Como as medidas objetivas dependem somente dos dados e da estrutura dos padrōes. elas sāo. por definição, mais genéricas que medidas subjetivas. Isso motivou o desenvolvimento de muitas medidas objetivas para avaliaçāo de regras, sendo algumas delas apresentadas nesta seção.

\subsubsection{Medidas de Surpresa}

Um conhecimento pode ser considerado surpreendente para o usuário se ele for previamente desconhecido ou contrariar seu conhecimento. Por ser bastante dependente do conhecimento que o usuário possui. a surpresa de regras ć, normalmente, considerada um aspecto subjetivo. Entretanto, em (Freitas 1998b) c mostrado que é possivel definir algumas medidas objetivas para identificaçào da surpresa de regras.

\section{Surpresa dos Pequenos Disjuntos}

Um conjunto de regras pode ser referenciado como uma disjunção de regras, e uma regra individual pode ser chamada de disjunto. O tamanho do disjunto representa o número de exemplos do conjunto de dados em que a parte condicional da regra é verdadeira, isto é, o nümero de exemplos cobertos pela regra. Pode-se então definir um pequeno disjunto como umá regra que cobre poucos exemplos do conjunto de dados. A determinação de quais regras são pequenos disjuntos é feita de acordo com algum critério específico. como por exemplo, um limite máximo para o número de exemplos cobertos pela regra. Nesse caso. 
uma regra será considerada um pequeno disjunto se o número de exemplos cobertos por ela nào ultrapassar o limite estipulado.

Normalmente, os algoritmos de induçào de regras ou árvores possuem um bias favorável à descoberta de modelos mais genéricos, ou seja, lavorável à descoberta de grandes disjuntos. Nesse caso. os pequenos disjuntos são normalmente removidos dos modelos para garantir generalidade. Entretanto, um pequeno disjunto pode representar um padrão de comportamento específico dos dados ou simplesmente um ruido. No primciro caso, o disjunto deve ser mantido, podendo representar algum aspecto do conjunto de dados que pode ser de interesse do usuário. No segundo caso, o disjunto representa um erro dos dados e deve ser clescartado. Descobrir a qual desses casos pertence um pequeno disjunto ć extremamente complicado, baseando-se somente nos dados (Freilas 1998a). Portanto. os pequenos disjuntos devem ser tratados de maneira mais cuidadosa, evitando assim a eliminaçāo de um conhecimento potencialmente interessante.

Em (Freitas 1998b) é proposto que um pequeno disjunto é surpreendente se ele prediz uma classe diferente das classes preditas pelas suas menores generalizaçōes. As menores generalizaçōes de um pequeno disjunto sào definidas como segue.

Um disjunto é composto por conjunçōes de $m$ condiçóes, na forma (ond, $1 \mathrm{~N} L$ ) (ond. $A N D$... AND cond $d_{m}$, en que cada elemento rond $k, k=1, \ldots . m$, possui a forma $<$ Atributo op Valor $>$, sendo op um elemento do conjunto $\{<.>\rangle,, \leq,-\}$.

Um disjunto possui um total de $m$ menores generalizaçōes, em que cada generalizaçāo

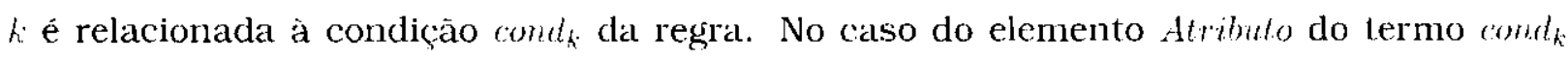
ser um atributo discreto, a k-ésima generalização é formada pela remoģão da comlk da rcgra. Caso contrário, quando o clemento Alibulo de comdk possui valor contínuo, a k-ésima generalizaçāo pode ser definida de duas formas: (a) removendo a condiçāo comdk, ou (b) adicionando um pequeno valor a ao elemento valor de cond se op é um elemento do conjunto $\{<, \leq\}$ ou removendo-se or de Valor se op é um elemento do conjunto $\{>, \geq\} . \operatorname{Lm}$ todos os casos, o número de exemplos cobertos por cada generalização de un disjunto é maior ou igual ao número de exemplos cobertos pelo disjunto original. Como resultado, a distribuiçāo do atributo meta em cada generalização pode ser bastante diferente da distribuição do atributo meta no conjunto de exemplos coberto pelo pequeno disjunto original.

A medida de surpresa dos pequenos disjuntos é calculada como segue. Seja ( a classe predita pelo pequeno disjunto original, $C_{k}$ a classe predita pela $k$-ésima menor generali/ação do disjunto, e $n$ o nümero de menores generalizaçōes em que $C \neq .(\%, k=1, \ldots, m$. Èn tão. a medida objetiva de surpresa do pequeno disjunto é definida pela Equação Smpl is.j $_{\text {- }}$ 
$n / m$. Como $n$ é um número inteiro no intervalo $0 . . m$, essa medida de surpresa possui seus valores no intervalo [0..1]. Quanto maior o valor de Surpl]is.j, maior será a surpresa do pequeno disjunto original (Freitas 1998b).

\section{Surpresa dos Atributos Individuais das Regras}

Normalmente, as medidas de avaliação consideram o antecedente das regras de forma única, não se importando com os atributos presentes nas condiçoes das regras. Entretanto, duas regras com um mesmo valor de alguma medida de avaliação podem possuir interessabilidade diferente para um determinado usuário, dependendo dos atributos que aparccem no antecedente das regras (Freitas 1998b).

Um atributo com alto valor do ganho de informação é um bom preditor para a classe quando considerado individualmente. Porém, devido a esse fato, é possivel que já seja de conhecimento do usuário que esse atributo seja um bom preditor. Assim, o usuârio pode ter uma tendencia a se surpreender mais se a regra possui atributos com valores de ganho de informação baixos, isto é, regras que possuem atributos que individualmentc não sāo bons preditores para a classe. A surpresa advèm do fato de que, apesar dos atributos individualmente não serem bons preditores, sua combinaçāo pode ter um alto valor preditivo. Isso pode ser bastante interessante ou surpreendente para o usuário.

O cálculo dessa medida de surpresa de atributos é feito como segue. Seja $A_{i}$ o i-ćsimo atributo da parte condicional da regra a ser analisada, $A_{i k}$ o $k$-ésimo valor do atributo $A_{i}$, $C$ o atributo meta da classificação. $C_{j}$ o j-ésimo valor do atributo meta $C, P(X)$ representa a probabilidade de $X$ e $P(X \mid Y)$ representa a probabilidade condicional de $X$ dado $Y$. Nas Equaçōes 3.1 e $3.2, m$ representa o número de valores possiveis do atributo $A_{i}$ e $n$ representa o número de possiveis valores do atributo meta. O valor do ganho de informaçāo de um atributo $A_{i}$ è calculado pela Equaçāo 3.3 .

A medida de surpresa dos atributos individuais das regras é calculada pela Equaçāo 3.4. o analisar a Equação 3.4, observa-se que quanto menor a média do valor da medida de ganho de informaçāo dos atributos que compōem o antecedente da regra, maior será o valor de SurpAtr e mais surpreendente para o usuário será a regra, segundo este crilério.

$$
\begin{aligned}
& \ln f o(C)=\sum_{j=1}^{n} P\left(C_{j}\right) \log P^{\prime}\left(C_{j}\right)
\end{aligned}
$$

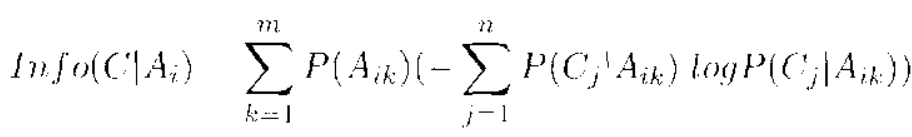




\subsubsection{Seleção de Regras não Redundantes}

Como apresentado anteriormente, um problema dos algoritmos de extração de padröes é a grande quantidade de padröes descobertos. Diversos trabalhos tèm mostrado que muitos desses padrões sāo redundantes, já que muitos dos padrōes podem ser derivados de outros (Padmanabhan \& Tuzhilin 2000).

Não é uma boa técnica simplesmente fornecer um subconjunto arbitrário das regras descobertas para o usuârio quando o número de regras geradas é muito grande. Isso advém do fato de que, dessa maneira, muitas regras possivelmente interessantes poderão ser descartadas. Assim, técnicas mais elaboradas para poda dessas regras redundantes têm sido propostas no sentido de reduzir o conjunto de regras e fornecer ao usuário somente aquelas realmente significativas.

Una dessas técnicas para poda de regras pode ser encontrada em (Liu, Hsu, \& Ma 1999). Esse trabalho é voltado ao tratamento de regras de associação, pois normalmente algoritmos para extraçāo de regras de associaçāo geram grandes conjuntos com muitas regras redundantes.

Essa técnica é composta por duas etapas. A primeira executa uma poda nas regras de associação descobertas para remover os padrōes irrelevantes. Entretanto, o conjunto de regras resultantes dessa primeira etapa ainda pode ser grande, sendo necessária a execução de uma segunda etapa da técnica para uma redução ainda maior no número de regras. Nessa segunda etapa, esse conjunto é analisado com o intuito de encontrar um subconjunto especial de regras, formando um sumário das regras encontradas, chamado conjunto IS (Direction Setting) (Liu. Hsu, Ma, \& Chen 1999; Liu, Hsu, \& Ma 1999).

O conjunto de regras DS fornece um sumário do comportamento das regras de associação descobertas, representando os relacionamentos principais do dominio. O conjunto das regras que naao pertencem ao conjunto $L S$, as regras nảo-DS, simplesmente fornecem detalhes adicionais que podem não ser importantes para o usuário.

Diversos experimentos mostraram que esse conjunto de regras DS é normalmente um conjunto bastante reduzido, permitindo que humanos possam analisá-lo manualmente e 
assim focar seu interesse nas regras interessantes, de acordo com seu conhecimento (Ma, Liu, \& Wong 2000). É importante ressaltar que essa técnica não identifica os padrōes interessantes, ela apenas gera um conjunto reduzido de regras não redundantes e sumarizadas que pode ser mais facilmente analisado pelo usuário.

Em (Ma, Liu, \& Wong 2000) é apresentada uma ferramenta que faz a utilização da sumarizaçāo de regras de associaçāo em regras 1$) S$ para auxiliar os usuários na análise de conjuntos de regras de associaçào. Esta ferramenta foi chamada de DS-WEB. Na análise de um conjunto de regras, a ferramenta faz a seleção das regras nāo redundantes e as organiza em uma estrutura hierárquica visando possibilitar ao usuário a navegação pelo conjunto de regras. Esta estrutura é então publicada por um conjunto de páginas WWW para facilitar o acesso ao conjunto de regras e o trabalho colaborativo cntre os divcrsos usuários do ambiente.

\subsubsection{Medidas Derivadas da Tabela de Contingência}

Normalmente, em tarefas de classificação, a principal medida utilizada para avaliação do conhecimento é a precisão. Entretanto, quando o numero de regras encontradas é muito grande, novas medidas para avaliação desse conhecimento são necessárias. Essas medidas tèm como objetivo auxiliar a filtragem c ordenaçăo desse grande conjunto de regras.

Em (Lavrac, Flach, \& Zupan 1999) é apresentado um conjunto de medidas para avaliação de conhecimento. Essas medidas de avaliação năo estão restritas ao conhecimento extraído por algoritmos de classificação, podendo ser aplicadas a qualquer conjunto de re-

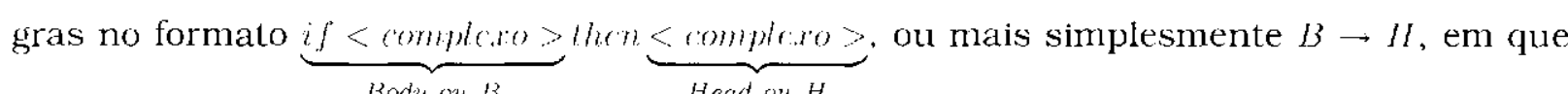
II pode possuir condiçōes sobre mais que um atributo do conjunto de dados. Além disso, essas medidas sāo geradas a partir da tabela de contingência, representada na Tabela 3.1.

A definiçāo dos clementos da tabcla de contingência de uma regra $R$ a partir de um conjunto de $n$ exemplos é dada como segue. Na Tabela $3.1, b$ corresponde ao numero de exemplos em que o corpo da regra $B$ é verdadeiro e $\bar{b}$ o número de exemplos em que $\bar{B}$ é verdadeiro, isto é, em que $B$ é falso. Da mesma maneira, $h$ e $\bar{h}$ correspondem ao número de exemplos em que a cabeça da regra $H$ è verdadeira e falsa, respectivamente. $b / h$ represcnta o numero de exemplos em que ambos $B$ e $l /$ são verdadeiros. Similarmente, sāo definidos $\bar{b} h, b \bar{h}$ e $\bar{b} \bar{h}$ (Prati, Baranauskas, \& Monard 2001a).

$\Lambda$ tabela de contingência também pode ser representada utilizando freqüências relativas. em que os valores contidos na tabela são divididos pelo número total de exemplos, obtendo as freqüências relativas $f_{x}=\frac{x}{n}$. Para o cálculo das medidas apresentadas em (Lavrac, Fla- 
ch. \& Zupan 1999), a freqüência relativa do evento $x$ é utilizada como uma estimativa para a probabilidade $P(x)$. A tabela de contingência com freqüências relativas está representada na Tabela 3.2

\begin{tabular}{|c|c|c|c|}
\hline & $\| l$ & $\overline{M I}$ \\
\hline$B$ & $b h$ & $\bar{b}$ & $b$ \\
\hline $\bar{B}$ & $\bar{b} h$ & $\overline{b h}$ & $\bar{b}$ \\
\hline & $h$ & $\bar{h}$ & $n$ \\
\hline
\end{tabular}

Tabela 3.1: Tabela de Contingència

$$
\begin{array}{|c|c|c|c|}
\hline & H & \bar{l} & \\
\hline B & f_{h h} & \int_{b \bar{h}} & f_{b} \\
\hline \bar{B} & f_{\bar{b} h} & \int_{\bar{b}} & f_{\bar{b}} \\
\hline & f_{h} & f_{\bar{h}} & 1 \\
\hline
\end{array}
$$

Tabela 3.2: Tabela de Contingência con Freqüencias Relativas

Algumas medidas derivadas da tabela de contingência säo (Lavrac, Flach, \& Zupan 1999; Prati, Baranauskas. \& Monard 200la):

Precisão Medida que indica o grau de contiabilidade da regra. Quanto maior seu valor, mais precisa será a regra.

$$
A c=P(H \mid B)=\frac{P(B H)}{P(B)}=\frac{f_{b,}}{f_{i}}
$$

Erro Medida definida como 1 - Ace. Quanto maior seu valor, menos precisa será a regra.

$$
E r r=P(\bar{H} \mid B)=\frac{f_{b t_{i}}}{f_{t}}
$$

Confiança Negativa Medida correspondente à precisāo, más para os exemplos que nāo sāo cobertos pela regra.

$$
N e g R e l=P(\bar{H}: \bar{B})=\frac{P(\overline{B I})}{P(\bar{B})}=\frac{f_{\overline{b i}}}{f_{\bar{b}}}
$$

Sensitividade Medida que corresponde ao numero relativo de exemplos cobertos pela re gra em que a condição $H$ é verdacte.

$$
S e n s=P(B \mid H)=\frac{P(B H)}{P(H)}-\frac{J_{b h}}{f_{h}}
$$


Especificidade Medida correspondentc à Sensitividade, mas para os exemplos que não são cobertos pela regra.

$$
\text { Spec: }-P^{\prime}(\bar{B} \mid \bar{I})=\frac{P(\overline{B H})}{P(\bar{H})}=\frac{f_{\overline{b h}}}{f_{\bar{h}}}
$$

Cobertura Medida do número relativo de exemplos cobertos pela regra.

$$
C o s-P(B)-f_{b}
$$

Suporte Medida do número relativo de exemplos cobertos corretamente pela regra.

$$
S u p-P(B H)=f_{b h}
$$

Novidade Medida que quantifica a correlaçāo estatistica cntrc $B$ e $I /$. Pode-se demonstrar que $-0,25 \leq N o v \leq 0,25$. Quanto maior o valor de Nov, maior é a correlaçâo entre $B$ e II. Guanto menor seu valor, maior é a correlaçāo entre $B$ e $\Pi$. Se $N o n=0$, entāo $B$ c II são variáreis estatisticamente independentes.

$$
N o n-P(B I I)-P(I /) P(B)-f_{b h}-f_{h} f_{b}
$$

Satisfação Medida que indica o aumento relativo na precisão entre a regra $B \rightarrow$ verdak e a regra $B \rightarrow I I$

$$
S u t=\frac{P(\bar{I})-P(\bar{H} \mid J)}{P(I)}=\frac{f_{\bar{h}}-\frac{f_{b \overline{\bar{H}}}}{f_{h}}}{f_{\bar{h}}}
$$

Precisão Relativa Medida relativa que indica o ganho de precisão em relação à regra verdade $\cdot H$ pela consideraçāo da condiçāo $B$.

$$
R A c:-P(H \mid B)-P(H)=\frac{f_{b h}}{f_{b}}-f_{h}
$$

Confiança Negativa Relativa Medida correspondente à Precisão Relativa para os exemplos que não são cobertos pela regra.

$$
R N \operatorname{lol} l=P^{\prime}(\bar{H} \mid \bar{B})-P^{\prime}(\overline{M I}) \quad \frac{f_{h_{l}}}{f_{\bar{b}}}-f_{h}
$$


Sensitividade Relativa Medida que mede o ganho de scnsitividade obtido em relaçào à sensitividade de uma regra $B \rightarrow$ cerdadc.

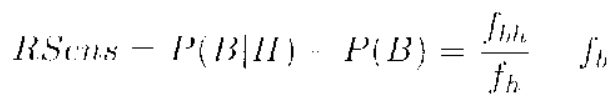

Especificidade Relativa Medida correspondente à Sensitividade Relativa para os exemplos que não são cobertos pela regra

$$
R S p e c=P(\bar{B} \bar{H})-P(B)=\frac{f_{L h_{i}}}{f_{\bar{h}}}-f_{\bar{b}}
$$

Com objetivo de garantir um balanceamento entre generalidade e relatividade para as regra, foi proposta em (Lavrac, Flach, \& Zupan 1999) a atribuição de um peso para as medidas relativas, obtendo-se as medidas relativas ponderadas.

\section{Precisão Relativa Ponderada}

$$
W R A c c=P(B)(P(H \mid B) \cdots P(H))=f_{b}\left(\frac{\int_{h h}}{f_{b}}-f_{h}\right)
$$

Confiança Negativa Relativa Ponderada

$$
\text { WRNegRel }-P(\bar{B})(P(\overline{I I} \mid \bar{B})-P(\overline{I I}))-f_{\bar{b}}\left(\frac{f_{\overline{b h}}}{f_{b}}-f_{\bar{h}}\right)
$$

\section{Sensitividade Relativa Ponderada}

$$
\text { WRSchs }=P^{\prime}(H)\left(P(B \mid H)-P^{\prime}(B)\right)=f_{h}\left(\frac{f_{b h}}{f_{h}}-f_{b}\right)
$$

\section{Especificidade Relativa Ponderada}

$$
\text { WRSPre: }=P(\bar{H})(P(\bar{B} \bar{H})-P(\bar{B}))-f_{\bar{h}}\left(\begin{array}{cc}
f_{b h} & f_{b} \\
f_{\bar{h}} &
\end{array}\right)
$$

Um aspecto importante sobre as medidas relativas (Equaçōes 3.14, 3.15. 3.16 e 3.17) é que elas trazem mais informaçāo sobre a utilidade de uma regra do que suas respectivas medidas absolutas (Equaçōes 3.5. 3.7. 3.8 e 3.9). P’or cxcmplo, se a precisão de uma regra é menor que a freqüencia relativa da classe que ela prediz, então a regra não tem um desempenho muito bom, independente de sua precisão absoluta. 
No entanto. é fäcil obter uma alta precisão relativa para regras muito especificas. Para solucionar esse problema, são propostas as medidas relativas ponderadas (Equaçōes 3.18, 3.19, 3.20 e 3.21). Fn (Iavrac, Flach. \& 7upan 1999) e demonstrado que as medidas relativas ponderadas e a medida Novidade (Equação 3.12) são equivalentes.

Uma biblioteca de ferramentas para cálculo das informaçōes referentes à tabela de con lingència de cada regra de um conjunto de regras de classificaçào loi proposta e implementada por Prati, Baranauskas, \& Monard (2001a). A partir dessas informaçōes, o cálculo de muitas medidas de avaliaçăo, incluindo as propostas em (Lavrac, Flach, \& Zupan 1999). pode ser facilmente realizado.

\subsubsection{Medida RI (Rule-Interesi)}

A medida RI (Rule-Interest). proposta em (Piatetsky-Shapiro 1991), è usada para quanlificar a correlação entre a cabeça c o corpo de rcgras do tipo $B \cdot H$.

A medida $R$ I I é dada pela Equação 3.22. Nesta equação, $n$ é o número total de exemplos, $' B|\mathrm{e}| / \mid$ representam o número de exemplos que satisfazem as condiçōes $B \mathrm{c} / /$, respectivamente. $\mathrm{c} \mid B\lceil H \mid$ representa o número de exemplos em que $B$ e $H$ são satisfeitos. O valor de $\frac{|B| \mid \| !}{\|}$ corresponde ao número de exemplos esperado se $B$ e $I /$ fossem variáveis estatisticamente independentes. O valor desta medida também pode ser obtido utilizando-se os valores da tabela de contingência, como pode ser observado na Equaçāo 3.22.

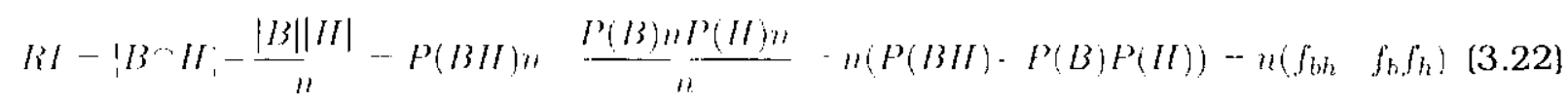

Se $R I=0$, entāo $/ /$ e $B$ são independentes e a regra não é considerada interessante. Guando $R I>0, H$ é positivamente correlacionado com $B$, ou seja, a probabilidade de $l l$ ocorrer aumenta quando a condição $B$ é considerada. Quando $R /<0, \|$ é negativamente correlacionado $\operatorname{com} B$, ou seja. a probabilidade de $I /$ ocorrer diminui quando a condiçāo $B$ é considerada. Guanto maior o valor absoluto de $R I$, mais interessante será a regra.

F́ importante observar que a medida Novidade, descrita na Seção 3.3.3. é equivalente à medidal $1: 1$

\subsection{Aspectos Subjetivos para Avaliação de Regras}

Medidas objetivas não consideram fatores especificos do dominio e do usuário e. dessa maneira, muitas regras que possivelmente não sāo de interesse para o usuảrio ainda sāo 
apresentadas pela utilização desses tipos de medidas na filtragem de regras, Apesar de úteis. essas medidas objetivas não são suficientes para solucionar o problema da interessabilidade de regras do processo de Extração de Conhecimento de Bases de Dados.

Medidas subjetivas de interessabilidade tem sido desenvolvidas com o objetivo de selecionar entre o conjunto de regras aquelas que são realmente interessantes para o usuário (Silberschatz \& Tuzhilin 1996; Klemettinen, Mannila, \& Toivonen 1996; Klemettinen, Mannila, Ronkainen. Toivonen, \& Verkamo 1994; Piatetsky-Shapiro \& Matheus 1994; PiatetskyShapiro 1991). Essas medidas subjetivas não consideram somente a estrutura de uma regra ou os dados utilizados no processo de descoberta, mas também o conlecimento que o usuário possui e seu interesse no momento da análise dos padrōes.

Nesta seção sāo apresentadas algumas medidas subjetivas para seleção e ordenação de regras interessantes.

\subsection{Sistema de Crenças}

Em (Silberschatz \& Tuzhilin 1996; Silberschatz \& Tuzhilin 1995) é proposto o uso de um sistema de crenças (beliefs) para identificar o grau de interessabilidade de um conhecimento. Crenças são definidas como fórmulas de predicados arbitrários expressos em lógica de primeira ordem. Nos artigos, sāo definidos dois tipos de crenças: Hard e Soft.

Crenças Soft representam conccitos que o usuário acredita serem verdadeiros com algum grau de certeza. Caso o usuário encontre novos padrões que prevém uma nova evidencia. crenças desse tipo podem ser alteradas ou podem ter seus graus de certeza alterados. O grau de certeza/confiança do usuário em séu conceito é chamado de grau do confidencia da crença Soft.

Jà as crenças IJard representam conhecimentos rigidos e fixos sobre os quais o usuário nāo possui dúvidas. Essas crenças não podem ser alteradas, mesmo que seja encontrada uma nova evidência que a contrarie. Se uma evidência contradiz uma crença do tipo Hard. deve ter ocorrido algum erro no processo de coleta dos dados que produziram a evidencia. Para uma crença Hard nāo é associado nenhum grau de confidencia, pois ela representa um conhecimento fixo, rigido que nāo pode ser alterado. É importante ressaltar que as crencas Soft c Hard são subjetivas e podem variar de usuário para usuário.

Um padrāo é considerado interessante em um sistema de crenças se ele afeta esse sistema. Além disso, quanto mais o padrão afeta o sistema, maior seu grau de interessabilidade. Nessa avaliaçāo da interessabilidade são identificadas duas razōes pelas quais um padrāo pode ser interessante para o usuário: 
Inesperabilidade Se um padrảo é inesperado para o usuário, então ele é interessante. Os padrōes inesperados contradizem a expectativa ou crença do usuário.

Utilidade Um padrào é interessante para o usuảrio se ele pode obter algum benefício do utilizá-lo.

Segundo Silberschatz \& Tuzhilirı (1996), esses dois tipos de interessabilidade são independentes entre si. Apesar disso, é discutido que a maioria dos padrões sào inesperados e úteis ao mesmo tempo e que, alèm disso, o conjunto dos padrōes inesperados ć uma boa aproximaçào do conjunto dos úteis e vice-versa. Somando-se a isso o fato de que a medida de utilidade de um padrão nảo pode ser facilmente calculada, foi proposta a utilizaçảo da medida de inesperabilidade de um padrāo como forma de prever sua interessabilidade.

Uma das maneiras apontadas para a identificação do grau de Inesperabilidade de um padrão e pela utilização da teoria Bayesiana. Essa abordagem assume que se pode acreditar cm algo de maneira parcial, ou seja, ć associado um grau, medida ou fator de confidència à crenca, como especificado anteriormente. Esse fator de confidència da crenca é associado à probabilidade condicional que a crença possui dada uma evidéncia prévia (o conhecimento prévio do usuário). Dessa maneira, pode ser calculado o grau em que uma crença é afetada dado um novo padrāo descoberto a partir dos dados.

Ao se descobrir um padrāo c realizar a avaliação de quanto ele afeta o sistema de crenças. algumas ações podem ser realizadas com relação às crenças e aos dados de onde o padrāo foi extraido.

No caso de uma crença Hard, se um padrāo a contradiz. então esse padrāo sempre ć interessante para o usuário. Porém. essa contradição não implica que alterações devem ser feitas na crença. Isso indica que deve existir algum erro no processo de coleta do conjunto de dados do qual o padrão foi obtido, devendo-se então checar tal processo para tentar identificar e corrigir a falha.

Caso um padrão contrarie uma crença Soft. os dados devem ser checados. Nesse caso, a realização de alguma ação com relação à crença depende do resultado da análise dos dados.

\subsubsection{Modelos de Regras}

Modelos de Regras (Rule Templates) foram propostos por Klemettinen, Mannila, Ronkajnen, Toivonen, \& Verkamo (1994) como uma abordagem subjetiva para selecão de regras interessantes para o usuário. Modelos de Regras tambem foram abordados nos trabalhos 
(Klemettinen, Mannila, \& Toivonen 1996; Klemettinen, Mannila, \& Toivonen 1997). Esses trabalhos foram voltados para a seleçāo de regras de associaçāo devido ao fato de que algoritmos para geraçāo dessas regras normalmente extraem um conjunto muito grande de regras. Apesar disso, csses modelos tambem podem ser aplicados a regras de classificação.

Nesses trabalhos é proposto que parte do problema de se fornecer regras interessantes pode ser resolvido pela possibilidade do usuário fornecer classes de regras interessantes e nāo intcressantes, que são especificadas através dos Modelos de Regras. Esses modelos especificam quais atributos devem e quais nāo devem aparecer no antecedente e conseqüente da regra, de forma a selecionar possiveis regras interessantes e excluir as que nāo interessam ao usuário.

Um Modelo de Regra è uma expressão na forma $A_{1}, \ldots A_{k} \rightarrow A_{k+1}, \ldots, A_{i}$, em que cada $A_{i}$ representa o nome de um atributo ou o nome de uma classe de atributos, ou mesmo uma expressāo $C^{+}$ou $C^{*}$. Nas expressōes $C^{*+}$ e $C^{* *}, C^{*}$ representa o nome de uma classe de atributos, $\mathrm{e}^{+} \mathrm{ou}^{*}$ correspondem a um ou mais, zero ou mais, respectivamente, instanciaçōes de elementos da classe $C$. Uma regra $B_{1}, \ldots, B_{m}: B_{m+1}, \ldots B_{n}$ "casa" com um Modelo de Regra $A$ se ela pode ser considerada uma instanciaçào de $A$.

Modelos de Regras podem ser seletivos ou restritivos. Em um ambiente que utiliza essa abordagem para seleção de regras, o usuârio pode fornecer um conjunto de modelos seletivos e um conjunto de modelos restritivos. No conjunto de modelos seletivos, o usuário deve especificar o seu foco de interesse, isto $\dot{c}$, os tipos de regras nas quais possui interesse. No conjunto restritivo, o usuário deve especificar tipos de regras nas quais cle não possui qualquer interesse. Para que uma regra seja considerada interessante e apresentada ao usuário, ela deve "casar" com pelo menos um dos modelos do conjunto seletivo e não "casar" com nenhum dos modelos do conjunto restritivo.

\subsubsection{Aplicativo AIAS}

Em (Liu, Hsu, Chen, \& Ma 2000; Liu, Hsu, Ma, \& Chen 1999) é apresentado o aplicativo Association Interestingness Analysis System (AIAS) que visa auxiliar os usuários na identificação das regras interessantes a partir de um conjunto de regras de associaçāo pela utilização de medidas subjetivas. De acordo com a técnica utilizada no aplicativo para o Pós-processamento das regras de associação, primeiramente, o AInS solicita que o usuário cspecifique seu conhecimento sobre o dominio ou seu foco de interesse atual. O aplicativo então utiliza esse conhecimento para analisar o conjunto de regras de acordo com vários 
critérios de interesse. Então, elas são apresentadas ao usuário por uma ferramenta de visualização que permite identificar visualmente as regras mais interessantes.

Desta maneira, os três componentes principais da ferramenta AIAS, bem como as possiveis linguagens de representacāo que podem ser utilizadas pelos usuários e os tipos de análises que podem ser feitas, sāo apresentados $\mathrm{cm}$ mais detalhes a seguir.

A linguagem de especificação O NIAS possui uma linguagem de especificação simples que permite ao usuário expressar seu conhecimento em diferentes graus de precisāo. Essas linguagens são: Impressōes Gerais, Conhecimentos Imprecisos e Conhecimentos Precisos. Os primeiros dois tipos representam conhecimentos que o usuário supõe ser verdadeiro. enquanto que o último tipo representa seu conhecimento preciso sobre o dominio (Liu, Hsu, Chen. \& Ma 2000). Estas linguagens de especificação são apresentadas a seguir.

Impressões Gerais (IG) As Impressões Gerais possibilitam aos especialistas informarem de maneira bastante simples conjuntos de atributos entre os quais acreditam que exista alguma relação. Uma $I G$ é uma expressāo na forma:

$I\left(i\left(<S_{1}, S_{2}, \ldots, S_{m}>\right) /\right.$ suporte, confidèncial

em que:

- Cada $S_{i}$ representa um item da base de dados, uma classe ou conjunto de itens, ou uma expressão na forma $C^{+}$e $C^{*}$, em que $C$ representa uma classe ou conjunto de itens e $C^{* *}$ e $C^{*}$ representam uma ou mais, zero ou mais, instanciaçōes de algum elemento de $C$. respectivamente;

- Uma regra $a_{1} \ldots, a_{n}, b_{1}, \ldots, b_{k}$ está em conforme com uma $/ C$ se $a_{1}, \ldots, a_{n}$ $b_{1} \ldots, b_{k}$ pode ser considerada uma instanciaça de $<S_{1}, S_{2} \ldots, S_{m}>$ :

- O suporte e a confidencía são opcionais. O usuário pode especificar suporte e confidencia minimos para que as regras sejam apresentadas no resultado.

Conhecimentos Imprecisos ( $\mathrm{Cl}$ ) O conhecimento impreciso possibilita informar um conhecimento que o especialista supōe ser verdadeiro. Um Cl l é uma expressão na forma:

$\left(I\left(<S_{1}, S_{2}, \ldots, S_{m}, V_{1}, V_{2} \ldots, V_{n}>\right)\right.$ Isuporte. confidencial

em que:

- Cada $S_{i}$ ou $V_{j}$ sào equivalentes aos elementos $S_{k}$ de uma $I C$; 
- Uma regra $a_{1}, \ldots, a_{n} \rightarrow b_{1}, \ldots b_{k}$ está em conforme com um $(I$ se ela pode scr considerada uma instanciaçào do $C \%$;

- O suporte e a confidência são opcionais, como na especificação das Impres sōes Gerais.

Conhecimentos Precisos $(C l)$ Deve ser especificado um $C l$ quando o usuário sabe da existência de uma associação na base de dados. C $P$ são expressos na forma: $\left(P\left(<S_{1}, S_{2}, \ldots, S_{m} \rightarrow V_{1}, V_{2}, \ldots, V_{y}>\right)\right.$ /suporte, confidêncial em que:

- Cada $S_{i}$ ou $V$, é um item da base de dados;

- Uma regra $a_{1}, \ldots, a_{n}, \cdots b_{1}, \ldots, b_{k} /$ suporte, confidencial é equivalente a um $C l$ se a regra é equivalente a $S_{1}, S_{2} \ldots, S_{m} \rightarrow V_{1}, V_{2}, \ldots, V_{y}$. Uma regra está em conforme ou é inesperada com relação a um Cl' dependendo do valor do suporte e da confidència:

- O suporte e a confidência sāo obrigatórios.

Analisando o conjunto de regras No processo de avaliação das regras, o aplicativo AIAS realiza as análises de Identificação de Conformidade. Conseqüente Inesperado. Antccedente Inesperado, e Antecedente e Conseqüente Inesperados, apresentadas a seguir (Liu, Hsu, Ma, \& Chen 1999):

Identificação de Conformidade Uma regra está em conformidade com o conhecimento fornecido se o antecedente e o conseqüente da regra "casam" com um subconjunto do conhecimento fornccido. Este tipo de análise pode ser utilizado para verificar quais regras estão totalmente ou parcialmente em conformidadc com o conhecimento fornecido pelo usuário.

Conseqüente Inesperado Nestc tipo de análisc, são apresentadas as regras em que o antecedente "casa" com um subconjunto do conhecimento fornecido pclo usuário, mas o conseqüente nāo. Nesse critério, são apresentadas as regras que sāo contrárias ao conhecimento do usuário.

Antecedente Inesperado São apresentadas as regras cujo conseqüente "casa" com algum subconjunto do conhecimento fornecido, mas o antecedente nào. Nesse critério, é mostrado ao usuário condiçōes näo previstas por cle que podem levar a uma determinada condição no conseqüente da regra. 
Antecedente e Conseqüente Inesperados Neste tipo de análise, são identificadas as regras em que ambos o antecedente e conseqüente não "casam" com nenhum subconjunto do conhecimento fornecido pelo usuário. Neste critério, sāo apresentadas regras cujo antecedente e conseqüente são desconhecidos pelo usuário.

Componente de Visualização Após os conjuntos de regras terem sido analisados, as regras sāo apresentadas em uma ferramenta de visualizaçāo que visa facilitar a identificaçāo das regras mais interessantes ao usuário (Liu. Hsu, Ma, \& Chen 1999).

Deve-se observar que a têcnica utilizada na ferramenta AIAS ć itcrativa c interativa. de maneira que após ter visualizado o resultado da análise na ferramenta de visualização, é permitido ao usuário adicionar conhecimentos ou revisar o conhecimento fornecido previa mente para entāo realizar uma nova análise.

\subsection{Sumário das Medidas Apresentadas}

Nesta seção, é apresentado um sumârio das medidas de avaliação de regras apresentadas nas seçōes anteriores. Essas medida são classificadas de acordo com dois critérios, como pode ser observado na Tabela 3.3. A coluna Problema apresenta o tipo de problema tratado pelas regras utilizadas por cada medida e a coluna Tipo indica se a medida é objetiva ou subjetiva. A coluna Referência cila uma publicação relevante em que a medida é especificada.

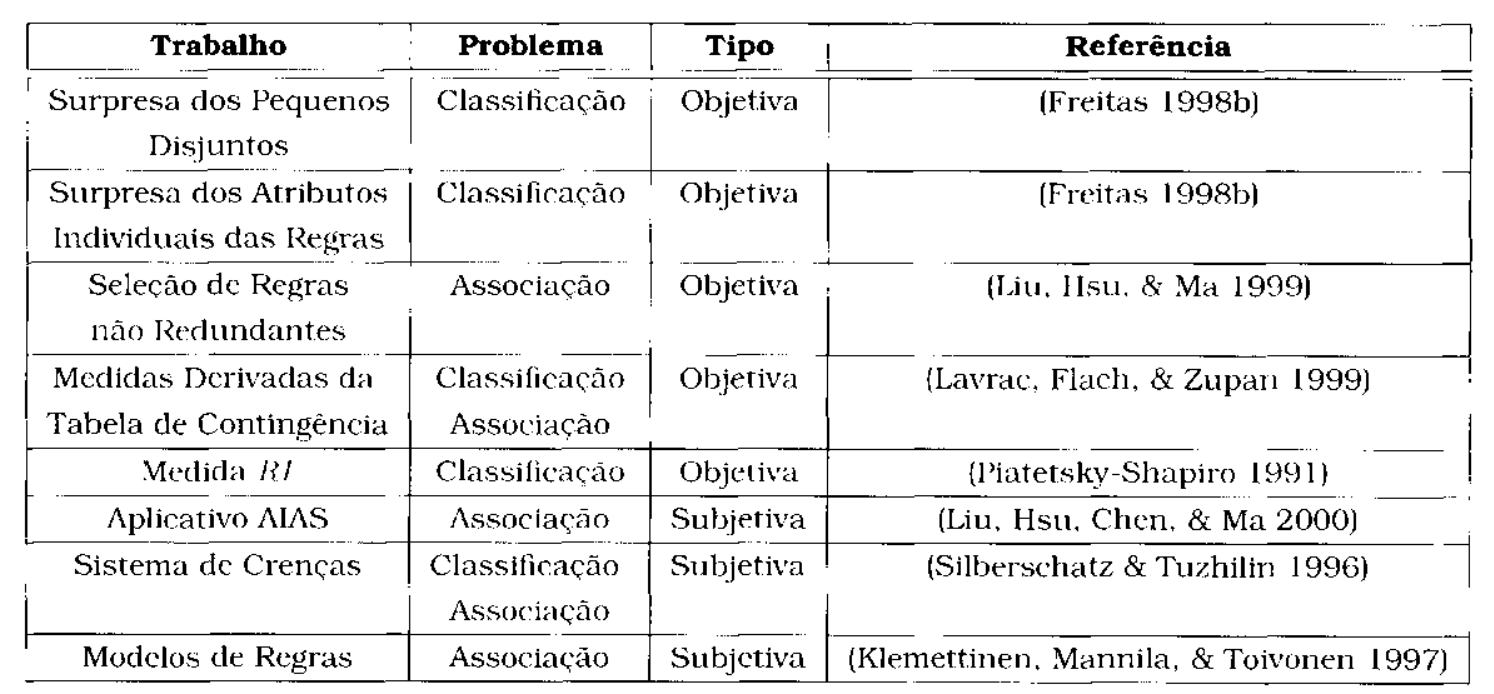

Tabela 3.3: Classificaçāo das Medidas de Avaliação de Conhecimento

Pode-se observar na Tabela 3.3 que tanto para os tipos de medidas objetivas quanto para as subjetivas existem medidas para tratamento de regras de classificaçāo e de associação. 
Entretanto, caso alguma medida adequada para somente um tipo de regra tenha alguma caracteristica interessante, esta possivelmente pode ser modificada para adequar-se também para um outro tipo de regra. Pode ser observado também na tabela que não foram apresentadas medidas para tratamento de regras de regressão. Isto pode ser contornado pela adequação de alguma dessas medidas para permitir o tratamento deste tipo de regrat (Pugliesi, Dosualdo, \& Rezende 2003).

\subsection{Considerações Finais}

Em diversas atividades do processo de Extracào de Conhecimento de Bases de Dados, a quantidade de padrões extraidos pode ser bastante grande. Esse volume pode sobrecarre gar o usuário, dificultando a tarefa de identificaçāo do conhecimento interessante. Dessa maneira, diversos trabalhos têm sido desenvolvidos no sentido de auxiliar o usuário na identificação e interpretação do conhecimento interessante.

A interessabilidade de um padrão se refere ao grau de interesse que o usuário possui sobre o mesmo. Na tentativa de determinar o grau de interesse de um padrāo para o usuário, diversas medidas de avaliação de padrões foram apresentadas. Essas medidas podem ser objetivas. quando dependem somente dos dados e da estrutura do padrào, ou subjetivas, quando consideram também aspectos relacionados ao conhecimento do usuário para identificar os padrōes interessantes. Para que se possa fazer uma avaliaçāo de interessabilidade realmente válida, diversos tipos de medidas devem estar disponiveis para o usuário. A utilizaçāo conjunta de medidas objetivas e subjetivas pode permitir que o conjunto dos padrōes a ser analisado manualmente pelo usuário seja bastante reduzido.

Assim, a utilizaçāo das medidas objetivas e subjetivas em um Ambiente para Exploração de Regras pode representar um excelente auxilio na identificação das regras interessantes. As medidas objetivas podem ser utilizadas para filtrar o conjunto inicial de regras a ser analisado e as medidas subjetivas podem ser utilizadas para permitir aos usuários focarem seu interesse em um pequeno conjunto de regras. Nesse sentido, no próximo capitulo e apresentado o Ambiente para Descoberta de Conhecimento Discover, alguns requisitos importantes de um Ambiente para Exploração de Regras, assim como é apresentado de maneira geral o Ambiente RULEE a ser integrado ao Discover. 


\section{Capítulo 4}

\section{Ambiente para Exploração de Regras}

\subsection{Considerações Iniciais}

Por ser um ramo de pesquisa relativamente recente e complexo, existem poucas ferramentas quc suportam o processo de Extração de Conhecimento de Bases de Dados como un todo, isto é, que automatizam o processo do início ao fim e que possuam uma variedade de técnicas disponiveis para utilização em cada uma de suas etapas. Esse fato é agravado pela utilização. por parte das ferramentas, de algoritmos proprietários. limitando ainda mais o trabalho dos pesquisadores. Dessa maneira. é comum aos pesquisadores desenvolverem aplicativos que os auxiliem na realizaça de seus experimentos científicos.

Dessa maneira, os pesquisadores do Laboratório de Inteligência Computacional (LABIC) do Instituto de Ciências Matemáticas e de Computação (ICMC) da USP/Sāo Carlos que trabalham com Aprendizado de Máquina e Mineraçāo de Dados sentiram-se motivados em desenvolver um ambiente que integre um conjunto de ferramentas para apoiar o processo de Extraçāo de Conhecimento de Dados e 'Textos como um todo, abrangendo os diversos trabalhos que vêm sendo desenvolvidos no laboratório, a fim de satisfazer suas necessidades relativas às pesquisas referentes ao processo. Este ambiente foi intitulado Discover c tem como objetivo dar suporte às fases do processo de Extração de Conhecimento. desde o Pré-processamento dos dados até o Pós-processamento do Conhecimento.

Recentemente, tem surgido a necessidade do desenvolvimento de um ambiente que permita o Pós-processamento em um ambiente colaborativo para auxiliar os usuários do processo de Extração de Conhecimento na compreensào. identificação do conhecimento interessante, além de possibilitar o acesso remoto a esse conhecimento. Nesse sentido, este capítulo fornece uma breve descrição de um Ambiente para Exploraçāo de Regras, focando 
em seus principais requisitos, bem como apresenta o Ambiente Discover ao qual o Ambiente para Exploração de Regras deve cstar integrado.

\subsection{O Ambiente Discover}

Com o objetivo de forneccr um ambiente integrado para apoiar as etapas do processo de Extração de Conhecimento de Dados e Textos, foi proposto o Ambiente Discover (Baranauskas \& Batista 2000). Nesse ambiente sāo utilizados algoritmos de AM implementados pela comunidade, bem como módulos com finalidades específicas desenvolvidos pelos pesquisadores do LABIC. Entre as funcionalidades desses módulos estāo: Pré-processamento de dados, Pré-processamento de textos e Pós-processamento de conhecimento.

Como ilustrado na Figura 4.1, o Ambiente Discover é capaz de acessar os dados na forma atributo-valor ou no formato texto, devendo conseqücntemente estar disponivel um conjunto de métodos para Pré-processamento de dados e de textos. Caso a quantidade de dados exceda a capacidade dos algoritmos de extração de padrōes, amostras representativas devem ser geradas para serem fornecidas aos algoritmos. Os resultados dos algoritmos de extração de padrōes ou modelos podem ser avaliados através de diversas medidas. entre elas precisão, compreensibilidade e interessabilidade.

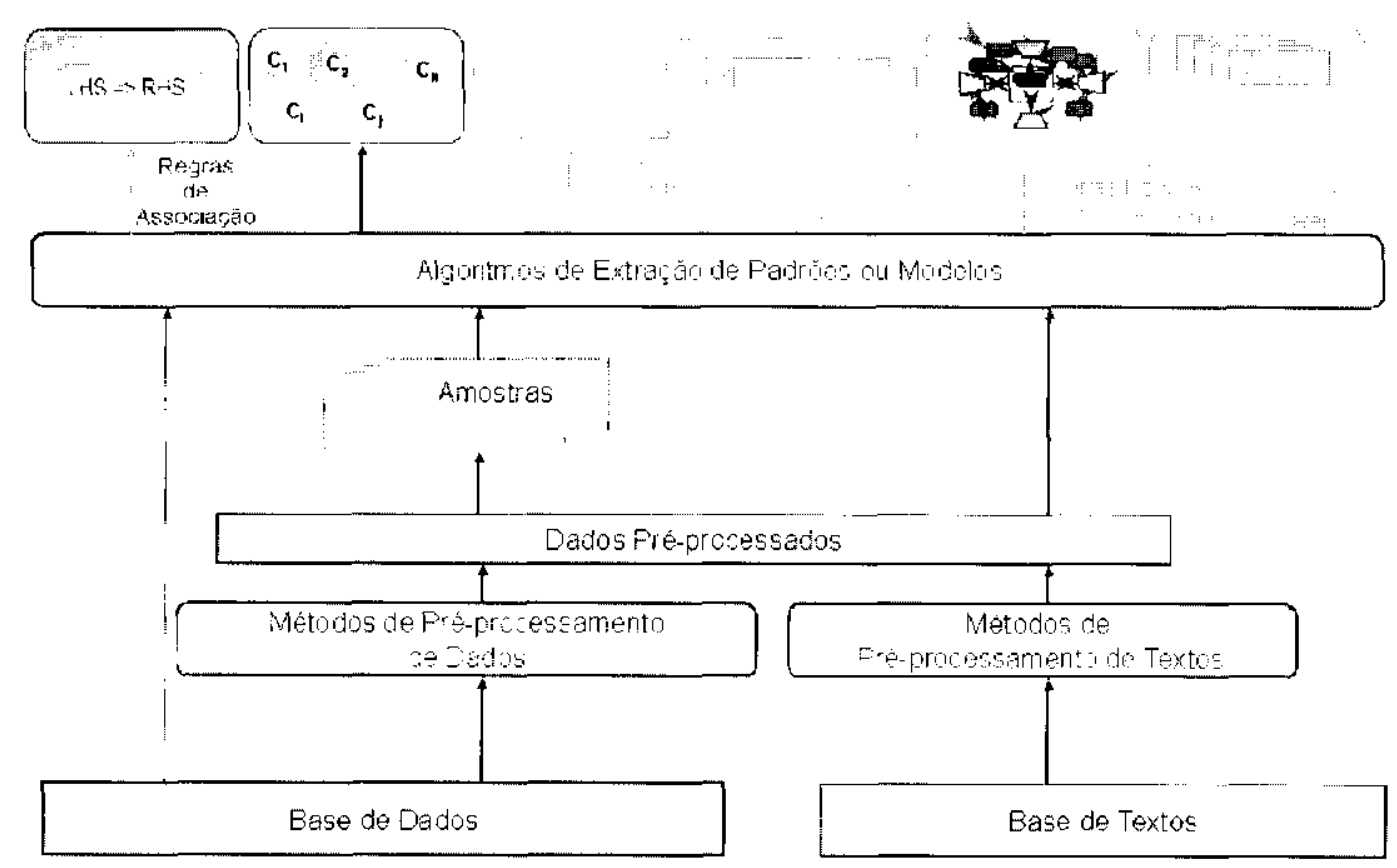

Figura 4.1: Estrutura do Ambiente Discover

Como apresentado anteriormente, o Ambiente Discover integra trabalhos dos diversos membros do LABIC. Isto é feito principalmente através da padronização do desenvolvimen- 
to dos diversos trabalhos de forma que os componentes desenvolvidos por um pesquisador possam ser reutilizados por outros que necessitem de sua funcionalidade nas pesquisas ou experimentos, Assim, um ponto crucial é que o projeto do Ambiente Discover seja suficientemente rigido para garantir a integracào dos trabalhos desenvolvidos, mas simultaneamente seja flexivel para permitir que novas pesquisas. projetos e algoritmos que venham a ser desenvolvidos pelos membros do LABIC ou por outros pesquisadores do processo de Extraçāo de Conhecimento também possam ser integrados ao ambiente.

A princípio, o Discover consistia apenas de un repositório de scripts, os quais seriam considerados apenas como pequenos programas para realizar tarefas atomicas. Entretanto, surgiu a proposta de se criar um ambiente integrado com uma interface gráfica bem definida que auxilie, visualmente, a composição do processo de Extração de Conhecimento (Geromini 2002). Desta maneira, a interface deve permitir que o pesquisador "monte" o processo de Extraçāo de Conhecimento atraves de componentes visuais e da configuraçāo dos atributos dos mesmos.

O Ambiente Discover pode ser entendido como um conjunto de métodos que são aplicados sobre dados e textos ou sobre o conhecimento extraido a partir dos mesmos. Dessa forma, é muito importante que o ambiente ofereça facilidades para manipular dados e conhecimento. Isto é obtido pela utilização de sinlaxes padrão para a representação de dados e conhecimento, e por componentes que ofereçam um conjunto de funcionalidades básicas para manipulação de dados e conhecimento. Atualmente, existem definidas sintaxes padrāo para representaçào de dados (Batista 2001: Prati, Baranauskas, \& Monard 2001 a), de regras de classificaçāo (Baranauskas 2001 ; Prati, Baranauskas, \& Monard 200lb), regras de regressäo (Pugliesi, Dosualdo. \& Rezende 2003) e regras de associação (Melanda \& Rezende 2003), além de bibliotecas para manipulação e conversão dessas sintaxes padrão. Essas sintaxes padrāo estāo detalhadas respectivamente nas Seçōes 4.2.1, 4.2.2, 4.2.3 e 4.2 .4 .

Através de interfaces bem definidas entre os mödulos e procedimentos para conversão de dados e de conhecimento para as sintaxes padrāo, são utilizados no Discover os algoritmos já desenvolvidos, testados e consolidados pela comunidade cientifica, evitando assim sua reimplementação e garantindo maior conliabilidade aos experimentos realizados. O IALIC dispōe de diversos sistemas computacionais que implementam alguns dos métodos mais conhecidos e utilizados para extraçao de conhecimento, sendo necessária a criaçào das interfaces que permitem a utilizacāo desses sistemas de forma combinada. 
Dessa maneira, pela integração dos diversos trabalhos que vem sendo desenvolvidos e utilização dos mais diversos algoritmos. espera-se obter um ganho de produtividade dos pesquisadores através da redução da repetitividade em seus trabalhos e maior facilidade para realização de experimentos.

\subsubsection{Sintaxe Padrão para Representação de Dados}

A sintaxc padrão para representaçāo de dados foi definida em (Batista 2001) como sendo uma extensão do formato utilizado como entrada do algoritmo C4.5. Esta extensão foi realizada para adequar o formato dos arquivos de dados para as necessidades do Ambiente Discover.

Um conjunto de exemplos na sintaxe padrão para representação de dados deve apresentar dois arquivos. Os nomes dos atributos do conjunto de dados, assim como seus respectivos dominios, devem estar especificados em um arquivo names. Os valores dos atributos para os exemplos devem estar contidos em um arquivo data. Esses dois arquivos devem possuir o mesmo nome, se diferenciando somente pela cxtensāo.

Na Figura 4.2 é apresentado um exemplo de arquivo .names. Nesse arquivo, a primeira linha apresenta o nome do atributo correspondente ao atributo classe, caso ele exista. Na Figura 4.3 é apresentado um exemplo de arquivo .data correspondente ao arquivo names apresentado na Figura 4.2 .

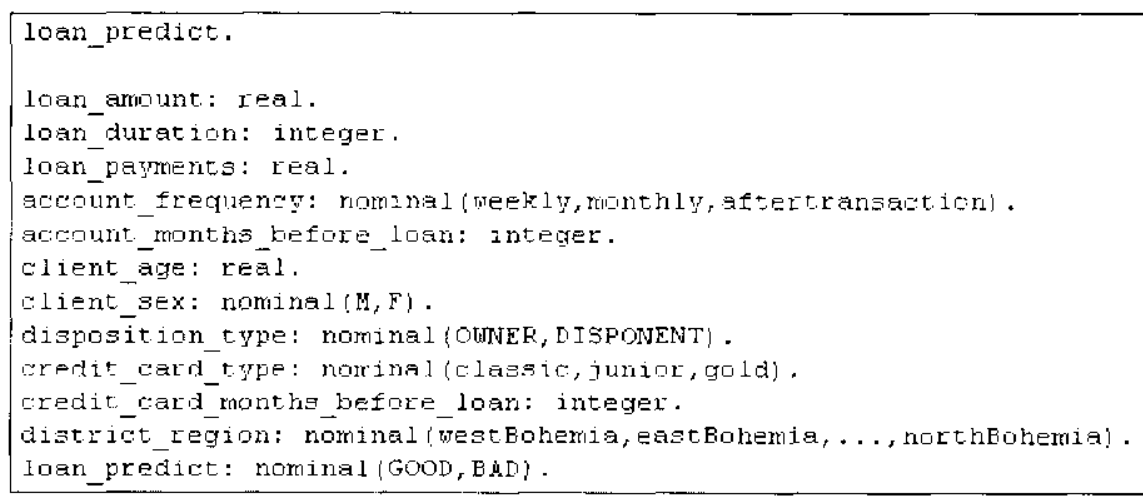

Figura 4.2: Exemplo de Arquivo names na Sintaxe Padrāo

Uma biblioteca. chamada de Dataset, foi implementada para manipulação de conjunto de dados na sintaxe padrão. Esta biblioteca apresenta métodos para conversāo de dados na sintaxe padrāo para os formatos de entrada dos algoritmos C4.5, C4.5rules, C5.0, Cubist. CN2, Newid, RT, RETIS, CART, WEKA, SNNS e SVMTorch (Batista 2001; Pugliesi. Dosualdo, \& Rezende 2003). 


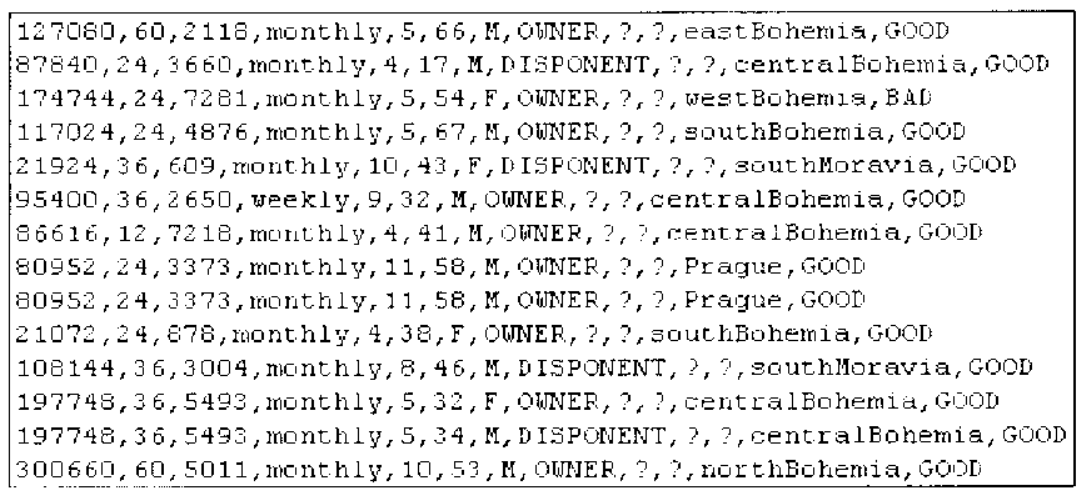

Figura 4.3: Exemplo de Arquivo data na Sintaxe Padrão

\subsubsection{Sintaxe Padrão para Representação de Regras de Classificação}

No Ambiente Discover foi desenvolvida uma sintaxe padrāo para representaçāo de regras de classificação, bem como scripts para conversão de regras ou árvores de decisāo extraídas por diversos algoritmos de Aprendizado de Máquina para esse formato padrāo, além de scripts para cálculo da tabela de contingência para cada regra (Prati, Baranauskas, \& Monard 2001b; Prati, Baranauskas, \& Monard 2001a).

Na Figura 4.4 è apresentada uma pequena parte de um arquivo contendo regras de classificação no formalo padrāo. Na figura, os clementos entre colchetes correspondem aos valores da tabela de contingência de cada regra, apresentada na Seção 3.3.3, e referem-se respectivamente a $f_{b h}, f_{h,}, f_{\bar{h},}, f_{\bar{b},}$ e n. Quando existe algum valor desconhecido nos dados, os valores da tabela de contingência encontram-se após o caracter?.

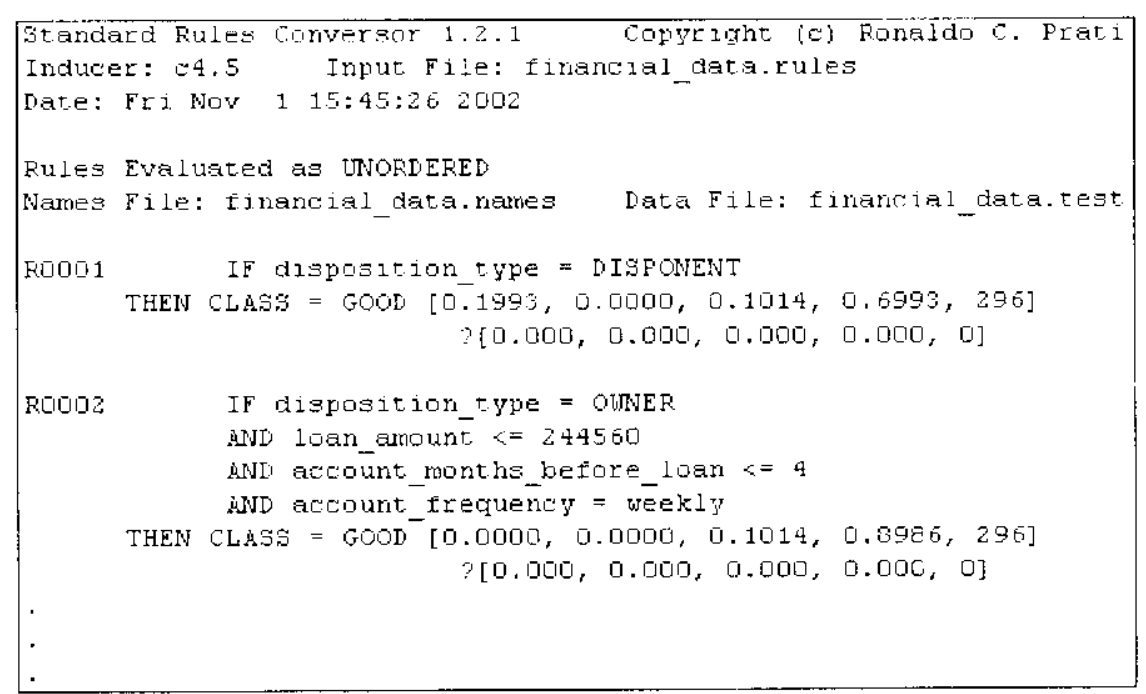

Figura 4.4: Exemplo de Arquivo de Regras de Classificação na Sintaxe Padrão 
Existem implementados scripts para conversão da saida dos algoritmos ID3. C4.5, C4.5rules, C5.0/Sec5, CN2, OC1, Ripper, T2 e MC4 para o formato padrāo de regras de classificação (Prati. Baranauskas, \& Monard 2001b). Para o cálculo dos valores da tabela de contingência e geraçāo dos arquivos no formato padrāo estendido foram desenvolvidos scripts por Prati. Baranauskas, \& Monard (200la).

\subsubsection{Sintaxe Padrão para Representação de Regras de Regressão}

Foi desenvolvida também uma sintaxe padrão para representaçāo de regras de regressāo adequada para cnglobar o tipo de representação da hipótese induzida por vários algoritmos de regressão. Alèm da definiçāo da sintaxe para regras de regressão, foram desenvolvidos scripts para conversāo dos conjuntos de exemplos da sintaxe padrāo do Discover para a sintaxe dos algoritmos M5, RT, Cubist. CART e RETIS. e conversāo da saida desses algoritmos para a sintaxe padrão de regressão. Todo essc trabalho foi desenvolvido por Pugliesi, Dosualdo, \& Rezende (2003).

Assim como nas sintaxes padrāo para representação de regras de classificaçāo c associaçào, é interessante que a sintaxe padrão para regras de regressāo apresentasse a labela de contingência para cada regra. Entretanto, regras de regressão nāo predizem um valor calegorico e sim um valor numérico, dificultando o cálculo do número de exemplos falsos e verdadeiros quanto ao atributo meta, por este ser continuo. Portanto, o cálculo dos valores relacionados à $H$ e $\bar{l}$ não são triviais. Entretanto, foi definido por Pugliesi, Dosualdo, \& Rezende (2003) um método para o cálculo da tabela de contingência para regras de regressão.

Na Figura 4.5 c aprescntado um exemplo contendo regras de regressào escritas na sintaxe padrão juntamente com a freqüencia relativa de cada um dos quatro valores da tabela de contingência e o número total de exemplos. Para cada regra, os elementos entre colchetes referem-se respectivamente a $\int_{h,}, f_{b \bar{h}}, f_{b,}, f_{\overline{b h}}, n$.

\subsubsection{Sintaxe Padrão para Representação de Regras de Associação}

Conforme a padronizaçào definida para classificação e regressão. também loi delinida para o Discover uma sintaxe padrāo para representação de regras de associação. Nesta sintaxe, para cada regra também estão presentes os valores da tabela de contingência. Uma regra de associaçào na sinı axe padrāo obedece à formatação apresentada na Expressão 4.1. 


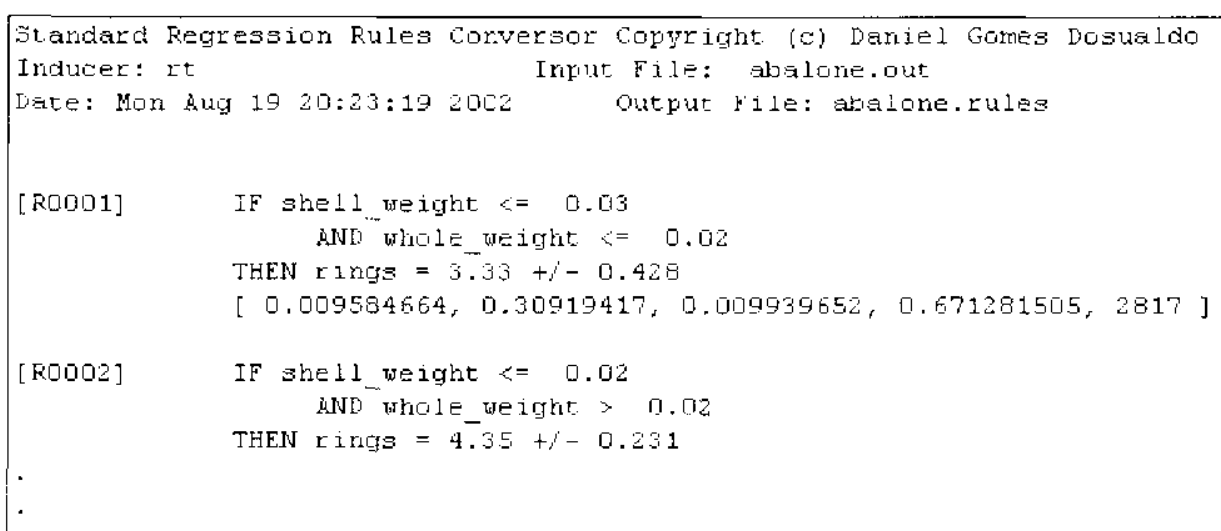

Figura 4.5: Exemplo de Arquivo de Regras de Regressão na Sintaxe Padrão

Um exemplo de um conjunto de regras de associação na sintaxe padrão é fornecido na Figura 4.6. Tèm sido desenvolvidos scripts para conversão dos dados na sintaxe padrão de exemplos para o formato de entrada dos algoritmos de extração de regras de associação Apriori, Magnumopus e do software Mineset. além de scripts para conversão da saída desses algoritmos para a sintaxe padrão de associacão.

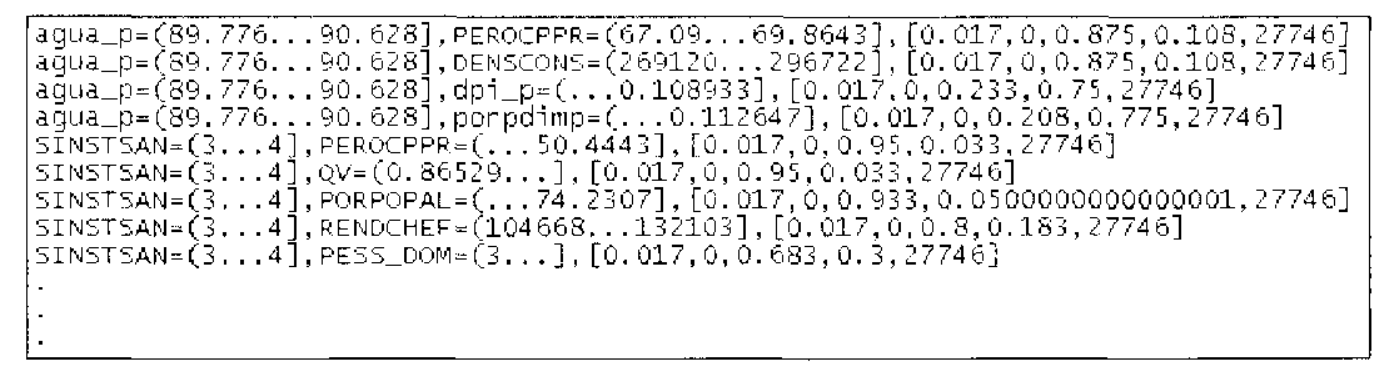

Figura 4.6: Exemplo de Arquivo de Regras de Associação na Sintaxe Padrão

\subsection{Requisitos de um Ambiente para Exploração de Regras}

Como já mencionado, muita pesquisa tem sido feita no sentido de desenvolver medidas para avaliaçāo de regras, e muitos protótipos têm sido desenvolvidos. No entanto. percebeu-sc que nāo é possivel definir uma melhor medida de avaliaçāo de conhecimento em todos os dominios (Freitas 1998a; Freitas 1998b). Somando-se a isso o fato de que todas essas medidas e metodologias normalmente são desenvolvidas independentemente. não é possivel a utilizaçāo de um único sistema para avaliação de regras no qual diversos tipos de análises possam ser feitos.

Além disso, apesar do processo de Extração de Conhecimento ter sido definido como "processo de identificação de padrões nos dados que sejam válidos, novos, potencialmente 
úteis e comprecnsiveis a seres humanos", muitos trabalhos têm tratado a validade do conhecimento, mas poucos têm tratado a novidade, utilidade e compreensibilidade (Pazzani 2000). Em (Pazzani. Mani, \& Shankle 1997) é mostrado que o conhecimento descoberto por algoritmos de extração de regras de classificação pode não fazer sentido para os especialistas do dominio. Um conhecimento nāo compreensivel, possivelmente, também não será útil ao usuário em um processo de tomada de decisāo.

Nesse contexto, o desenvolvimento de um Ambiente para Exploração de Regras que auxilie os especialistas do dominio e usuários finais na comprecnsão e identificaçăo do conhecimento interessante é de grande relevância para o sucesso do processo de Extração de Conhecimento. Além disso, o ambiente pode possibilitar que novas pesquisas relacionadas aos métodos para avaliação de regras e ao processo de MD como 11 m todo possam ser feitas. $O$ desenvolvimento de um Ambientc para Exploraçào de Regras vem suprir essas deficiências por disponibilizar o conhecimento para facilitar o acesso aos usuários, além de agregar métodos para avaliar as regras quanto a precisão. compreensibilidade ou interessabilidade, por exemplo.

Um aspecto importante do processo de Extração de Conhecimcnto é que normalmente as regras extraidas se cncontram em arquivos texto, o que dificulta sua análise. Pela utilizaçāo de ferramentas comerciais mais completas, algumas funcionalidades adicionais podem estar disponiveis, como por exemplo ferramentas $3 D$ para visualizaçāo dos modelos. Entretanto, cxistem poucos métodos implementados para auxiliar na análise, identificaçāo e utilizaçāo do conhecimento interessante.

A implementaçào de um Ambiente para Exploração de Regras implica no desenvolvimento de uma arquitetura para facilitar o cálculo e armazenamento do valor de medidas de avaliação de regras, além de facilitar a incorporação de novos métodos para cálculo de novas medidas. É interessante que cada conjunto de regras disponibilizado apresente um conjunto de medidas tanto objetivas quanto subjetivas armazenadas visando o apoio ao usuário em sua análise. Entretanto. com o acúmulo desses dados sobre avaliação, uma nova base de dados valiosa para os pesquisadores do processo de Extraçào de Conhecimento também fica disponivel. A partir desses dados, análises podem ser feitas sobre as medidas ou métodos de avaliaçāo visando. por exemplo, identificar medidas mais efetivas para avaliaçāo, relacionamentos entre as mesmas. entre outras. Somando-se a esses dados o feedback fornecido pelos usuários durante a consulta às regras disponibilizadas, algumas análises bastante intercssantes podem ser feitas. Dentre essas análises utilizando o feedback do usuário, destaca-se a possibilidade da análise das funcionalidades mais 
utilizadas com o objetivo de encontrar as medidas de avaliação mais efetivas e verificar a existência de alguma relaçāo entre medidas objetivas e subjetivas

Para auxiliar o usuário na compreensão e identificaçāo do conhecimento interessante, algumas caracteristicas desejảveis para um Ambiente para Exploração de Regras sāo:

Interatividade e Iteratividade Como citado anteriormente, muitos pesquisadores do processo de Extração de Conhecimento de Bases de Dados têm concentrado suas pesquisas na fase de descoberta do conhecimento. Entretanto, a inferencia de padròes é somente uma pequena parte do problema de se obter conhecimento útil a partir de dados. Além disso, o processo de Extração de Conhecimento de Bases de Dados é descrito de maneira a enfatizar a importância da intcraçāo com o usuário e iteração entre suas fases, sendo que a principal iteração do processo è a repetição das fases de Pré-processamento e Extraçāo de Padrōes após a análise do conhecimento na etapa de Pós-processamento. A qualidade do conhecimento extraido pode ser melhorada cm cada iteração ao reutilizar informações coletadas nas iterações anteriores (Kle mettinen, Mannila, Ronkainen, Toivonen, \& Verkamo 1994; Klemettinen, Mannila, \& Toivonen 1996; Klemettinen, Mannila, \& Toivonen 1997).

No entanto, a iteratividade e interatividade do processo de Extração de Conhecimento também podem ser realizadas na fase de disponibilizaçāo do conhecimento. A iteratividade dessa fase pode ser leita através da visualização do conjunto de regras. permitindo ao usuário escolher a cada momento um tipo de filtro ou medida para ordenaçāo das regras $e$ assim identificar as mais interessantes. Caso não seja obtido sucesso, outros filtros podem ser escolhidos. Desta maneira, um aspecto extremamente importante para um Ambiente para Exploraçāo de Regras é permitir que o usuário possa explorar iterativamente e interativamente o conhecimento, especifican do a cada instante o foco de interesse desejado.

Medidas de Avaliação Outro requisito importante para um Ambiente para Exploração de Regras é a disponibilizaçāo ao usuário de diversos métodos para poda e ordenaçāo dos padrōes. Além disso, tanto as medidas objetivas quanto as subjetivas devem estar disponíveis para seleção de regras. As medidas objetivas podem ser consideradas como um filtro inicial para seleção de regras. enquanto que medidas subjetivas podem ser utilizadas para focar o interesse do usuário em um conjunto de regras realmente interessante (Freitas 1998a). 
Na disponibilização, as medidas de avaliação podem ser utilizadas para:

Poda do conjunto de regras O usuário pode escolher alguma medida de avaliação para selecionar um subconjunto das regras apresentadas. Para isso, cle pode definir algum limite de valor para a medida, sendo apresentadas somente aquelas regras em que o valor da medida é superior ou inferior ao limite estipulado, ou utilizar alguma medida que selecione somente regras interessantes segundo algum critério definido:

Ordenação O usuário pode escolher alguma medida para ordenar o conjunto de regras apresentado.

Visualização dos Modelos ou Regras Como em Mineraçāo de Dados busca-se por padrōes de comportamento dos dados que nāo são previamente conhecidos pelos usuários, a compreensão dos modelos encontrados pode ser difícil. Dessa maneira. a compreensảo dos modelos é um tópico que precisa ser bastante pesquisado. Uma das maneiras utilizadas para auxiliar os usuários na compreensāo e interpretaçāo do conhecimento é através da utilização de ambientes em que os modelos possam ser visualizados de maneira adequada pelo usuário.

Diversas ferramentas de Mineração de Dados possuem módulos de visualizaçāo de modelos e de dados bastante completos e úteis. Entretanto, nessas ferramentas a visualização é realizada somente nas estações em que a ferramenta está instalada. Um aspecto adicional de um Ambiente para Exploração de Regras é a possibilidade de visualização do conhecimento através de uma interface baseada na WWW. Algumas vantagens obtidas pela visualização do conhecimento pela WWW são a independència de plataforma. facilidade de uso e, especialmente, a acessibilidade, permitindo a visualizaçāo do conhecimento pelos usuários do processo indepcndente de sua localizacāo fisica (Grinstein \& Ward 2002; Ma, Liu, \& Wong 2000].

Durante a visualização de um modelo, é importante que o usuário possa interagir com ele. Isso significa permitir que o usuário possa selecionar valores de atributos c ver os efeitos que isto pode causar. Esta interaçāo provê a compreensão de causa-efeito, isto é, o usuário pode entender quanto cada atributo do conjunto de dados afeta a classificação final (Thearling, Becker, DeCoste, Mawby, Pilote. \& Sommerfield 2002).

A visualização interativa dos modelos deve permitir que usuários com pouco conhecimento em Aprendizado de Máquina e Estatística sejam capazes de compreender 
fatores que influenciam nas classificaçoes e que eles também possam visualizar o modelo completo para compreenderem como os exemplos sào tratados (Becker, Kohavi. $\&$ Sommerficld 2002)

Integração Uma outra forma de se auxiliar o usuário na compreensão do conhecimento é fornecer um contexto. Esite contexto pode ser fornecido, por exemplo, ao mostrar a relação existente entre o conhecimento extraido e o conjunto de dados em que fol gerado. Isto é chamado de integraça (Thearling, Becker, DeCoste, Mawby, Pilote, \& Sommerficld 2002). Uma forma de integração é a possibilidade de se selecionar parte de um modelo e obter acesso aos dados originais a partir dos quais essa parte foi gerada.

Ambientes Colaborativos Outro requisito importante para um Ambiente para Exploraçāo de Regras é que ele seja um ambiente colaborativo, propiciando a interação e integração entre os diversos usuários do ambiente (Foster \& Gee 2002). No caso de um Ambiente para Exploração de Regras, o primeiro passo para fornecer um suporte eficiente a múltiplos usuários é armazenar as seçoes dos usuários em um sistema de $\log$.

O sistema de logs deve armazenar os trabalhos dos usuários, permitindo que eles possam repeti-los ou que outros usuários possam analisá-los (Foster \& Gee 2002). Isto pode permitir um ganho geral de produtividade entre os usuários do ambiente. além de possibilitar que as informaçōes contidas nos logs possam ser utilizadas pelos analistas do processo de Extração de Conhecimento para auxiliar na obtenção de melhores resultados em uma próxima iteraçāo do processo.

A utilização da WWW como interface para disponibilização de regras pode facilitar também a implementaçăo de um ambiente que permita o trabalho cooperativo dos usuários do processo de Extraçāo de Conhecimento. Dessa maneira, os diversos usuários do processo podem analisar e compreender o conhecimento individualmente, forneccrem e compartilharem feedback para o ambiente na forma de comentários, idéias. dicas ou sugestōes (Ma, Liu, \& Wong 2000). Além disso, através dessá interface, os diversos usuários finatis e especialistas do dominio poderão analisar os conjuntos de regras em suas estaçōes de trabalho sem necessidade de instalar as ferramentas de Mineraçāo de Dados. 
A partir das informaçōes contidas nos logs de utilizaçāo dos usuários e de seu feed back, algumas anảlises poderāo ser feitas. entre elas:

- Permitir aos especialistas do processo de Extração de Conhecinento verificar o que é de interesse do usuário, fornecendo novos subsídios para apoiar uma prôxima iteração de todo o processo e trazer resultados mais interessantes para o usuário final;

- Possibilitar uma análise das funcionalidades mais utilizadas com o objetivo de encontrar as medidas de avaliação mais efetivas:

- Verificar a cxistência de alguma rclação entre medidas objetivas c subjetivas. dadas as consultas realizadas pelos usuários.

Na seção seguinte é apresentado o Ambiente para Exploração de Regras desenvolvido neste projeto de mestrado.

\subsection{O Ambiente RulEE}

Neste projeto de mestrado foi proposto um Ambiente para Exploração de Regras que viabilize tanto a análise quanto a disponibilização de regras. Com intuito de mostrar a viabilidade desse tipo de ambiente, foi desenvolvido o Ambiente RulEE (Rule Exploration Environment).

O RulEE apresenta alguns dos requisitos apresentados anteriormente e contem as funcionalidades necessárias para mostrar a vialibilidade do ambiente. Nas próximas seçóes. o Ambiente RulEE ć aprescntado, sendo especificadas quais funcionalidades foram implementadas. Também ć apresentada uma comparação do Ambiente RulEE com ambientes com funcionalidades semelhantes existentes na literatura. No Capitulo 5 , a implementaçăo do Ambiente RultE c apresentada em mais detalhes.

\subsubsection{Descrição Geral}

O Ambiente RulEE suporta análise de regras de classificação. regressão e associação. $O$ ambiente tem como cntrada arquivos com conjuntos de regras representados utilizando a sintaxe padrão definida no Discover. Por utilizar esses formatos de regras e pela utilizacão dos scripts de conversão dos diversos tipos de regras para a sintaxe padrão. também implementados no Discover, podem ser inseridas no ambiente as saidas de uma grande variedade de algoritmos para Extração de Conhecimento de Dados. Dentre esses algoritmos. encontram-sc os mais utilizados na literatura, como o C4.5. CN2, Cubist e Apriori. A lista 
completa dos algoritmos suportados pelos scripts de conversão para as sintaxes padrāo foi apresentada nas Seçōes 4.2.1, 4.2.2, 4.2.3 e 4.2.4.

O processo de obtençāo das regras a serem manipuladas pelo Ambiente RulEE esta exemplificado na Figura 4.7. De acordo com a figura, inicialmente, os conjuntos de dados de origem sāo pré-processados e convertidos para a sintaxe padrāo de dados do Discover. Após a preparação dos dados e definição do algoritmo a ser utilizado, os dados sāo convertidos para o formato de cntrada do algoritmo selecionado. Deve-se ressaltar que, para cada tipo de conjunto de regras, diversos algoritmos podem ser utilizados. $\Lambda$ conversāo pode ser leita utilizando os métodos definidos na biblioteca para tratamento dos dados na sintaxc padrão (Batista 2001).

Após a execuçào dos algoritmos, seus resultados sāo convertidos para a sintaxe padrāo do lipo de problema tratado (classificaçāo, regressāo ou associaçāo). A partir das regras expressas na sintaxe padrāo e de um conjunto de dados de teste, devem ser utilizados os scripts para cálculo dos valores da tabela de contingência (Prati, Baranauskas, \& Monard 2001a; Pugliesi, Dosualdo, \& Rezende 2003; Melanda \& Rezende 2003). Os resultados desses scripts sāo utilizados como entrada no RulEE, não sendo portanto necessário o cálculo dessas informaçòes internamente no ambiente.

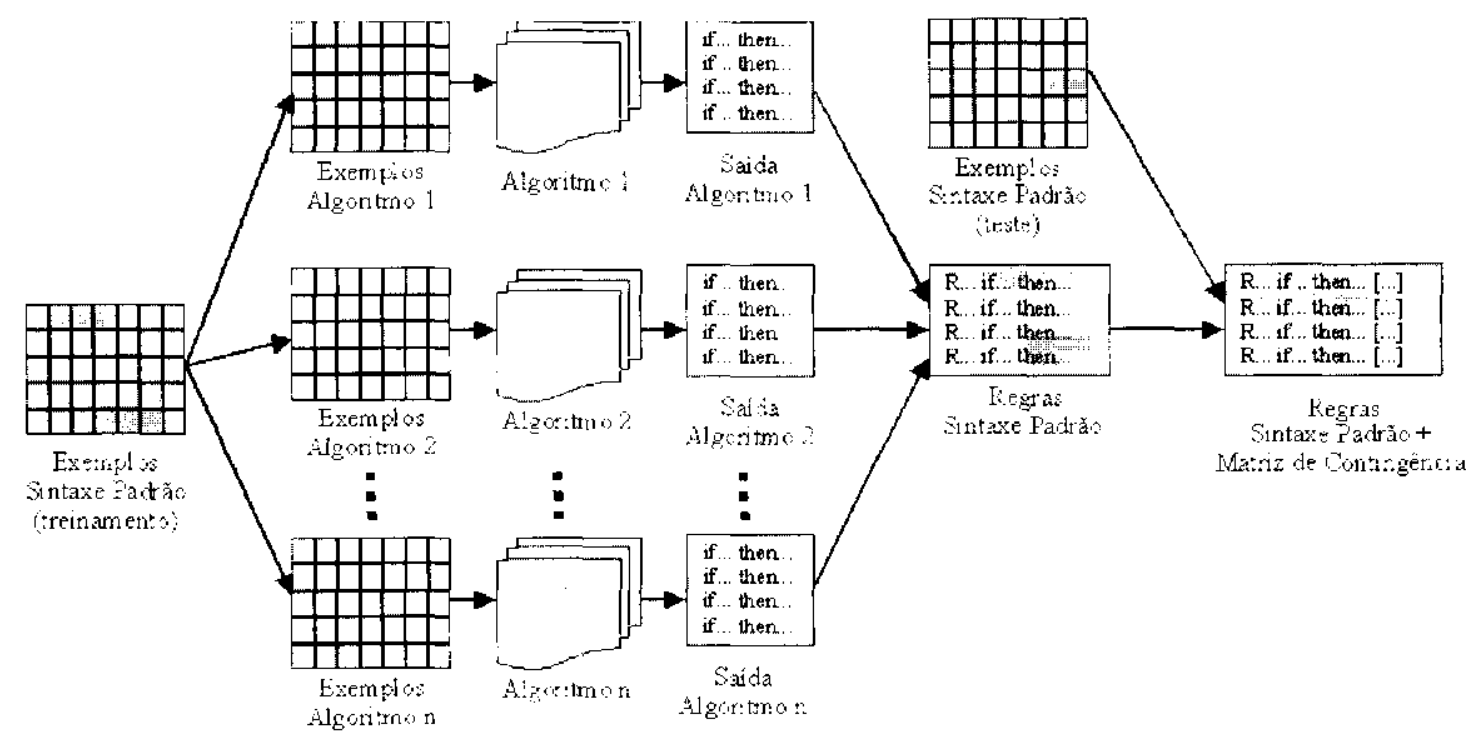

Figura 4.7: Metodologia para Obtençāo de Regras nas Sintaxes Padrão

O RulEE aprescnta um conjunto de medidas para avaliaçāo de regras para classificaçāo, regressāo e associação de forma que diversos tipos de análise possam ser realizadas. Após um conjunto de regras ter sido inserido no ambicnte, os valores das diversas medidas são calculados c ficam disponiveis para os usuários. O ambiente provè um fácil acesso 
às regras $\mathrm{e}$ aos valores dessas medidas, e permite que várias medidas sejam utilizadas de forma combinada para a análise das regras pcla aplicação de restriçocs ou filtros e utilização de medidas para a ordenação dos conjuntos de regras. Esse acesso às regras e aos valores das medidas é possibilitado pelo uso de consultas. Além disso, com o intuito de auxiliar a criação de novas medidas e a realização de experimcntos, nesse ambiente é possivel definir de maneira simples novas medidas cujo valor pode ser oblido a partir de uma expressão que utiliza o valor de outras medidas.

I)eve-se ressaltar que vários trabalhos relacionados com a avaliaçāo de conhccimento estāo sendo descnvolvidos no Ambiente Discover. O Ambiente RulEE apresenta uma arquitetura que visa facilitar o armazenamento e disponibilização dos valores das medidas desenvolvidas permilindo uma fảcil utilização conjunta de todas as medidas existentes. O cálculo do valor de novas medidas deve ser realizado pelos procedimentos desenvolvidos pelos próprios pesquisadores, bastando ao ambiente invocar esses procedimentos de maneira correta e buscar o valor desejado no arquivo contendo o resultado da exccução do procedimento. A implementação do Ambiente RulEE permite que estas configuraçōes possam ser feitas facilmente, sem necessidade de alteração de código fonte. Desta maneira. o Ambiente RulEE é independente dos procedimentos para Pós-processamento de conhecimento.

O RulEE provê duas formas para sua utilizaçāo. A primeira é através de uma biblioleca de classes que permite o acesso às diversats funções implementadas, como inserção, recuperação de regras c de valores de medidas, bem como acesso aos dados disponíveis na base de dados do ambiente. A utilizaçāo dessa biblioteca deve ser realizada através de programas escritos na linguagem PERL, sendo voltada a usuários analistas do processo de Extracāo de Conhecimento de Bases de Dados e que necessitam de recuperar as informações em seus scripts para Pós-processamento ou mesmo para definir alguma função desejada que nāo esteja implementada no ambiente. A segunda forma de interação é atravès da interface WWW. Esta interface possui a função principal de facilitar o acesso às informações armazenadas no ambiente e apresenta as mais diversas funçoes para acesso às regras e valorés de medidas, além de facilitar a inserçāo de novos conjuntos de dados. A interface c voltada para usuários năo especialistas ou usuários que nāo necessilem da flexibilidade da utilização da biblioteca de classes. O objetivo da existência dessa interface é lacilitar o acesso e apresentação das regras descobertas atravès de uma interface mais intuitiva de maneira que os usuários finais ou especialistas do domínio possam acessá- 
las sem necessidade de o fazer através da leitura de arquivos texto, propiciando assim a disponibilização desse conhecimento na WWW.

\subsubsection{Funcionalidades do Ambiente RulEE}

Na Seçāo 4.3 foram apresentadas caracteristicas e requisitos importantes para um $\Lambda$ mbiente para Exploração de Regras genérico. O RulEE foi implementado buscando-se atender à toda especificação apresentada. Entretanto. como um primeiro trabalho desenvolvido nesse sentido, o objetivo principal foi a construçāo da arquitetura básica do ambiente, de forma a possibilitar que todas as caracteristicas propostas pudessem ser implementadas em trabalhos futuros. Dessa maneira, as principais características ou requisitos implementados no Ambiente RulEE sāo:

- As medidas objetivas para avaliação de regras descritas no framework apresentado em (Lavrac, Flach, \& Zupan 1999) e a medida RI estão disponiveis para análise;

- Implementação de consultas para recuperação dos conjuntos de regras e dos respectivos valores de medidas:

- Implementação de uma interface simples baseada na WWW;

- Interface interativa e possibilidade de análise dos conjuntos de regras pela utilização de consultas de forma iterativa;

- Armazenamento de valores inseridos por usuários como indicativos da interessabilidade, compreensibilidade, utilidade e novidade das regras, além de armazenamento de comentários anexados a regras, conjuntos de regras e consultas.

\subsection{Considerações Finais}

Recentemente, ao observar que a Extraçāo de Padrōes não deve scr a etapa final do processo de Extração de Conhecimento de Bases de Dados, o Pós-processamento de conhecimento tèm sido foco de muitas pesquisas. Nesse sentido, muitas ferramentas têm sido desenvolvidas para apoiar os usuảrios na avaliaçāo do conhecimento encontrado. A inte graçāo dessas ferramentas em um Ambiente para Exploração de Regras pode representar um auxílio efetivo para os usuários do processo na compreensão, identificação do conhecimento interessante e utilização do mesmo. Neste capitulo foram apresentadas algumas caracteristicas e requisitos importantes para um Ambiente para Exploração de Regras, assim como apresentado de maneira geral o protótipo desenvolvido neste projeto, o Ambiente RuLEE. 
Uma sintese de algumas funcionalidades existentes em ferramentas cujo objetivo é auxiliar a análise de conjuntos de regras é apresentada na Tabela 4.1. Nesta tabela estāo presentes o Ambiente RuLEE e as ferramentas AIAS, apresentada na Seçāo 3.4.3, e DSWHB, apresentada na Seção 3.3.2.

\begin{tabular}{|c|c|c|c|}
\hline Funcionalidade & AJAS & DS-WEB & RulEE \\
\hline Tipo de Problema & Associaça & Associação & $\begin{array}{l}\text { Classificação, } \\
\text { Regressão e } \\
\text { Associação }\end{array}$ \\
\hline Tipo de Análise & $\begin{array}{l}\text { Identificaça de Conformidade, } \\
\text { Conseqüente Inesperado, Ante- } \\
\text { cedente Inesperado, e Antece- } \\
\text { dente c Conseqüente Inespera- } \\
\text { dos }\end{array}$ & $\begin{array}{l}\text { Seleção de re- } \\
\text { gras não re- } \\
\text { dundantes }\end{array}$ & $\begin{array}{ll}\text { Utilização } & \text { de } \\
\text { medidas } & \text { de } \\
\text { avaliação } & \end{array}$ \\
\hline Medidas Subjetivas & $\operatorname{sim} \quad \square$ & Não & Não \\
\hline $\begin{array}{l}\text { Disponibilização } \\
\text { dos Resultados na } \\
\text { WWW }\end{array}$ & Nāo & Sim & $\operatorname{Sim}$ \\
\hline Iteratividade & Sim & Não & $\operatorname{Sim}$ \\
\hline Interatividade & sim & $\operatorname{Sim}$ & Sim \\
\hline $\begin{array}{l}\text { Disponibilizaçá } \\
\text { das Análises }\end{array}$ & Nāo & Nào & $\overline{\operatorname{Sim}}$ \\
\hline
\end{tabular}

Tabela 4.1: Síntese de Funcionalidades de Ambientes para Análise de Regras

Cada linha da Tabela 4.1 corresponde a uma funcionalidade das ferramentas. Na linha correspondente à característica Tipo de Análise, não são especificadas medidas para o Ambiente RulEE, pois as análises realizadas no ambiente são independentes de medida ou procedimento para Pós-processamento, conforme apresentado anteriormente. Para a funcionalidade Medidas Subjetivas. o Ambiente RulEE apresenta o valor Não. pois ainda não estão sendo utilizadas no ambiente medidas desta natureza, apesar dele ter sido projetado para isto. Trabalhos futuros deverão estar relacionados com a utilizaçāo destes tipos de medidas no ambiente. A caracteristica Iteratividade indica se a análise dos conjuntos de regras pode ser feita iterativamente, isto é, em diversos passos de análise, e a caracteristica Interatividade indica se o usuário pode interagir com a ferramenta. Por fim. a característica Disponibilização das Análises indica se a ferramenta pode armazenar e disponibilizar para outros usuários algum tipo de análise realizada por algum usuário.

A disponibilização de regras deve estar integrada a um ambiente para apoiar as diversas etapas do processo de Extraçāo de Conhecimento de Bases de Dados. O Ambiente para Exploração de Regras proposto neste projeto é integrado ao Discover, um ambiente que vem sendo desenvolvido em conjunto pelos pesquisadores do processo de Mineração de Dados e Aprendizado de Máquina do LABIC. Este ambiente deve apresentar uma interface integrada, com vários métodos para apoiar as diversas etapas do processo de Extração de 
Conhecimento de Bases de Dados e Textos. desde o acesso aos dados até a avaliacão do conhecimento.

No próximo capítulo é apresentada a implementação do Ambiente RulEE, sendo mostrada sua arquitetura, a base de dados, a biblioteca de classes, as formas de obtençāo de medidas, as medidas disponiveis, a intterface e as consultas que podem ser realizadas no repositório de regras e medidas 


\section{Capítulo 5}

\section{Implementação do Ambiente RulEE}

\subsection{Considerações Iniciais}

De maneira geral, o objetivo principal deste projeto de mestrado é a proposta e implementaçāo de um Ambiente para Exploração de Regras que apresente os conceitos discutidos no Capítulo 4. Conforme a proposta discutida, esse ambiente deve apoiar tanto os usuários finais, por fornecer facilidades e flexibilidade para avaliaçāo e compreensāo das regras disponibilizadas, quanto os pesquisadores do processo de Extração de Conhecimento, por auxiliar a criação e alteração de medidas de avaliação. Neste capitulo é apresentada a implementação do Ambiente RulEE (Rule Exploration Environment), que apresenta as características de um Ambiente para Exploraçāo de Regras proposto neste projeto de mestrado. descrevendo primeiramente a sua arquitetura e então detalhando seus principais elementos.

\subsection{Implementação}

A implementação do Ambiente RuLEE está baseada em três elementos:

1. Biblioteca de classes, na qual estão implementadas as funçōes disponiveis pelo ambiente;

2. Base de dados, na qual estāo armazenados o conhecimento no formato de regras, as medidas de avaliação das mesmas, os dados referentes aos usuários e os utilizados na extraçāo e leste das regras;

3. Interface, construida baseada na WWW visando facilitar o acesso aos conjuntos de regras. 
A arquitetura geral do Ambiente RulEE pode ser visualizada na Figura 5. 1 . No contexto do RulEE, o processo de análise e disponibilização de regras está baseado na idéia de se utilizar um Repositôrio de Regras e Medidas, que é a entidade principal do ambiente. Neste Repositório devem ser armazenados os conjuntos de regras, os valores das medidas e as consultas realizadas pelos usuários sobre o repositório de regras e medidas.

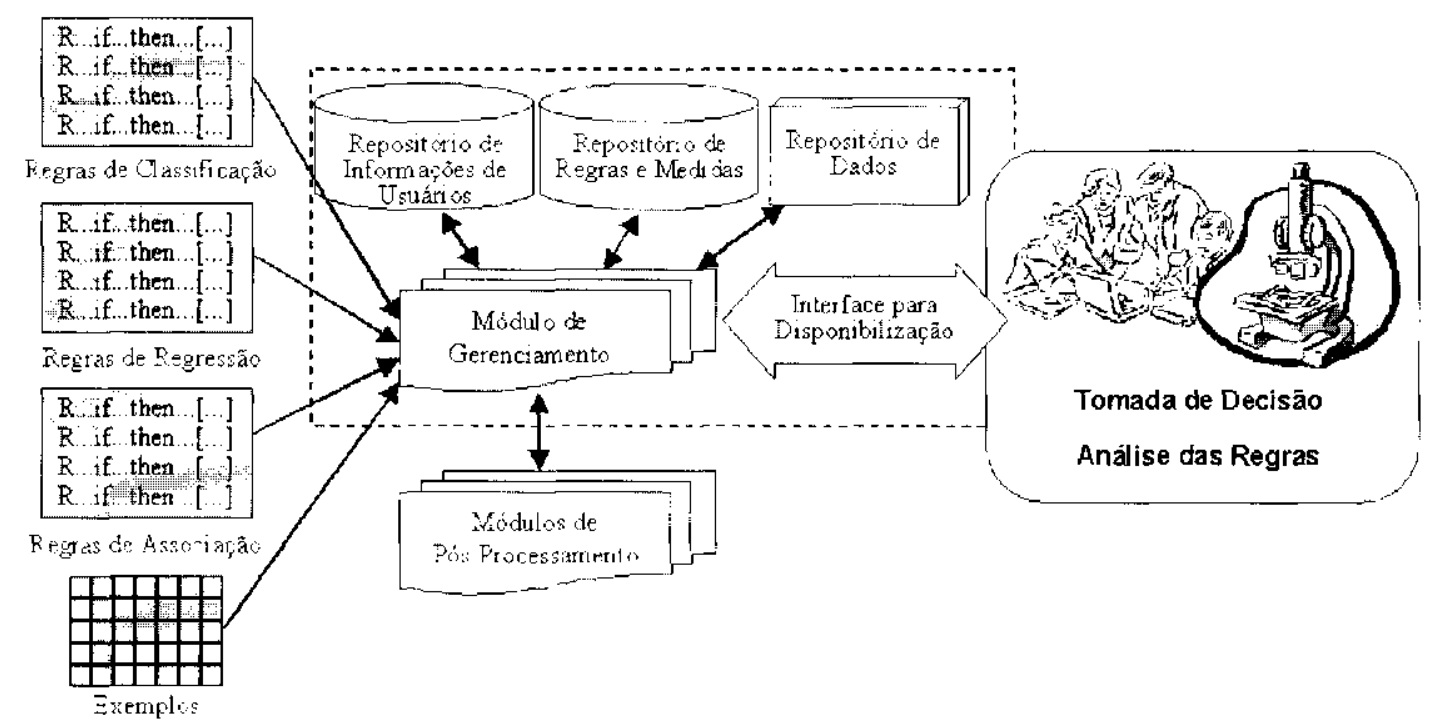

Figura 5.1: Arquitetura Geral do Ambiente RulEE

Conforme a Figura 5.1, a disponibilização das regras deve ser iniciada pela inserção no Repositório de Regras dos conjuntos de regras representados na sintaxe padrão. Esta atividade é realizada por métodos existentes no Módulo de Gerenciamento. Após estarem disponiveis no Repositorio, as regras podem ser acessadas pela interface WWW ou pela biblioteca de classes, podendo ser analisadas pelos usuários e, possivelmente, utilizadas cm um processo de tomada de decisão. Os clementos da figura que estão no retângulo pontilhado correspondem ao Ambiente RulEE.

Uma descrição mais detalhada dos elementos representados na Figura 5.1 é fornecida a seguir:

Módulos de Processamento São os programas escritos para processamento de dados, regras e informaçōes dos usuários. Seguindo o padrão de desenvolvimento do Ambiente Discover, esses programas foram implementados na linguagem PERL. Os módulos de processamento encontrados no ambiente sāo:

Módulo de Gerenciamento Responsável pelo gerenciamento das regras disponibilizadas no ambicnte. Este módulo recebe requisiçōes da Interface do ambiente, 
busca as regras correspondentes no Repositório de Regras, invoca os módulos de Pós-processamento ou rccupera algum conjunto de dados no Repositório de Dados, para então retornar o resultado da requisiçào para a Interface. Este módulo é responsável também pela obtenção ou cálculo dos valores de medidas para as regras.

O Módulo de Gerenciamento possui também um conjunto de métodos que re ccbem como entrada conjuntos de regras nos formatos padrāo de classificaçāo. associação ou regressāo, e fazem a inserção desses conjuntos de regras no Repositório de Regras e Medidas. Foram implementados métodos independentes responsáveis pela inserção das regras de classificaçāo, associação c regressão.

O Módulo de Gerenciamento está implementado como uma biblioteca de classes que realiza todo esse processamento. Uma breve descriçāo das classes disponiveis é apresentada na Seção 5.2.3.

Módulos de Pós-processamento São os módulos responsāveis pelo cálculo das medidas de avaliação das regras disponibilizadas. Esses módulos contém procedimentos para cálculo das medidas e apresentam métodos distintos para tratamento de regras de classificação, associaçào e regressăo. É importante destacar que no Ambiente RulEE sào utilizados os módulos de Pós-processamento implémentados no Ambiente. Discover. Portanto. a implementação desses módulos de Pós-processamento năo faz parte do escopo do RulEE, sendo definida somente uma interface para invocar os métodos de Pós-processamento quando necessário e para a obtenção dos valores das medidas para as regras nos arquivos contendo o resultado do Pós-processamento. Apesar de estar projetada nas tabelas e nas classes do ambiente, a utilização desses procedimentos não está completamente finalizada, ainda sendo necessária a implementação de alguns métodos. Devese ressaltar que, para a incorporação de medidas subjetivas no ambiente, faz-sc neccssária a utilização desses procedimentos.

Na implementaçāo atual, as medidas existentes no Repositório têm seus valores obtidos a partir da tabela de contingència das regras, que é calculada antes da inserção das regras no ambiente.

Uma descrição mais detalhada sobre como os procedimentos sāo executados e como os valores das medidas são obtidos pode ser encontrada na Seção 5.2.4. 
Interface Por meio da Interface, o usuário pode acessar todas as informações disponibilizadas pelo Ambiente RulEE. A Interface é bascada na WWW, a fim de aproveitar algumas de suas vantagens. como independência de plataforma e, especialmente. facilidade de utilização pelos usuários do processo independente de sua localizaçāo fisica, conforme aprescntado na Seçāo 4.3 .

Pcla Interface de disponibilizaçāo, o usuário interativamente seleciona as regras que julgar mais interessantes pela utilização das medidas para então interpretâ-las e utilizá-las. Uma outra funçāo da Interface é coletar, armazenar e disponibilizar infor maçōes dos usuários. A implementaçāo da Interface foi realizada utilizando o pacote EmbPerl para facilitar a utilização das classes PERL do ambiente na geração das páginas. Todas as funçōes disponiveis na Interface estāo implementadas na biblioteca de classes correspondentes ao Módulo de Gerenciamento, de forma que nāo exista acesso direto à base de dados do ambiente. A Interface é abordada em mais detalhes na Secão 5.2 .5

Repositórios Correspondem à base de dados, desenvolvida utilizando o gerenciador MySql, ou aos arquivos nos quais sāo armazenadas as informaçōes disponibilizadas. No ambiente, são encontrados três tipos de repositórios:

Repositório de Informações de Usuário Conjunto de tabclas MySql nas quais são armazenadas as informaçōes relacionadas aos usuários do ambiente. Algumas informaçōes armazenadas sāo: cadastro de usuários, comentảrios e votaçōes em regras.

Repositório de Regras e Medidas Conjunto de tabelas para armazenamento das regras e dos valores das medidas a serem disponibilizadas no ambiente. Um aspecto importante foi a definição do modelo deste repositório, de forma a facilitar o armazenamento e recuperaçāo das regras, o cadastro e inserçāo de novas me didas para avaliação, c o cálculo c recuperação dos valores das medidas para as regras.

Repositório de Dados Arquivos nos quais são armazenados os dados referentes aos conjuntos de regras disponibilizados. Estes dados podem ser utilizados para auxiliar o usıário na compreensão das regras, assim como podem ser utilizados por algum módulo de l'ós-processamento. A fim de facilitar a utilizaçāo dos métodos de Pós-processamento implementados no Ambiente Discover, estes arquivos de dados devem seguir a sintaxe padrāo para representação de dados proposta em 
(Batista 2001). Estes arquivos são armazenados em um subdiretório do ambiente. sendo referenciados em sua base de dados.

$\Lambda$ base de dados do ambiente é melhor detalhada na Seçāo 5.2.2.

Conjuntos de Regras Representam as regras extraidas e padronizadas para suas respectivas sintaxes padrāo. Como citado anteriormente, o Ambiente RulEE trata regras expressas no formato padrão, permitindo que o resultado de uma grande variedade de algoritmos possa ser tratado pela ulilização das bibliotecas de conversào. No ambiente, são tratados os seguintes tipos de regras:

Regras de Classificação Conjuntos de regras de classificação extraidos pelos mais diversos algoritmos de indução de regras e árvores de decisão e expressos na sintaxe padrāo de regras de classificação delinida em (Baranauskas 2001; Prati, Baranauskas. \& Monard $200 \mathrm{lb}$ ). Atualmente existem implementados procedimentos para conversão para esse formato padrāo dos conjuntos de regras extraídos pelos algorimos ID3, C4.5, C4.5rules, CN2, OC1, Ripper, C5.0 See5, T2 e MC 4

Regras de Regressão Os conjuntos de regras extraidos por diversos algoritmos de regressão e convertidos para o formato padrão de regras de regressāo também sāo tratados pelo Ambiente RulEE. Foi desenvolvida a sintaxe padrão para regras de regressão, bem como uma biblioteca que converte as saidas dos algoritmos M5, RT, Cubist, CART e RETIS para esta sintaxe (Pugliesi, Dosualdo, \& Rezende 2003).

Regras de Associação O terceiro tipo de regras tratado pelo Ambientc RulEE são as regras de associação. Um formato padrāo de regras de associaçāo bem como uma biblioteca para conversão dos resultados dos algoritmos Apriori, Magnumopus e do softuare Mineset para este formato têm sido definidos por Melanda \& Rezende (2003).

Uma breve descriçảo das sintaxes padrāo para representaçāo de dados. de regras de classificação, regressão e associação é apresentada nas Seçoes 4.2.1, 4.2.2, 4.2.3 e 4.2.4, respectivamente. 


\subsubsection{Informaçōes Gerais}

Nesta seçāo sāo apresentadas algumas informaçōes gerais relacionadas à implementação do Ambiente RuLEE e a suá utilização pela biblioteca de classes ou pela interface.

Variável de Ambiente Para permitir o acesso ao ambiente pela utilizaçào de scripts, é necessário que os usuários LINUX apresentem dentre suas variáveis de ambicnte a variàvel RULEE_DATABASE_NAME, a qual deve armazenar o nome da base de dados do Ambiente RulEE existente no servidor MySql em que o ambiente está instalado. Na implementaçāo realizada, o nome da base de dados do ambiente é ruleé. Caso o ambiente nāo encontre a variável RULEE_DATABASE_NAME, o acesso à base de dados fica impossibilitado, e ocorre o erro Database name not found (nome da base de dados não encontrado). $\dot{\mathrm{E}}$ importante ressaltar que, para obter acesso à base de dados, o usuário necessita de direitos para acesso no servidor de base de dados MySql

Direitos de Acesso à Base de Dados Conforme apresentado no item anterior, além de apresentar a variável de ambiente indicando o nome da base de dados do Ambien te RulEE, cada usuário que desejar utilizar os scripts deve possuir acesso a todos os objetos da base de dados. Assim, para esses usuário, deve ser executado o comando na base de dados grant all on rlilee. * to mfpalilaslocalhost;. Neste comando, mfpatila deve ser substituido pelo username do usuário que desejar utilizar os scripts.

Estrutura de Diretórios O Ambiente RulEE é composto por um conjunto de classes PERL scripts SQL, conjuntos de regras. conjuntos de dados, programas para Pós-processamento, entre outros. Para organizar todos esses clementos, foi definida uma estrutura de diretórios para o ambiente.

Na implementaçāo do Ambiente RulEE, o diretório raiz é /home/m/paula/rulee è está localizado no servidor em que ele está instalado. Seus subdiretorios, bem como seus respectivos conteúdos, estão apresentados na Tabela 5.1 .

Bibliotecas Necessârias Para o processamento e acesso aos conjuntos de dados de treinamento e teste dos conjuntos de regras cadastrados no ambiente. c utilizada a biblioteca Dataset definida por Batista (2001) para o Ambiente Discover. Além disso, para facilitar a leitura das regras existentes nos arquivos escritos na sintaxe padrāo de classificaçāo e sua inserçào no ambiente, foi utilizada a classc Rule implementada 


\begin{tabular}{|c|c|}
\hline Subdiretório & Conteúdo \\
\hline $\bar{c} / d b$ & $\begin{array}{l}\text { Diretório que contem os arquivos com a definiçáo dos objetos da base } \\
\text { de dados. }\end{array}$ \\
\hline /documentation & Diretório que contem a documentaçäo disponivel. \\
\hline / source code & $\begin{array}{l}\text { Diretório que contém os códigos fonte das classes PERL correspondentes } \\
\text { ao Modulo de Gerenciamento. }\end{array}$ \\
\hline /interface/scripts & $\begin{array}{l}\text { Diretório que contem os scripts EmbPerl correspondentes à interface do } \\
\text { ambiente (arquivos html). }\end{array}$ \\
\hline interface/images & Diretório que contém as imagens utilizadas na interface do ambiente. \\
\hline Truke repository & $\begin{array}{l}\text { Direlório que contem os arquivos que representam os conjuntos } \\
\text { de regras armazenados no ambiente. Os nomes desses arqui- } \\
\text { vos săo definidos pelos padröes ruleset_ID.classification.model. rule } \\
\text { set_ID.regression.model ou ruleset_ID.association.ruleset. nos quais ID } \\
\text { represcnta o identificador do conjunto de regras. }\end{array}$ \\
\hline /data_repository & $\begin{array}{l}\text { Diretório que contém os arquivos de dados. Os nomes dos arquivos } \\
\text { sáo: ruleset ID.dala para os arquivos de dados de treinamento, rule- } \\
\text { set_ID.test para os arquivos de testes e ruleset_ID.names para os arqui- } \\
\text { vos com a descriçäo dos dados. }\end{array}$ \\
\hline /html_files & $\begin{array}{l}\text { Diretório que contém descriçōes de conjuntos de regras, projetos, proce- } \\
\text { dimentos ou medidas. Os nomes dos arquivos existentes neste diretório } \\
\text { são definidos pelos padróes: ruleset_ID.html. proj_PROUECT_CODE.html, } \\
\text { proc_PROCEDURE.html e measure_MEASURE.html, nos quais PRO- } \\
\text { JECT_CODE representa o código do projeto, PROCEDURE representa o } \\
\text { nome do procedimento e MEASURE representa o nome da medida des- } \\
\text { critos pelos arquivos. }\end{array}$ \\
\hline /pos_proc scripts & $\begin{array}{l}\text { Diretorio destinado para armazenamento dos scripts responsáveis pelo } \\
\text { Pós-processamento. O armazenamento dos arquivos neste diretório é } \\
\text { opcional. }\end{array}$ \\
\hline$\overline{t m p}$ & Diretorio destinado para armazenamento de arquivos temporários. \\
\hline
\end{tabular}

Tabela 5.1: Subdiretórios do Ambiente RulEE

por Prati. Baranauskas, \& Monard (2001a). No ambiente, classes semelhantes foram criadas para a inserçāo de regras de regressāo e associaçāo.

Pacotes PERL Necessários Para a execução do Ambiente RulEE, é necessária a instalação de alguns pacotes PERL. Dentre os pacotes necessários, estāo:

- Pacote DBI, versão 1.18-1, para o acesso à base de dados:

- Pacote Exception, versāo 1.4, para o tratamento de erros:

- Pacotes Date-Calc, versào 5.0, Math-CDF, versão 0.1, e Math-Round, versão 0.02, necessários para a utilização da biblioteca Dataset:

- Pacotes EmbPerl, versão 1.3.4, e mod_perl, versão 1.27, utilizados na implemen taçāo da interface do Ambiente RulEE.

O pacote $D B I$ é normalmente obtido na distribuição LINUX utilizada. Os outros pacotes necessários podem ser obtidos em www. cpan. org. 
Exceções O Ambiente RulEE apresenta um conjunto de exceçōes que podem ocorrer durante a execução dos algoritmos. Quando ocorre um erro. é criado um objeto da classe Exception e gerada uma exceçảo que finaliza a exccuçāo do script. Se o usuário estiver utilizando as classes do ambiente em algum script, ć possivel identificar se foi algum erro por alguma condição inválida do ambiente. ou se foi algum outro tipo de erro. como uma permissão requerida para acessar algum arquivo, um erro de conexāo com a base de dados. entre outros. Caso o ambiente esteja sendo utilizado pela interface WWW e alguma exceção ocorrer, é apresentado ao usuário a mensagem completa do erro sem nenhum tratamento.

Criação e Acesso dos Usuários Do ponto de vista da forma de utilização do ambiente. existem dois tipos básicos de usuários: usuários que utilizam somente a interface WWW e usuários que utilizam a interface e as classes. Para permitir o acesso ao ambiente desses dois tipos de usuários, algumas configuraçóes de acesso devem ser feitas:

Usuários que acessam a interface e as classes Para que os usuários possam utilizar o ambiente através da biblioteca de classes, é necessário que eles apresentem códigos de usuário e senha para utilização da estação de trabalho em que o ambiente está instalado. É necessário que ele possua também direito de acesso aos diretórios de scripts e dados, direito de acesso à base de dados, além de cadastro na base de dados do ambiente. Com essa configuração. é possivel também o acesso direto ao conteúdo das tabelas existentes na base de dados do ambiente.

Usuários que acessam somente a interface Para acesso pela interface, não é necessário código de acesso e senha na estaçāo onde o ambicnte está instalado, pois a interação com a base de dados e com a biblioteca de classes é feita através da WWW. Entretanto, é necessário o cadastro do usuário na base para que seja possivel o login no RulEE.

Na próxima seção scrá apresentada em mais detalhes a implementação da base de dados do Ambiente RulEE

\subsubsection{Implementação da Base de Dados}

Conforme apresentado anteriormentc, a base de dados do Ambiente RulEE foi implementada no gerenciador de base de dados MySql. Todas as tabelas do ambiente foram implementadas em uma única base de dados. Estas tabelas estāo descritas na Tabela 5.2 
e o diagrama físico da base de dados, contendo as colunas, chaves e restrições, está representado na Figura 5.2.

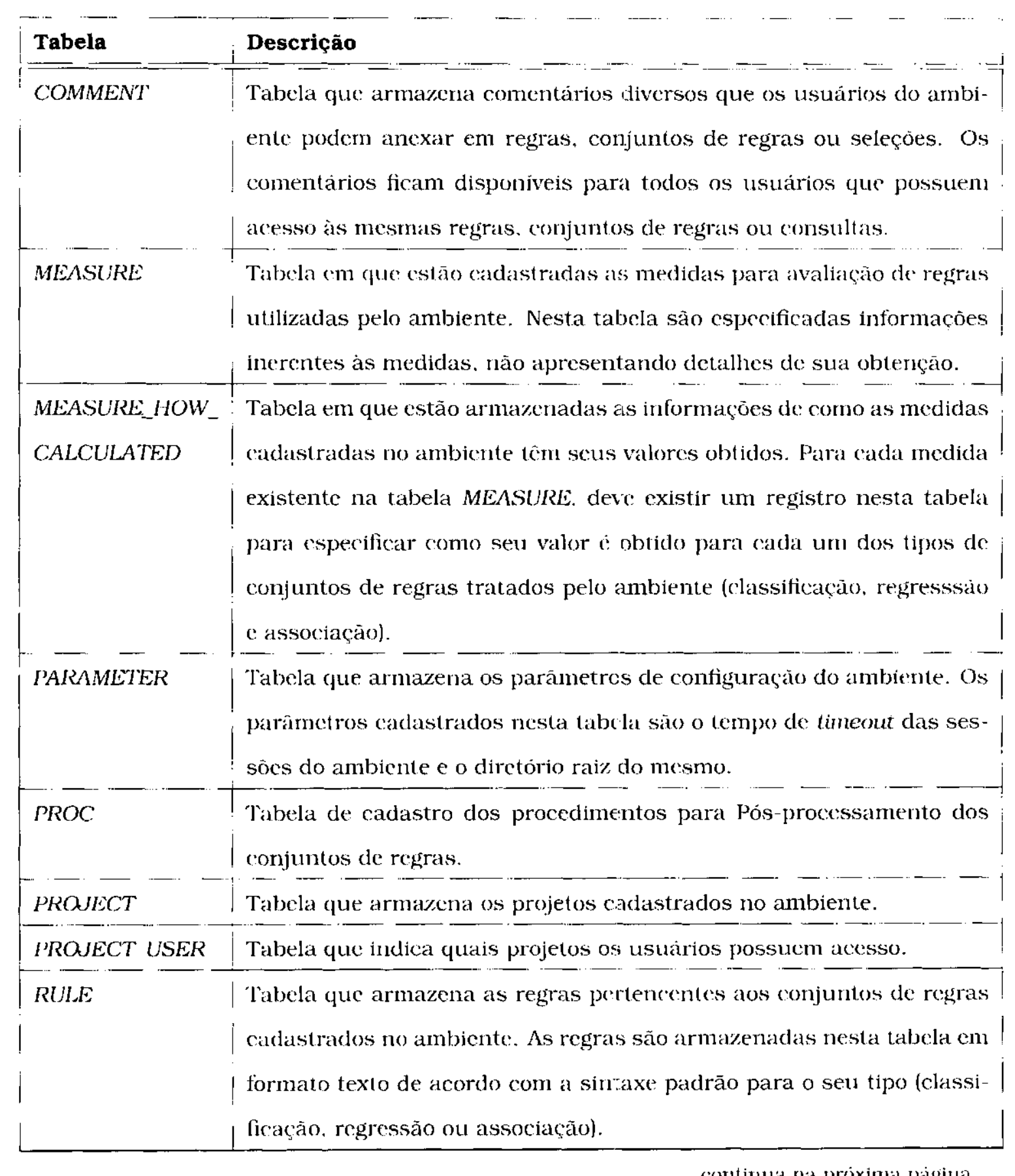

continua na proxima paigina.. 


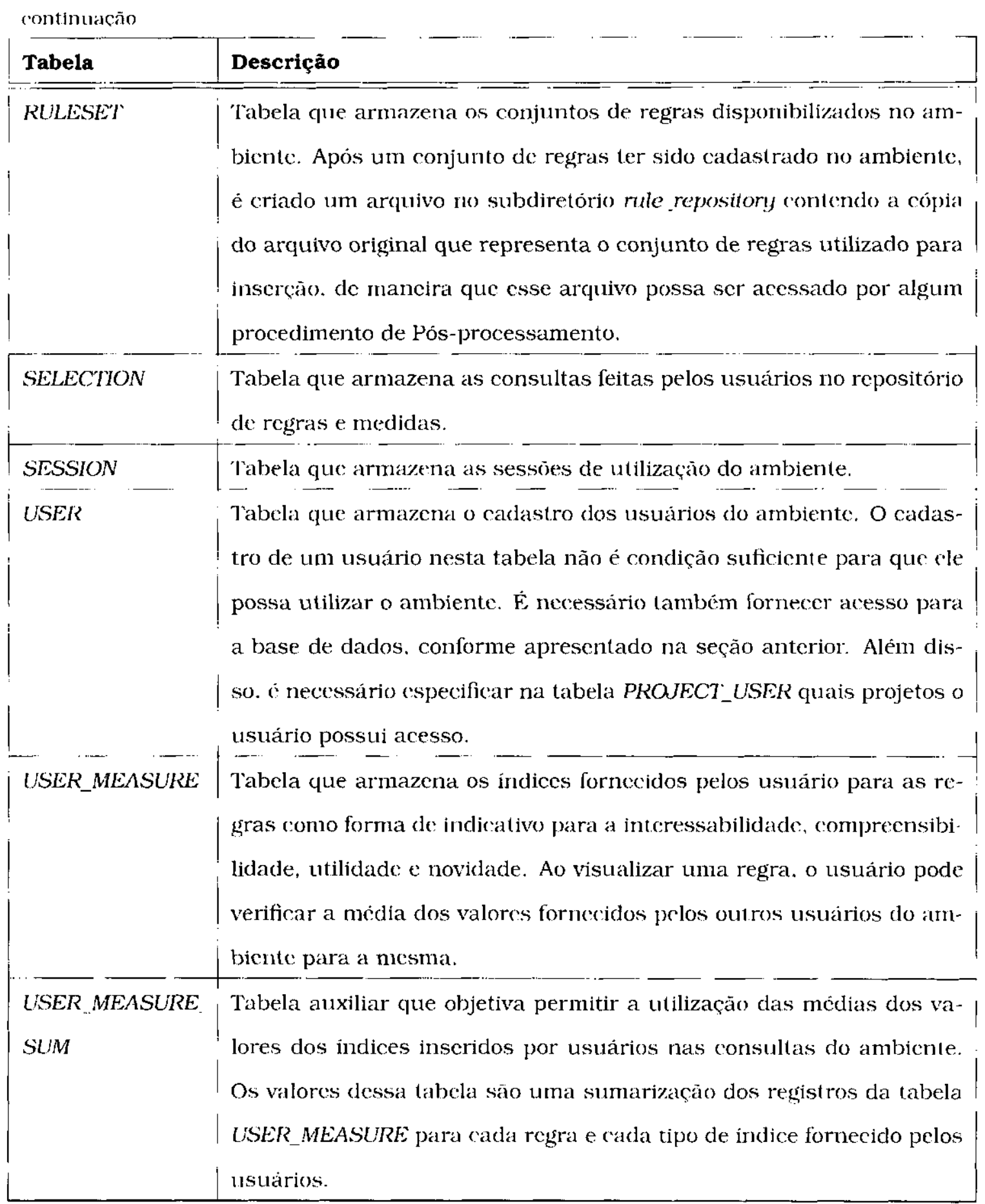

continua na próxima página... 


\begin{tabular}{|c|c|}
\hline Tabela & Descrição \\
\hline $\begin{array}{l}\text { VALUE_MEASURE } \\
\text { RULE }\end{array}$ & $\begin{array}{l}\text { Tabela que armazena os valores das medidas das regras disponibiliza- } \\
\text { das. Sempre que o usuário requisita o valor de uma medida de uma } \\
\text { determinada regra, o ambiente verifica nesta tabela se o valor ja está } \\
\text { calculado. Caso esteja, o valor é retornado. Caso o valor nāo esteja } \\
\text { presente, ele é obtido, armazenado nesta tabela para futuros acessos } \\
\text { e retornado ao usuário. }\end{array}$ \\
\hline $\begin{array}{l}\text { VALUE_MEASURE } \\
\text { RULESET }\end{array}$ & $\begin{array}{l}\text { Tabela com os valores das medidas referentes a conjuntos de regras. } \\
\text { Da mesma maneira que para a tabela VNLUE_MEASURE_RULE, o am- } \\
\text { biente armazena nesta tabela os valores das medidas que foram aces- } \\
\text { sadas pelos usuarios. }\end{array}$ \\
\hline
\end{tabular}

Tabela 5.2: Descrição das Tabelas da Base de Dados do Ambiente RulEE

Na Figura 5.2, são apresentadas as restriçöes de integridade existentes entre as tabelas do ambiente. É importante destacar que o gerenciador de base de dados MySql nāo implementa as chaves estrangeiras e restriçōes do tipo check. Apesar disso, nos scripts de definição dos objctos da base, as restriçôes foram todas especificadas de mancira a auxiliar possíveis desenvolvedores a compreender melhor o modelo e a facilitar a utilizaçāo de um gerenciador mais robusto que implemente essas restriçōes. 


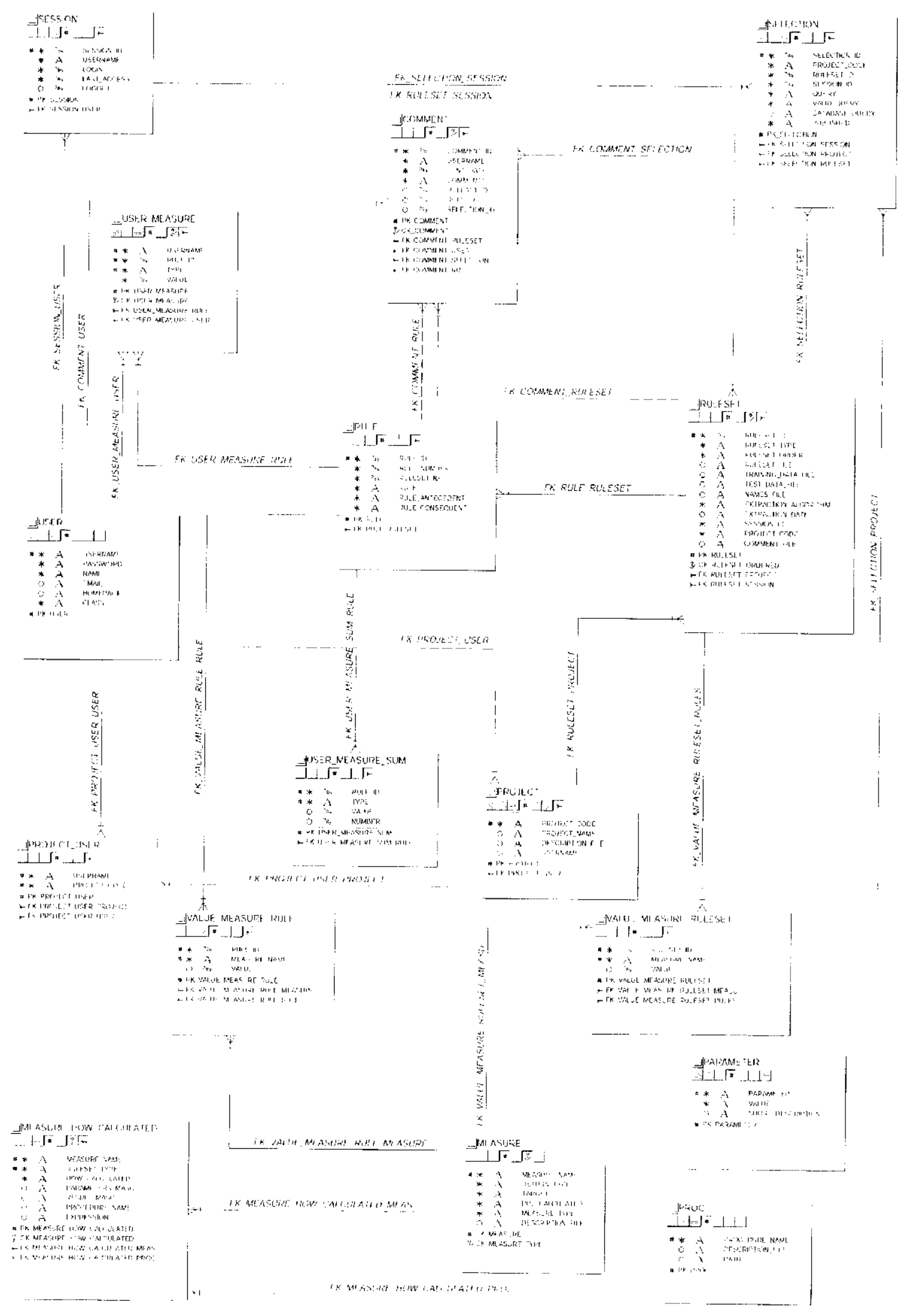

Figura 5.2: Diagrama Fisico da Base de Dados do Ambiente RulEE 


\subsubsection{Classes}

Nesta seção, sào apresentadas as classes que compōem o Módulo de Gerenciamento do Ambiente RulEE. Na Tabela 5.3, as classes estāo descritas de maneira bastante resumida e na Figura 5.3 é apresentado o diagrama de classes que apresenta os relacionamentos entre elas.

\begin{tabular}{|c|c|}
\hline Classe & Descrição \\
\hline Comment & $\begin{array}{l}\text { Classe que representa um comentario que pode ser anexado por um usuário a } \\
\text { una regra, um conjunto de regras ou a una comsulta. }\end{array}$ \\
\hline Meusure & Classe que representa uma medida de avaliaçào. \\
\hline Procedure & Classe que representa um procedimento do ambiente. \\
\hline Project & $\begin{array}{l}\text { Classe que representa um projeto existente no Ambiente RuLEE. Essa classe é } \\
\text { utilizada para retornar informaçoes referentes a um determinado projeto, como } \\
\text { sua descriçào e seus conjuntos de regras. }\end{array}$ \\
\hline Repository & $\begin{array}{l}\text { Classe utilizada para retornar elementos referentes ao IRepositorio de Regras e } \\
\text { Medidas como um todo, cono as medidas cadastradas no ambiente. }\end{array}$ \\
\hline Rule & Classe que representa uma regra cadastrada no ambiente. \\
\hline Ruleset & $\begin{array}{l}\text { Classe que encapsula um conjunto de regras de classificaçào, regressão ou } \\
\text { associaçào. }\end{array}$ \\
\hline Selection & $\begin{array}{l}\text { Classe que representa uma consulta feita pelo usuário no Repositório de Regras } \\
\text { e Medidas. }\end{array}$ \\
\hline Session & \\
\hline
\end{tabular}

Tabela 5.3: Descriçāo das Clásses do Módulo de Gerenciamento

Na Figura 5.4 pode-se encontrar um outro diagrama que contém os relacionamentos de herança, os atributos e os métodos de cada classe do Módulo de Gerenciamento. Como pode ser observado na figura, todas as classes são subclasses de Session. Esta decisão foi tomada para permitir que todas as classes do ambiente possuíssem métodos para a conexão com a base de dados. Também na Figura 5.4, podem ser observados os métodos e atributos públicos e privados de cada classe. Os métodos ou atributos privados estào identificados com o icone de uma chave anterior ao nome do atributo ou metodo. Apesar de não existir definição de metodos ou atributos privados em PERI, no projeto do Ambiente 


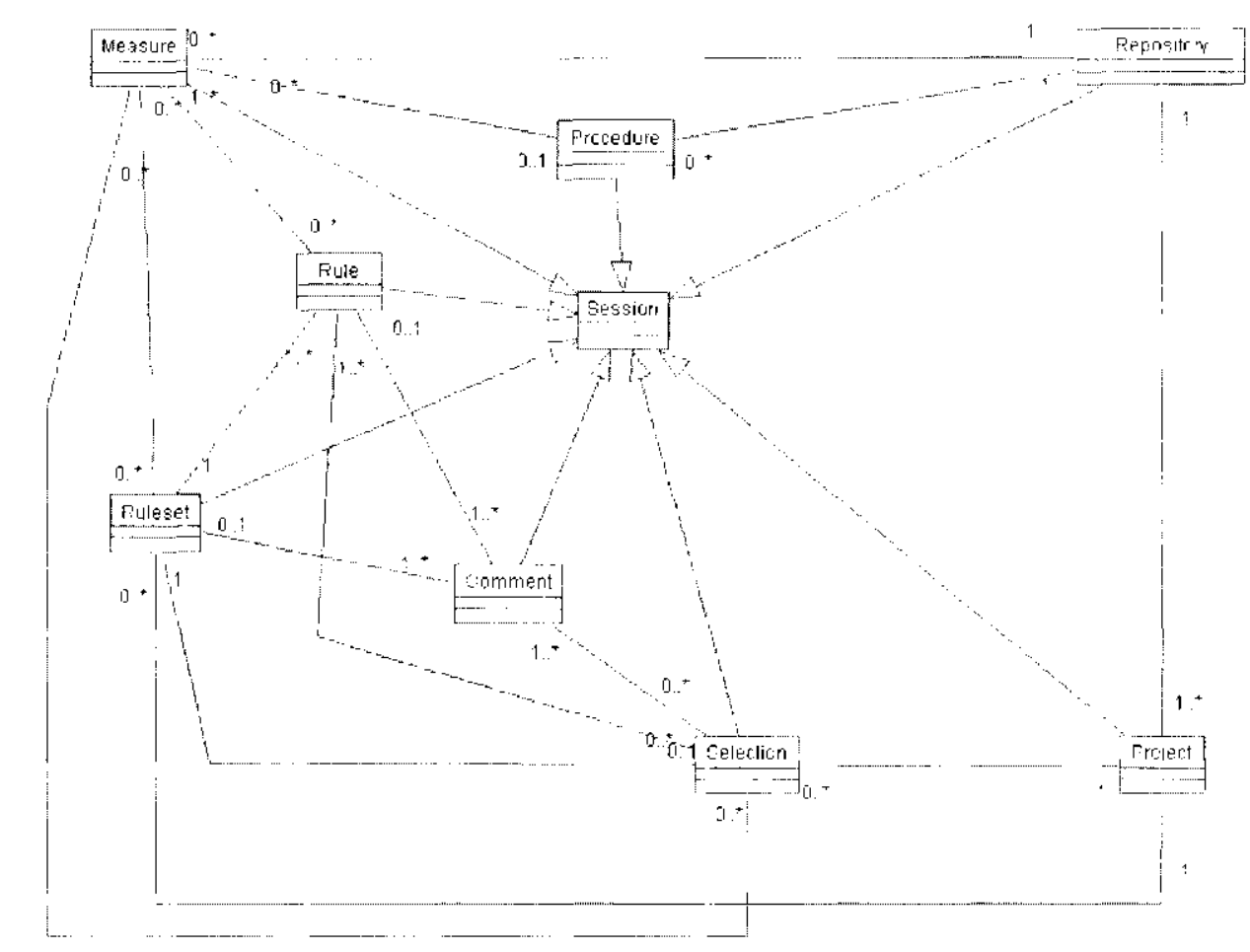

Figura 5.3: Relacionamentos entre as Classes do Módulo de Gerenciamento

RulEE alguns métodos c atributos foram assim definidos, pois não ć recomendada sua utilização pelos usuârios.

Como pode ser observado na Figura 5.4. todos os atributos das classes são privados. O acesso aos valores desses atributos deve ser realizado pelos métodos que retornam seus valores.

\subsubsection{Obtenção e Cálculo de Valores de Medidas}

Todas as medidas disponiveis no Ambiente RulEE devem estar cadastradas na tabela MEASURE. Entretanto, para cada tipo de conjunto de regras, deve cstar especificado na tabela MEASURE_HOW_CALCULATED como o valor da medida é obtido. Por exemplo, a medida Acc, que corresponde à precisão de uma regra, deve estar cadastrada na tabela MEASURE. Mas, para que cla csteja disponivel para regras de classificação, deve existir um registro na tabela MEASURE_HOW_CALCULATED indicando a maneira pela qual o valor de Acc é obtido para problemas de classificaçāo. Ao se tentar utilizar essa medida em uma consulta $\mathrm{cm}$ um tipo de conjunto de regras (classificação, regressão ou associaçāo) não existente na tabela MEASURE_HOW_CALCULATED, é apresentado um erro ao usuário indicando que ela não é válida para este tipo de regra. 


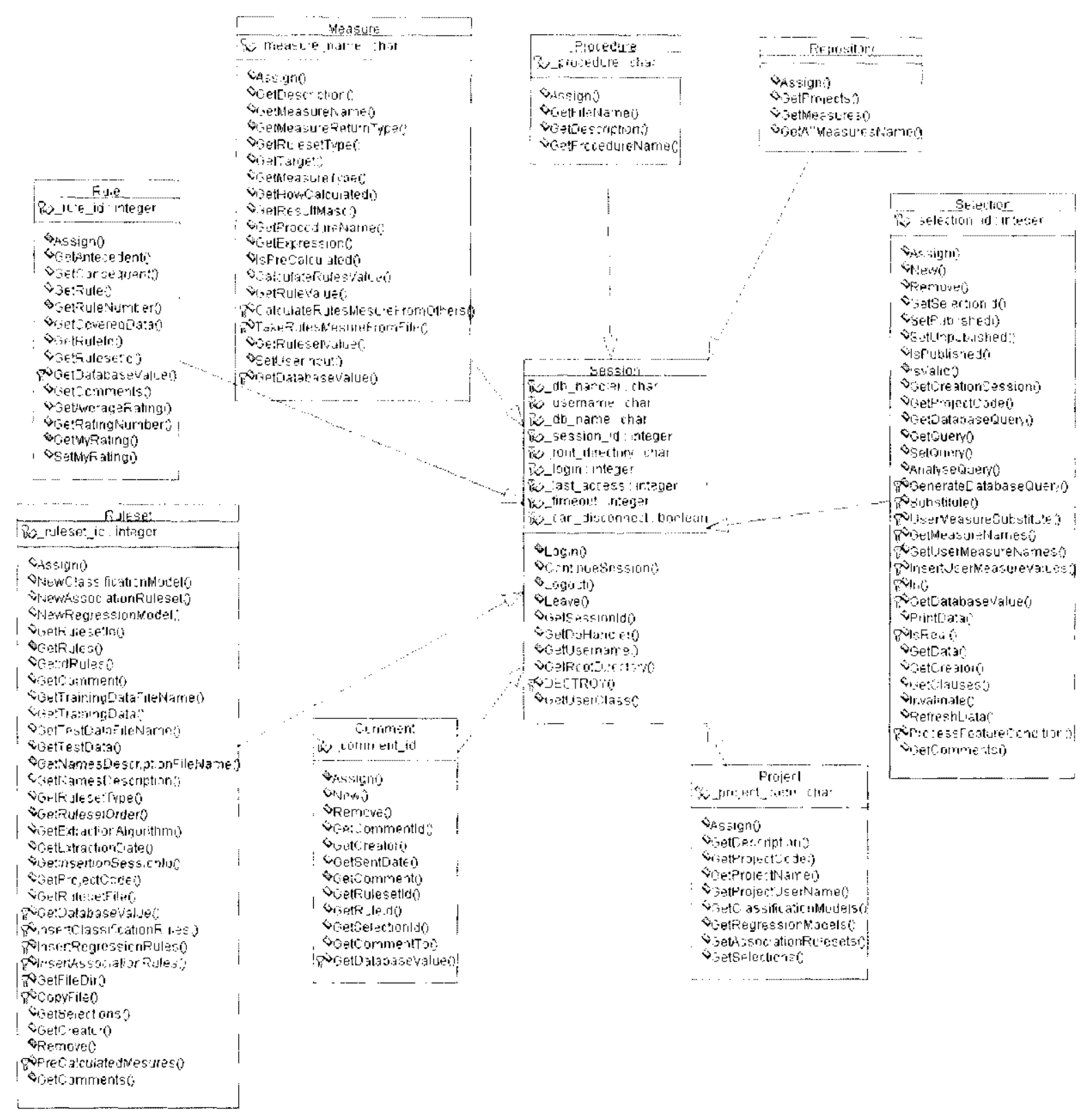

Figura 5.4: Ilerança, Atributos e Métodos das Classes do Módulo de Gerenciamento

Conforme descrito nas seçòes anteriores, a obtenção dos valores das medidas dispo. níveis no ambiente pode ser feita de três maneiras: leitura das medidas do arquivo que contém o conjunto de regras, execução de procedimentos e cálculo de medidas derivadas a partir do valor de outras medidas cadastradas no ambiente. Essas urès possibilidades para obtençāo dos valores das medidas para as regras estāo descritas a seguir.

Obtenção pelo Arquivo de Regras Para a inserção de conjuntos de regras, devem ser fornecidos ao ambiente arquivos que contenham o conjunto de regras na sintaxe padrào com os valores da tabela de contingência para cada regra. Assim, os valores da tabela 
de contingência são obtidos a partir destes arquivos, sendo as medidas derivadas da tabela de contingéncia calculadas pelo próprio ambiente pela utilização de medidas derivadas.

Desta maneira, os registros correspondentes aos valores da tabela de contingência da tabela MEASURE_HOW_CALCUIATED devem apresentar a coluna HOW_CALCULATED com valor RULESET_DESCRIYIION, indicando que o ambiente deve buscar no arquivo de regras o valor dessas medidas. Alèm disso, a coluna RESULT_MASC deve apresentar uma máscara para permitir ao ambiente buscar no arquivo o valor da medida para cada regra do conjunto. Para estas medidas, as colunas PARAMETERS_MASC, PROCEDURE_NAME e EXPRESSION devem ficar com valores nulos.

Para que o contcúdo da coluna RESULT_MASC possa ser utilizado para identificar o valor de uma medida para cada regra do ambiente. ele devc corresponder a um padrão válido da linguagem $P E R L$ que, para cada regra do conjunto de regras, deve casar uma única vez, com o arquivo de regras como um todo. Desta maneira, variáveis de substituiçēo devem ser utilizadas nas máscaras para a identificaçào de cada regra. Para cxemplificar a obtenção de valores a partir dos arquivos de descrição dos conjuntos de regras, no padrāo \$rlize_antecedent, \$rlile_consequent, \[ $\backslash t] * 1-?[0-$ 9] * $(?[0.9] *)(\backslash t] *$, as variáveis de substituiçāo \$ruie_antecedent $e$ \$rule_consequent sāo utilizadas para identificar uma regra dentro de um arquivo de regras. Uma outra variável de substituiçào que pode ser utilizada nas máscaras c \$rule number. representado o numero da regra no arquivo de regras. O padrão apresentado corresponde ao conteúdo da coluna RESULT_MASC para o valor da tabe la de contingência $l_{b}$, para conjuntos de regras de associaçāo. Neste exemplo, para cada regra de um conjunto de regras. \$rule_antecedent c \$ruze_consequent são substituídos pelos respectivos antecedente e conscqüente dá regra. Assim. esse padrão "casa" com o arquivo de regras uma única vez, e após isso, o valor de fit para uma determinada regra é obtido pela variável $\$ 1$, isto $\dot{e}$. o valor da medida fica instanciado com o primeiro sub-padrão entre parênteses do conteúdo de RESULT_MASC. No exemplo, o valor da medida c obtido pelo sub-padrāo $(-?[0-9] * \backslash$ ? $[0-9 * *)$.

Obtenção pela Execução de Procedimento É importante que o Ambiente RuLEE permita. de maneira simples, a utilizacão de procedimentos para cálculo de medidas. Essa funcionalidade está completamente modelada ná base de dados. mas está parcialmente 
implementada no ambiente, pois alguns métodos necessảrios não estão implementados.

Como previsto na tabela MEASURE_HOW_CALCULATED, medidas que deveriam ter seu valor obtido a partir da execução de um procedimento devem aprescntar a coluna HOW_CALCULATED com o valor PROCEDURE e valores vâlidos para as colunas PARAMETERS_MASC, RESULT_MASC E PROCEDURE_NAME. A coluna EXPRESSION deve ficar com valor nulo.

Para uma medida calculada por procedimento, a coluna PROCEDURE_NAME deve apresentar o nome de um procedimento cadastrado na tabela PROC. A coluna PARAMETERS_MASC deve apresentar uma máscara para obtençāo dos paràmetros a serem utilizados na execuçào do procedimento. Por exemplo, a coluna PARAMETERS_MASC pode conter o valor \$ruleset_file name \$rule_number \$output_file_name, em que \$ruleset_file_name é substituído pelo nome do arquivo que contém o conjunto de regras na sintaxe padrão, \$rlile number é substituído pelo número da regra que se deseja processar e \$output_file_name ć substituído pelo nome do arquivo no qual o ambiente deve buscar o resultado. A coluna RESULT_MASC deve conter a máscara para obtenção do resultado para cada regra dentro do arquivo de sáida criado pelo procedimento. Esta máscara deve ser semelhante às mascaras de obtenção de valores de medidas nos arquivos contendo os conjuntos de regras.

Obtenção pelo Cálculo de Medidas Derivadas Tendo obtido o valor de alguma medida a partir do arquivo de descrição de regras ou pela execução de um procedimento, é possivel a definição de medidas derivadas. que têm seu valor calculado a partir do valor dessas outras medidas. Com este tipo de medida, é possivel o cálculo das vărias medidas derivadas a partir dos valores da tabela de contingência.

Medidas derivadas são identificadas na tabela MEASURE_HOW_CALCULATED por conter o valor DERIVED na coluna HOW_CALCULATED. Um registro de medida derivada deve apresentar a expressāo de como o valor da medida é obtido na coluna EXPRESSION, e as colunas PARAMETERS_MASC, RESULT_MASC e PROCEDURE_NAME devem ter valor nulo, pois nāo sāo necessárias para o cálculo do valor desse tipo de medida.

O valor da coluna EXPRESSION deve ser uma expressāo aritmética válida em que são utilizados os nomes de outras medidas, como variáveis $P E R L$, e operadores matemáticos para o cálculo do valor da medida referente ao registro. Por exemplo, a expressão 
$\$ f b h / \$ f b$ é utilizada para calcular o valor da medida $A \subset$ de uma regra de classificaçāo. Nessa expressão, $f b h$ e $f b$ devem corresponder a nomes de medidas válidas para o mesmo tipo de conjunto de regras que a medida $A c e$. Para calcular o valor de $A$ er para uma detcrminada regra, o ambiente identifica as medidas que são utilizadas na expressão, calcula seus valores para a regra em questão para entāo calcular o valor de $A \times r$.

Na próxima seção, é apresentada a interface do Ambicnte RulEE.

\subsubsection{Descrição da interface}

Conforme os requisitos de um Ambiente para Exploração de Regras apresentados no Capitulo 4, é importante que esteja disponivel uma interface WWW para permitir um acesso facilitado de seus usuários às regras disponibilizadas. O desenvolvimento da interface do Ambiente RulEE foi realizado com objetivo de facilitar a demonstração das funcionalidades c potencialidades do ambiente na análise e disponbilizaçào das regras e medidas. Dessa maneira, foi desenvolvida uma interface bastante simples voltada à apresentação das informaçōes, não havendo grande preocupação com a usabilidade da mesma. $\dot{E}$ importante destacar que o foco principal do trabalho foi a proposta e a implementação de uma arquitetura para exploração de regras, de maneira que trabalhos futuros possam se desenvolver utilizando esta arquitetura. Por ser de grande importância para um Ambiente para Exploração de Regras, a interface do Ambiente RulEE deve ser abordada em trabalhos futuros. conforme apresentado no Capitulo 7.

Para a construçào da interface do Ambiente RulEE, foi utilizado o servidor Apache c os pacotes EmbPerl e mod_perl para a construção dinâmicas das páginas acessadas pelo usuário. Na construção destas pãginas, foram utilizadas as classes existentes no Módulo de Gerenciamento, descritas na Sessão 5.2.3.

Para utilizaçào da interface ć necessário que o browser da estação cliente esteja com a opcão Java Script habilitada. Caso contrário. muitas funcionalidades da interface não cstarào disponíveis. Além disso, a interface do ambiente foi desenvolvida para que suas funçoes funcionem corretamente nos browsers Mozilla versão 0.9 .9 no sistema operacional LINUX e no Internet Explorer versão 5.0 no sistema operacional Windows. O Ambiente RulEE pode ser utilizado pela interface no endereço htto: //143.107.232.90/rulee/index. html.

Nesta scção sāo apresentadas as principais funçōes disponiveis aos usuários pela interface WWW através da descrição das telas do ambiente. As funçōes disponiveis aos usuários pela interface do Ambiente RuLEE são: 
- Login no ambiente;

- Visualização de informaçōes sobre o projeto;

- Inserção, visualizaçāo e remoção de conjuntos de regras;

- Criaçāo, visualizaçāo, edição e remoção de consultas sobre conjuntos de regras e valores de medidas:

- Inserção, visualização e remoção de comentários sobre regras, conjuntos de regras ou consultas;

- Inserção, visualização e alteração de indices de Interessabilidade, Compreensibilidade, Utilidade e Novidade fornecidas por usuários sobre regras;

- Visualizaçāo das medidas disponiveis no ambiente.

A seguir, serảo apresentadas as principais telas do ambiente, sendo descritas suas principais funcionalidades.

Login no Ambiente

Ao entrar na interface do ambiente, a tela de login, correspondente à Figura 5.5, é apresentada ao usuário. Para acessar o ambiente, é necessário que os usuários forneçam seu código de acesso e senha.

Menu Principal

Após fornecer o código de acesso e senha na tela de login, o ambiente apresenta a tela com o menu principal e as informaçōes de um projeto que o usuário possui acesso, con forme pode ser observada na Figura 5.6. As principais funçòes disponiveis neste menu são:

Troca de Projeto Ao clicar no campo em que está presente o nome do projeto, contendo DadosFinanceiros na Figura 5.6. é apresentada ao usuário a lista dos projetos aos quais ele possui acesso. Ao escolher um projeto da lista, é aberta a tela para acesso das informaçòes do projeto e todas as informaçōes seguintes serão relativas ao projeto escolhido.

Link Todas as Consultas Link utilizado para acessar a tela contendo todas as consultas do projeto atual. 
Para cada um dos tipos de conjuntos de regras tratados pelo Ambiente RulEE (classificação, regressāo c associação), estāo presentes no menu os seguintes links:

Link Conjuntos de Regras Link de accsso à tela com a listagem dos conjuntos de regras disponíveis no projeto atual do usuário.

Link Consultas Link de acesso à tela com a listagem das consultas sobre regras e valores de medidas disponiveis no projeto atual do usuário.

Link Medidas Link de acesso à tela com a listagem das medidas disponiveis no ambiente.

Link Novo Conjunto de Regras Por estc link o usuário tem acesso à tela de inserção de um novo conjunto de regras.

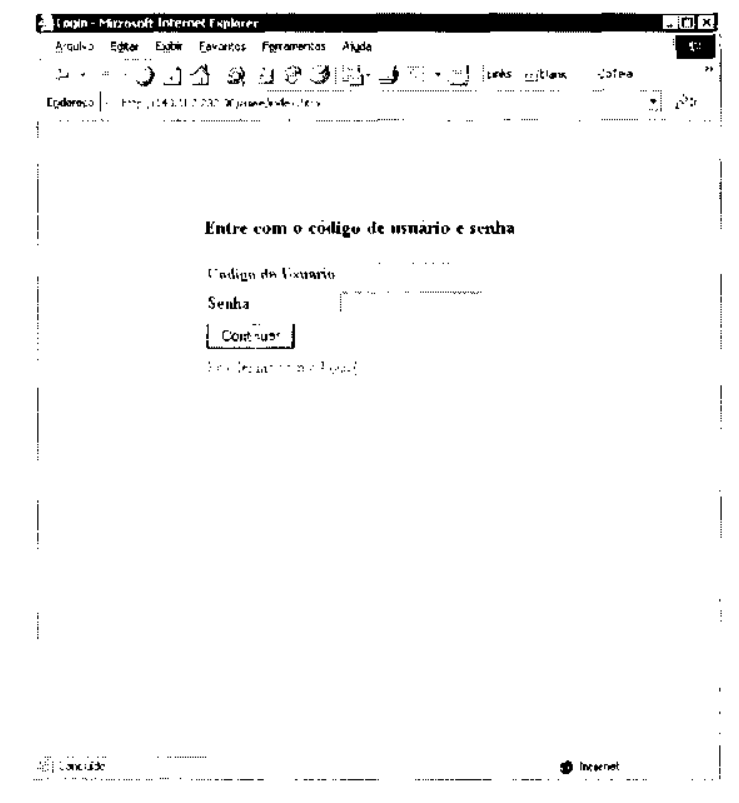

Figura 5.5: Login no Ambiente

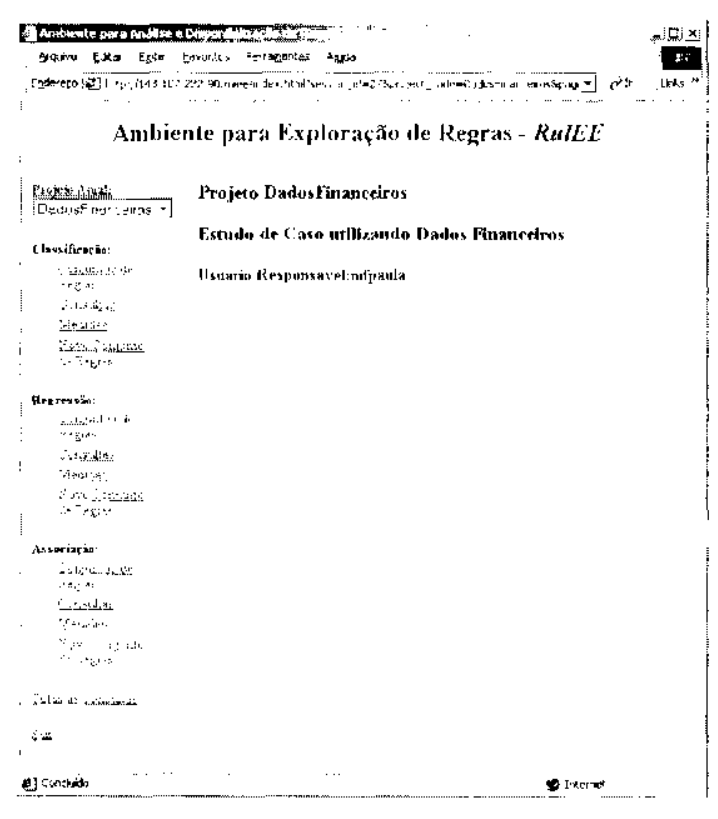

Figura 5.6: Menu Principal do Ambiente

Inserçāo de um Conjunto de Regras

Na Figura 5.7 é apresentada a tela utilizada para inserção de um conjunto de regras de classificação. A inserção de conjuntos de regras de regressão e associação é realizada por telas equivalentes. Para inserir o conjunto de regras de classificação no ambiente. o usuário deve selecionar, pelos botōes Procurar. o arquivo que apresenta o conjunto de regras (arquivo .rules). os arquivos contendo a descriçāo dos dados (arquivo names), arquivos com os dados de treinamento (arquivo data). os dados de testes (arquivo test) e o arquivo com algum comentário sobre o conjunto de regras. Após selecionar os arquivos. ao pressionar o botào Enviar. o conjunto de regras é inserido na base de dados do ambiente e 
apresentado ao usuário. Caso ocorra algum erro em scu processamento, uma mensagem com a descriçāo do erro é apresentada ao usuário.

É importante destacar que é obrigatória a inserçào do arquivo contendo o conjunto de regras. A inserção dos arquivos com os dados de treinamento, de teste, o arquivo names e o arquivo com comentários sobre o conjunto de regras c opcional. É obrigatório tambem que o arquivo contendo o conjunto de regras esteja na sintaxe padrão. seguindo as sintaxes apresentadas nas Seçòes 4.2.2. 4.2.3 e 4.2.4. É importante também que os arquivos de dados estejam na sintaxe padrāo de dados, também apresentada na Seçào 4.2.l.

Listagem de Conjuntos de Regras

Na Figura 5.8 é apresentada a tela com a listagem dos conjuntos de regras de associaçào disponiveis no projeto atual do usuário. As telas de listagem dos conjuntos de regras de regressāo o classificaçào sāo equivalentes a essà

Visando facilitar a identificação de um conjunto de regras, para cada elemento da lista. estāo presentes als segunintes informacooes: o identificador do conjunto de regras, a data de extraçāo, o algoritmo utilizado. o usuário que cadastrou o conjunto de regras no ambiente e um comentário. No campo Comentário, é mostrada uma pequena parte do comentário inserido pelo usuário juntamente com o conjunto de regras.

O acesso a um determinado conjunto de regras pode ser feito pelo link existente no identilicador do conjunto escolhido.

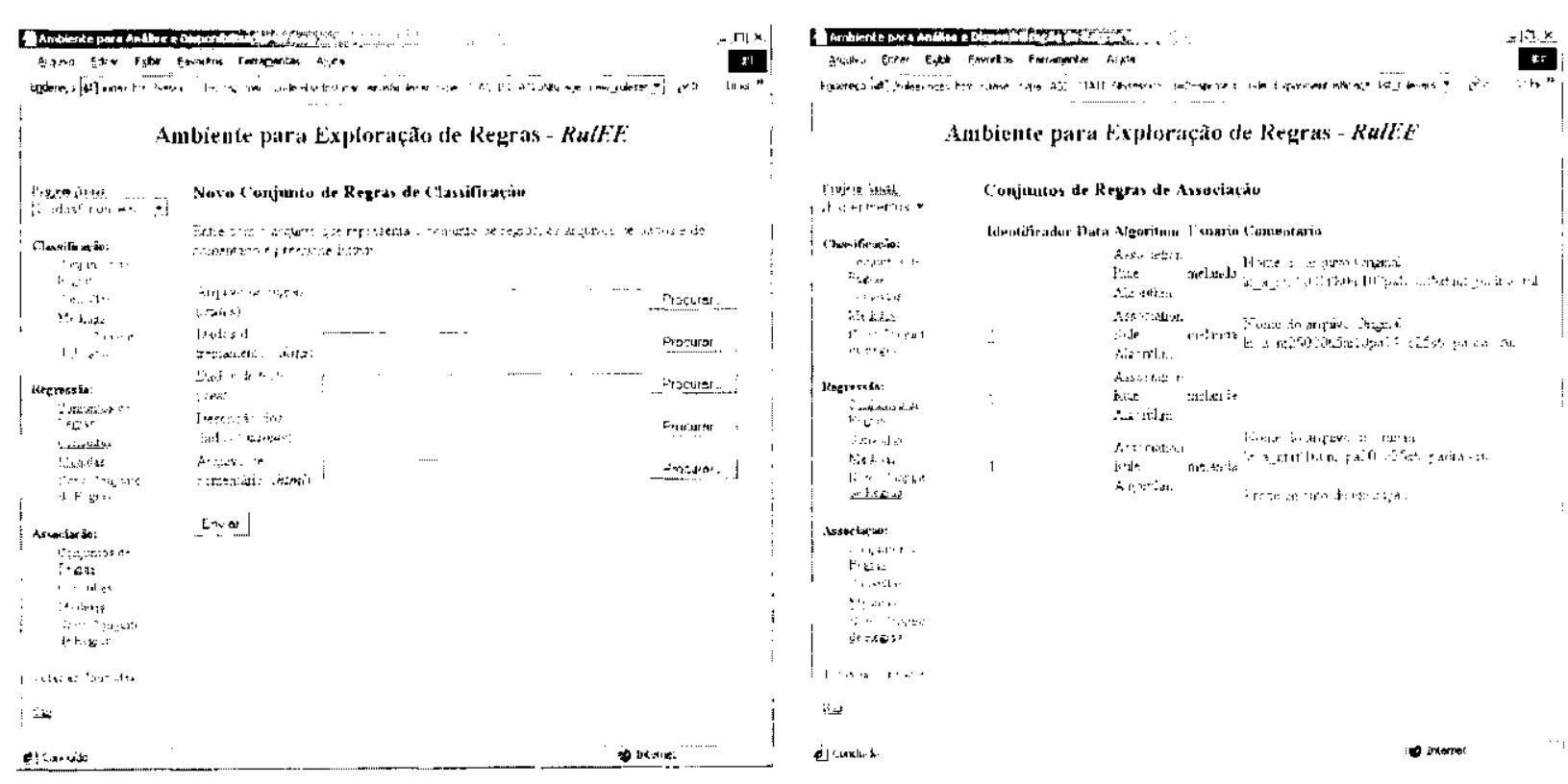

ligura 5.7: Inserção de Conjuntos de Regras Figura 5.8: Listagem de Conjuntos de Regras 


\section{Visualização de um Conjunto de Regras}

Na Figura 5.9 é apresentada a tela de visualização de conjuntos de regras. Nesta tela podem ser observadas as seguintes informaçôes:

- Código identificador do conjunto de regras;

- Tipo do conjunto de regras (classificação, regressão ou associação);

- Tipo de ordenação entre as regras (nāo ordenadas, ordenadas entre classes e ordenadas):

- O algoritmo utilizado para cxtraçāo das regras

- Data de extração das regras:

- Algum comentário inscrido pelo usuário juntamente com o arquivo que contém o conjunto de regras:

- As regras pertencentes ao conjunto de regras. Para cada regra é apresentado um indicativo dos valores das medidas de Interessabilidade, Compreensibilidade. Utilidade c Novidade inseridas pelos usuários. Estes indicativos obedecem a seguinte regra, sendo $m$ a média dos valores inseridos para cada uma das quatro medidas por todos os usuários:

$$
\begin{aligned}
& m \geq 0.5: \text { Seta para cima: } \\
& m<0.5 \text { : Seta para baixo; } \\
& -0.5<m<0.5 \text { : Seta horizontal; }
\end{aligned}
$$

- Comentários inseridos por outros usuários do ambiente sobre o conjunto de regras:

Nlém das informações listadas anteriormente, a tela de apresentaçào de conjuntos de regras disponibiliza links para acesso a outras informacōes, listadas a seguir:

Link Arquivo com o Conjunto de Regras Por este link, o usuário pode visualizar ou salvar o conjunto de regras original, utilizado para inserção das regras no ambientc. Ao clicar nestc link. é mostrada ao usuário uma tela semelhante ao exemplo apresentado na Figura 5.10.

Link Arquivo Names e Arquivos de Dados de Treinamento e Teste Caso os arquivos conten do a descriçāo dos dados (.names), os dados de treinamento (.data) e teste (.test) te- 


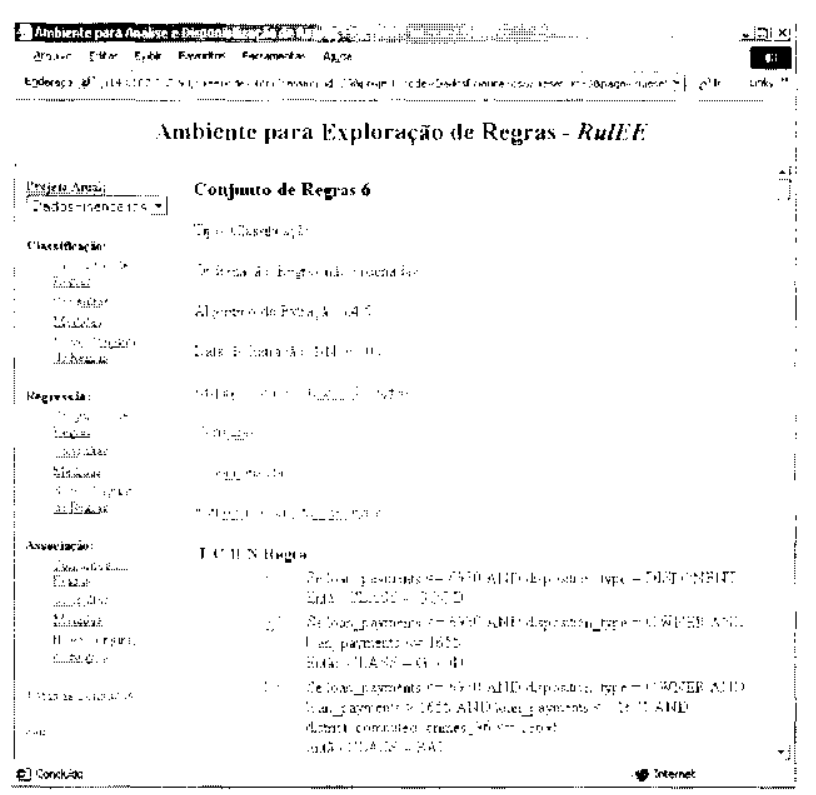

Figura 5.9: Visualização de um Conjunto de Regras

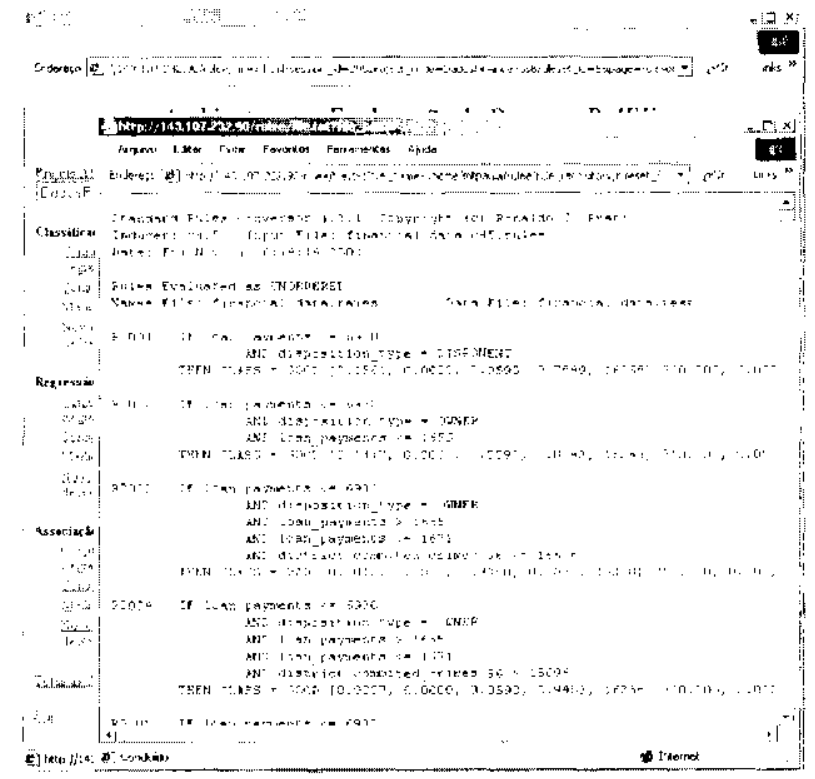

Figura 5.10: Download ou Visualizaçāo do Arquivo de Regras Original

nham sido inseridos no ambiente juntamente con o arquivo de regras. estes ficam disponiveis para visualizaçāo e dounload.

Link Consultas Por este link, o usuário tem acesso à tela com a listagem das consultas realizadas sobre o conjunto de regras criadas por ele e aquelas criadas por outros usuários e que estāo com status igual a Publicada.

Link Nova Consulta Link para acesso à tela para edição de uma nova consulta sobre o conjunto de regras acessado.

Link Remover Conjunto de Regras Link utilizado para remover o conjunto de regras apresentado. Após clicar neste link, é apresentada ao usuário uma tela requisitando uma confìrmação da remoção.

Link Adicionar Comentário Ao visualizar o conjunto de regras, ficam disponiveis ao usuário todos os comentários inseridos para esse conjunto de regras. Pelo link Adicionar Comentário, é apresentada ao usuảrio uma tela na qual ele pode adicionar algum comentário sobre o conjunto de regras. Na Figura 5.11 é apresentada a tela pcla qual o usuário insere um novo comentário sobre um conjunto de regras.

Link Identificador da Regra Para cada regra do conjunto de regras apresentado. é disponivel um link no identificador da regra para acesso às informaçōes referentes à mesma. 
Visualização de Informações sobre uma Regra

Na Figura 5.12 pode ser observada a tela de apresentação de uma regra. Esta tela apresenta o identificador da regra, o identificador do conjunto de regras ao qual ela pertence. o número dela dentro do arquivo de dados e a própria regra. Além disso, é apresentado ao usuário uma tabela contendo indicativos fornecidos pelos usuários quanto a Interessabilidade, Compreensibilidade, Utilidade e Novidade para a regra apresentada. Nesta tabela, são apresentados o número de usuários que forneceram valores para cada índice da regra. o valor médio de cada índice e o valor inserido pelo usuârio atual. Caso ele nào tenha inserido nenhum valor, então a última linha da tabela fica em branco.

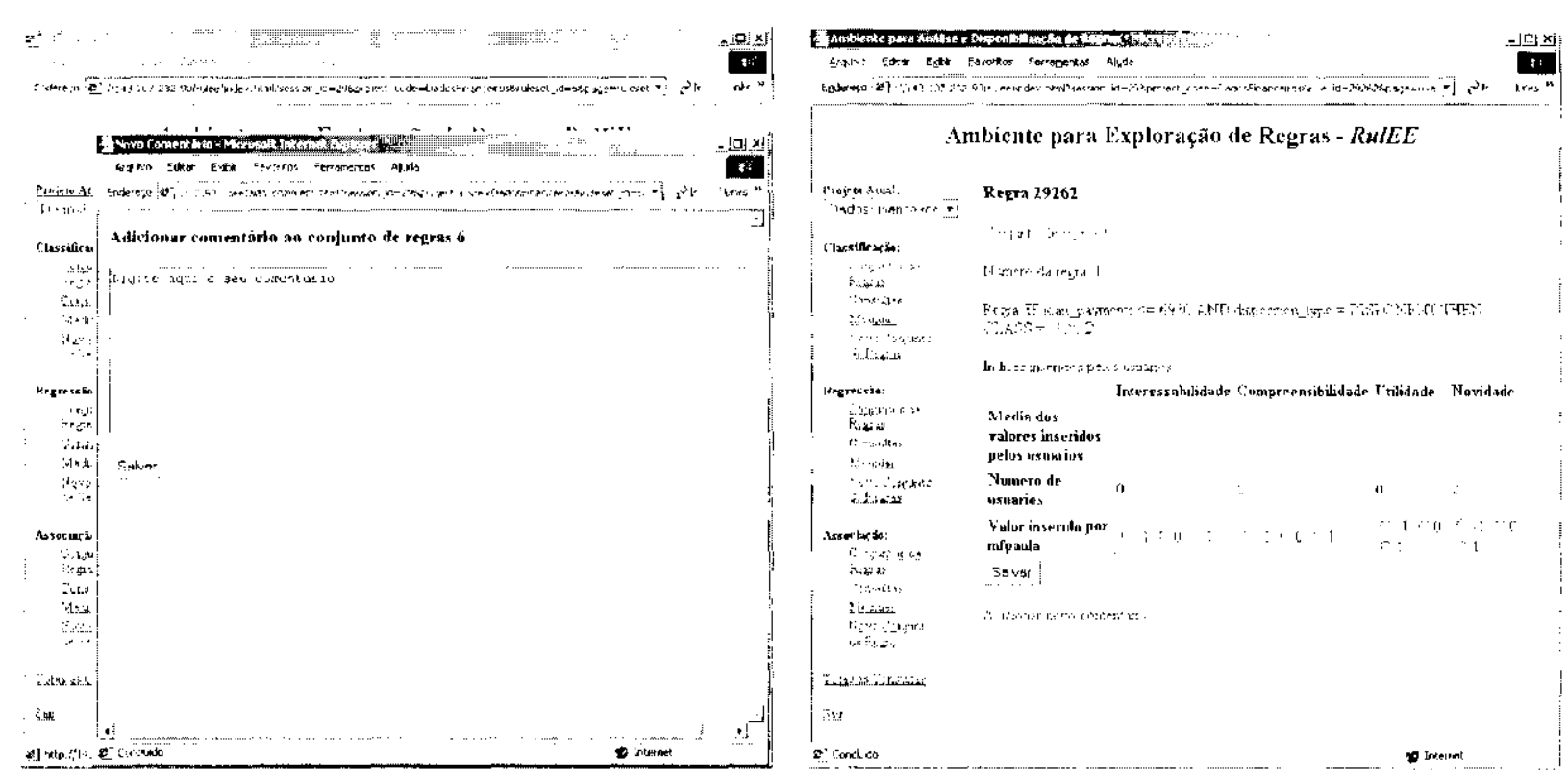

Figura 5.11: Inserçāo de um Novo Comentá- Figura 5.12: Visualizaçāo de Informações rio sobre uma Regra

\section{Listagem de Consultas}

Na Figura 5.13 é apresentada a tela com a listagem de todas as consultas criadas no projeto acessado pelo usuário. Deve-se destacar que esta tela apresenta todas as consultas do projeto, independente do tipo do conjunto de regras a que ela se refere e se ela apresenta ou nāo algum tipo de erro. Assim, sāo apresentadas também as consultas com status Inválida. Na apresentaçāo das consultas específicas de cada tipo de conjunto de regras. sào apresentadas aquelas em que o Módulo de Gerenciamento do ambiente pode identificar o conjunto de regras ao qual a consulta pertence. Em alguns casos. consultas com status Inválida sāo apresentadas somente na lista total de consultas. 
Na listagem das consultas são apresentados o identificador da consulta, contendo um link para o acesso a informaçōes referentes à consulta, o texto correspondente à consulta. o indicativo se a consulta está publicada, se está vălida e o código do usuărio que a inseriu. No tinal da lista ć aprescntado um link para à criaça de uma nova consulta.

\section{Visualização de Consulta}

$\Lambda$ tela de visualizaçāo de consultas está exemplificada na Figura 5.14. Como pode ser observado, esta tela apresenta o código identificador da consulta. a consulta inserida pelo usuário, indicativos se a consulta está válida e publicada, e os dados referentes à consulta em formato de tabela. Na tela de visualização de consultas estão disponiveis alguns links contendo funcionalidades adicionais, listadas a seguir:

Acesso aos arquivos de dados e descrição dos dados da consulta Pelos links Arquivo de Dados e Arquivo de Descrição dos Dados é possivel a visualização e domnload dos dados referentes à consulta no formaio padrão. Ná Figura 5.15 e apresentado um exemplo contendo os dados da consulta e o arquivo de descrição.

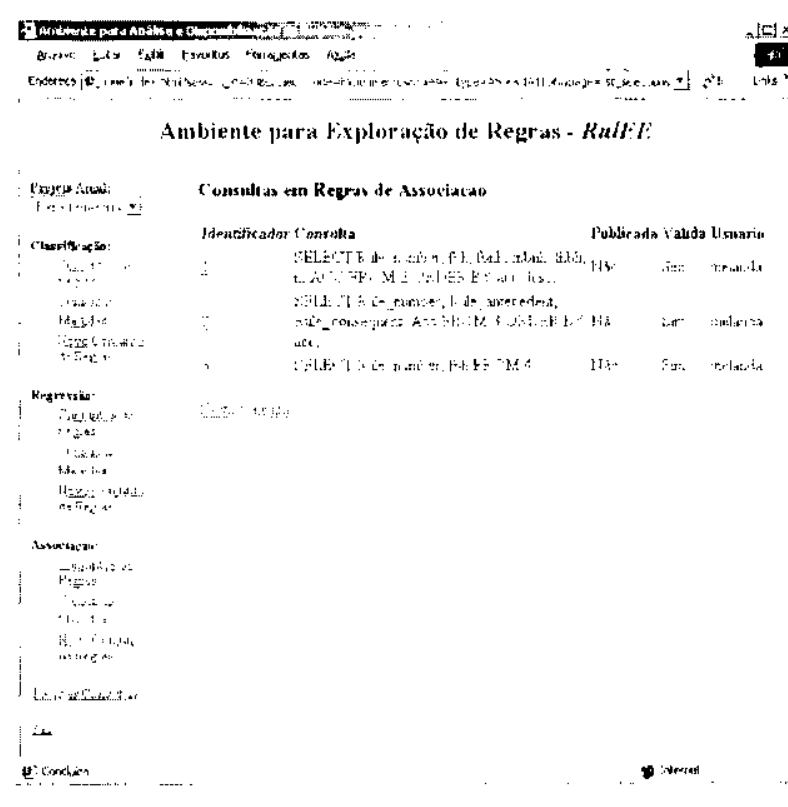

Figura 5.13: Listagem de Consultas

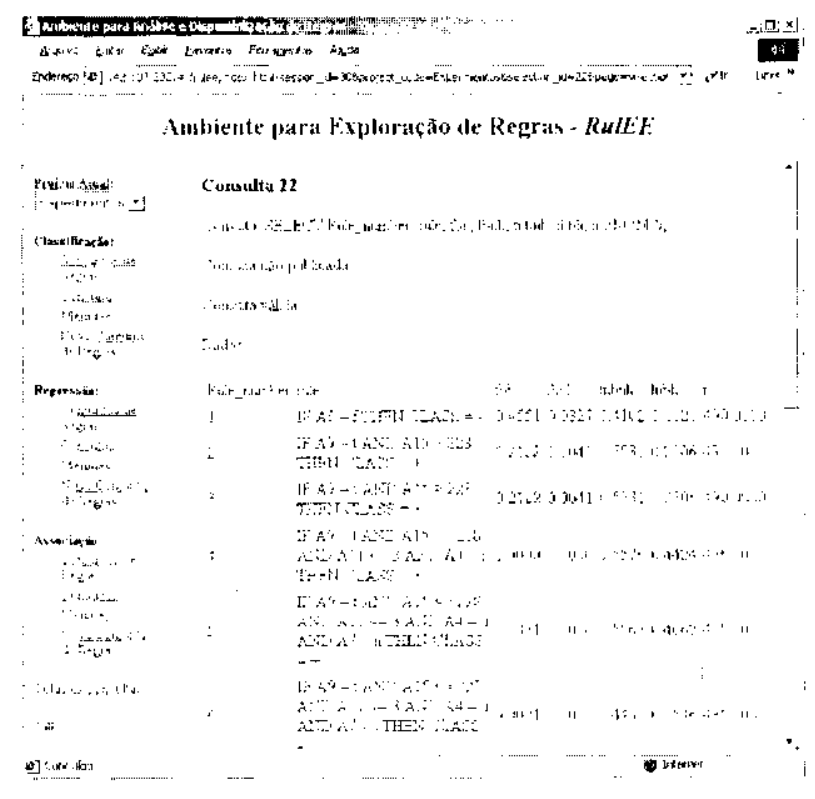

Figura 5.14: Visualização de Consulta

Link Atualizar Dados Ao clicar nesse link. os valores das medidas para as regras do conjunto de regras utilizado na consulta são removidos da base de dados e loda a busca por esses valores das medidas é realizada novamente. Após isso, a consulta é apresentada novamente ao usuário contendo os dados atualizados. Como conseqüència 


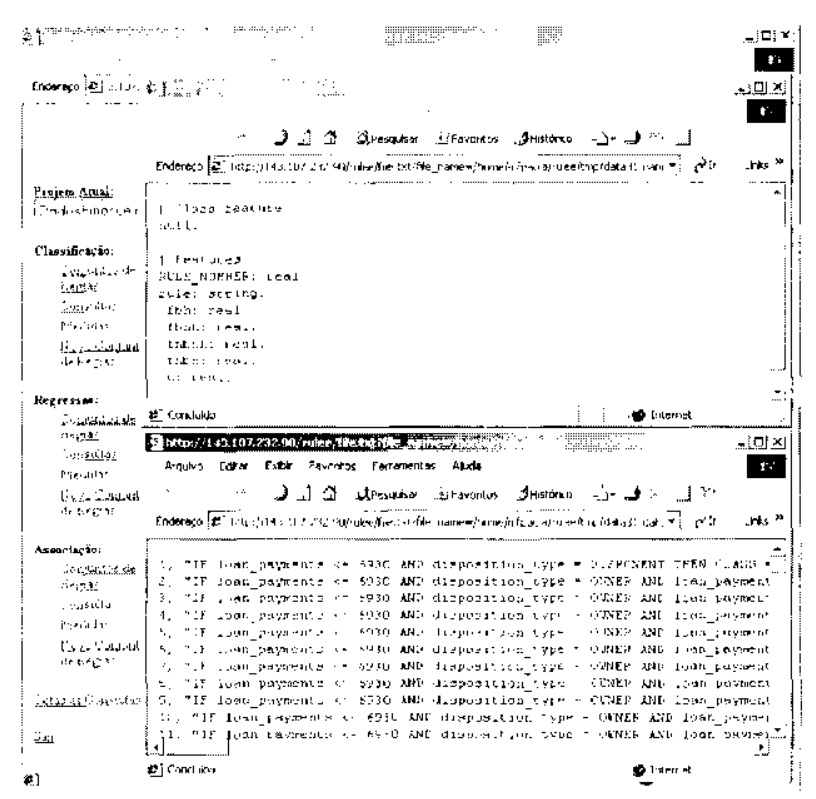

Figura 5.15: Arquivos de Descrição e de Dados Referentes à Consulta

da utilização dessa funcionalidade, todas as consultas referentes ao mesmo conjunto de regras utilizado pela consulta cujos dados foram atualizados se tornam inválidas.

Link Analisar Consulta Quando uma consulta está com status Inválida, o link Analisar Consulta fica disponivel ao usuário. Ao clicar neste link, a consulta é processada novamente para verificar sua validadc. Caso nenhum erro ocorra, a consulta é apresentada ao usuário com status Válida. Conforme citado anteriormente, quando o usuário utiliza a função Atualizar Dados, muitas consultas podem se tornar inválidas, sendo necessário analisá-las novamente.

Link Editar Consulta Link de acesso à tela para alteraçào da consulta atual

Link Criar uma Cópia Este lirkk permite ao usuário criar uma cópia da consulta atual, permitindo realizar alguma alteraçāo na mesma sem afetar a consulta original.

Edição de Consulta

A interface do Ambiente RulEE apresenta dois modos para criaçāo e edição de consultas. detalhados a seguir:

Modo Simples A edição de consultas no modo simples foi desenvolvida visando facilitar a criaçāo de consultas por usuários não experientes no ambiente. Por este modo de cdição, não é possivel a utilização de todas as funcionalidades disponiveis, descritas na Seçāo 5.2.6. mas a ediçāo das consultas é consideravelmente facilitada. Conforme 
pode ser obscrvado na Figura 5.16. a tela para edição de consultas no modo simples apresenta alguns campos para a entrada das informaçōes da consulta:

Colunas Neste campo devem ser inseridas as colunas a serem visualizadas nos dados finais referentes a consulta. Dentre as colunas que podem ser utilizadas neste campo, encontram-se RULE, referenciando a regra completa, RULE_NUMBER. referenciando o número da rega dentro do conjunto de regras, c os nomes das medidas disponiveis para o tipo do conjunto de regras, por exemplo. Acc refe. renciando a precisāo da regra. Uma lista contendo as colunas disponiveis para utilização se encontra ao lado do campo Colunas.

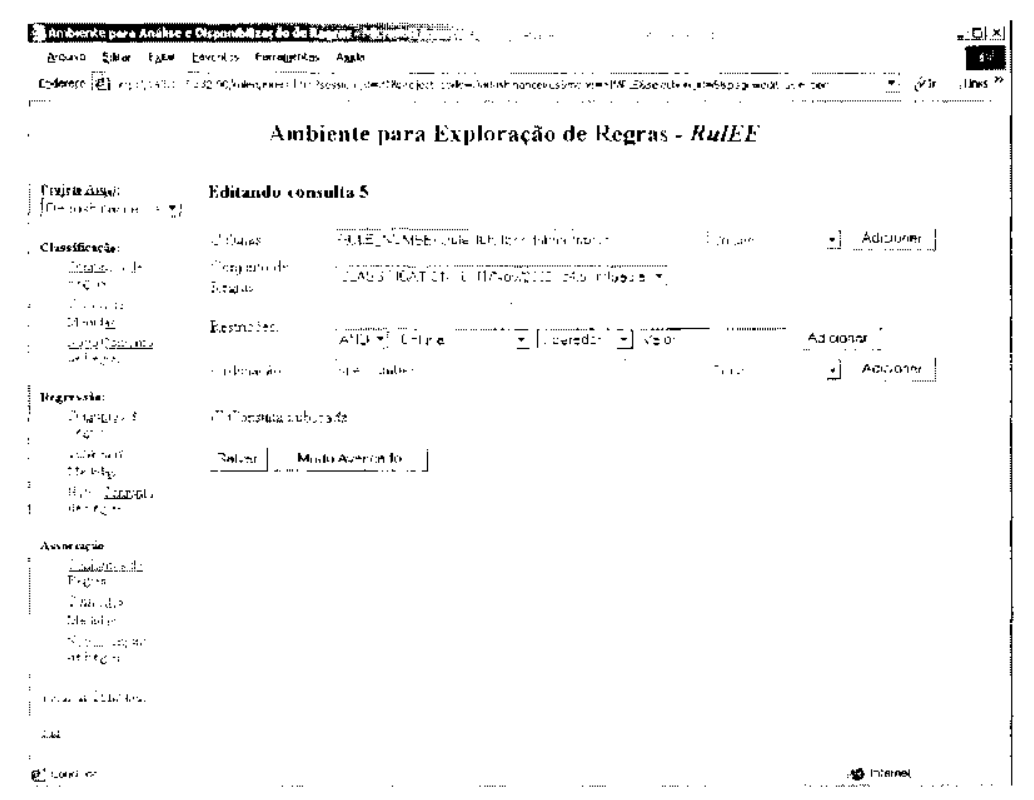

Figura 5.16: Ediçāo de Consultas - Modo Simples

Conjunto de Regras Neste campo deve ser selecionado o conjunto de regras do qual a seleçào fará a leitura das regras a serem apresentadas. Visando facilitar a identificaçào do conjunto de regras, cada elemento deste campo apresenta as seguintes informaçoes: lipo do conjunto de regras, identificador, data de extraçāo, algoritmo e usuário.

Restriçōes Neste campo devem ser inseridas as restriçōes a serem aplicadas às regras visando verificar quais delas devem ser selecionadas pela consulta. Neste cam po podem ser utilizadas restriçōes sobre quaisquer medidas disponiveis para o conjunto de regras utilizado. Abaixo do campo Restriçōes existe alguns campos para auxiliar o usuário na claboração das restriçōes. Por estes campos, o usuário 
pode selecionar a coluna sobre a qual deseja aplicar a restrição, o operador a ser utilizado e o valor de teste.

Ordenaçāo Neste campo, deve ser especificada a lista de colunas para ordenaçāo das regras, podendo ser utilizadas quaisquer colunas disponiveis para o tipo do conjuntos de regras utilizado

Consulta Publicada Caso seja do interesse do usuário que a seleçāo a ser criada esteja disponivel para acesso por outros usuários, ele deve selecionar o campo Consulta Publicada.

Durante a ediçāo da consulta, caso o usuário queira utilizar o modo avançado, ele pode clicar no botão Modo Avancado.

Modo Avançado Pela edição no modo avançado. o usuário deve especiffcar completamente a consulta a ser enviada ao ambiente, sem nenhum auxilio. A consulta dever ser especificada conforme a descrição da sintaxe das consultas fornccida na Seção 5.2.6. A Figura 5.17 apresenta um exemplo da tela para ediçāo avancada de consultas. Como pode ser observado, existe um campo no qual o usuário deve fornecer a consulta, o campo do tipo check que indica se ela deve ficar disponivel aos usuários e o botão para salvá-la no ambiente.

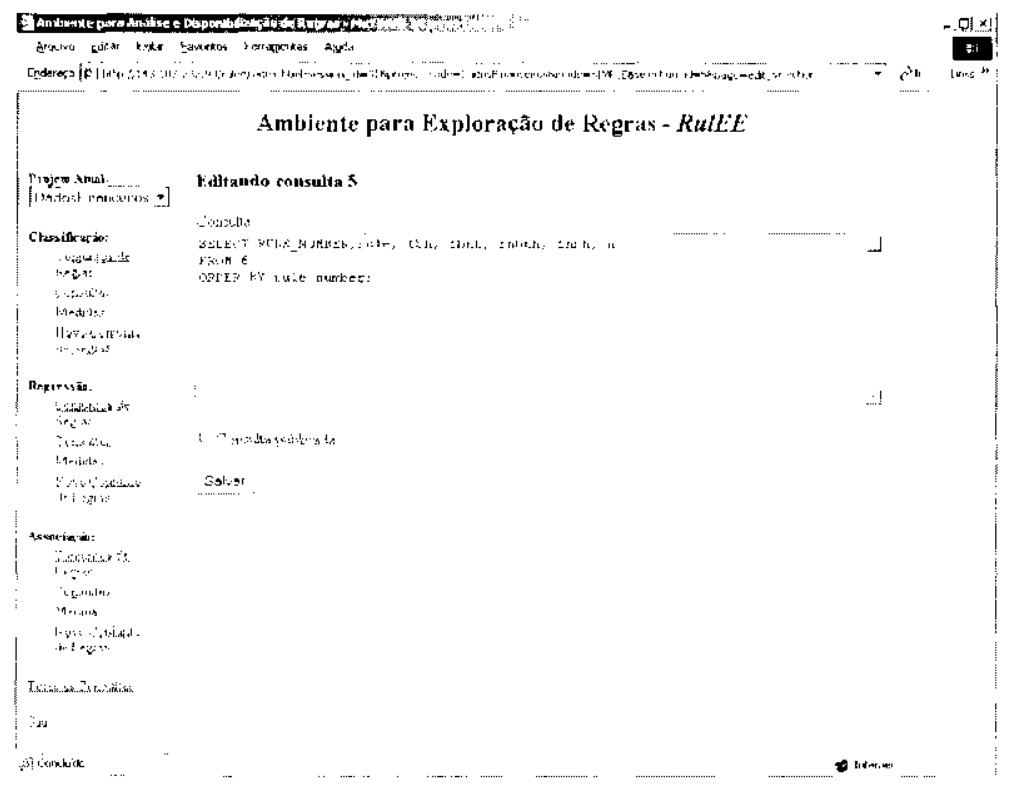

Figura 5.17: Edição de Consultas - Modo Avançado

Após editar a consulta, ao clicar no botão Salvar, o ambiente faz a análise da consulta inserida $c$, caso nenhum erro ocorra, é apresentada a tela para visualizaça da consulta 
previamente editada. Caso algum erro ocorra. uma mensagem é mostrada ao usuário e a interface continua na tela de ediçāo de consultas.

Mais detalhes sobre a utilizaçāo das consultas podem ser obtidos na Seçāo 5.2.6.

Listagem de Medidas

Para cada tipo de conjunto de regras tratado pelo ambiente existe disponivel um conjunto de medidas cujos valores podem ser requisitados para as regras. Na Figura 5.18 é apresentada a tela com a listagem das medidas disponiveis para classificação. A listagem das medidas de regressāo c associação é semelhante.

Na lista de medidas, são apresentadas as seguintes informaçōes:

- Nome da medida:

- Tipo, contendo os possiveis valores:

OBJECTIVE para medidas objetivas,

SUBJECTIVE para medidas subjetivas e

INFORMATION para medidas que representam informaçōes sobre a regra, como o número de exemplos que ela cobre;

- Tipo de retorno (inteiro ou real);

- Escopo da medida, isto é, se ela é válida para regras ou para conjuntos de regras.

Para cada medida, existe um link para acesso a informaçōes adicionais.

Informaçōes sobre Medidas

Ao buscar por informaçōes sobre uma determinada medida, o ambiente apresenta a tela exemplificada na Figura 5. 19. As seguintes informacōes são apresentadas nesta tela: nome da medida, tipo da medida, tipo do conjunto de regras a que ela se refere, tipo de retorno, escopo. como ela é obtida no ambiente e uma descriçāo.

Na próxima seçāo é apresentada a sintaxe para a criaçāo das consultas no Repositório de Regras e Medidas.

\subsubsection{Utilização de Consultas}

Com o objetivo de possibilitar um acesso facilitado ao conjunto de regras e valores de medidas, no Ambiente RulEE foram criadas as consultas sobre regras e medidas. A elaboraçāo das consultas visa também o auxílio à análise dos conjuntos de regras, permitindo a 


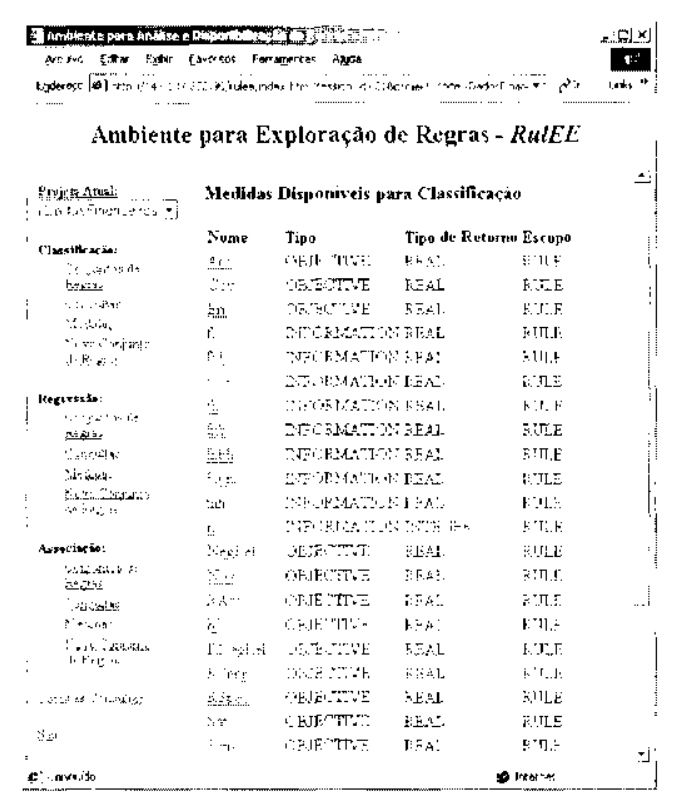

Figura 5.18: Listagem de Medidas

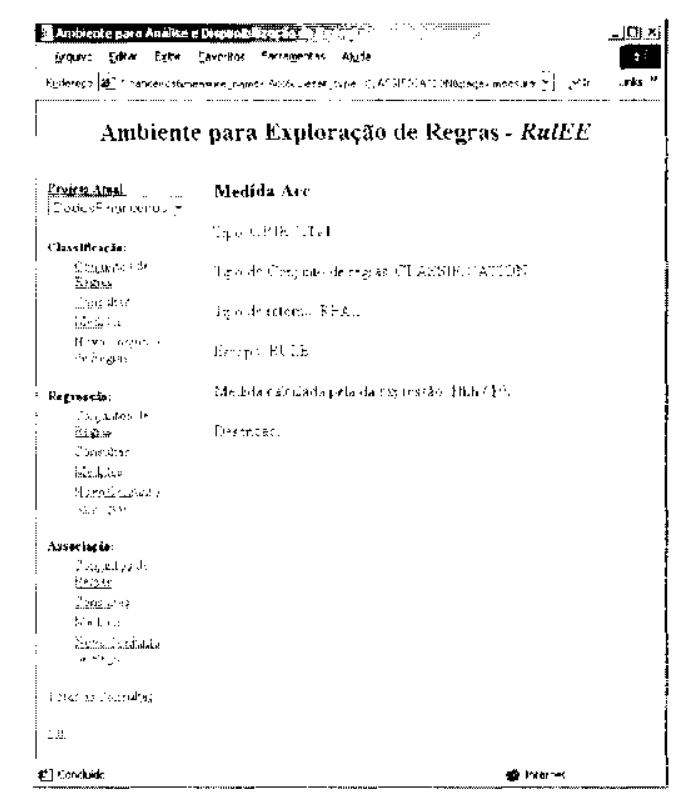

Figura 5.19: Informaçōes sobre Medidas

recuperaçāo das regras juntamente com os valores de medidas para o tipo de regra tratado, apresentando a possibilidade de se aplicar restriçōes ou filtros nas regras com relação aos valores das medidas e sobre os atributos presentes nas condiçōes do antecedente, do conseqüente e na regra como um todo. As consultas possibilitam também a ordenação do conjunto de regras e o agrupamento do resultado, como uma cláusula SQL GROUP BY. A interface do Ambiente RulEE é iterativa para ediçāo e visualização dos resultados das consultas.

Após criada uma consulta, cla recebe um identificador único e é armazenada no ambiente. Desta maneira, a consulta pode ser visualizada futuramente pelo usuário que a criou ou pelos outros usuários do projeto, caso ela esteja publicada. É possível também a alteração e remoção da consulta pelo usuário que a criou. e sua cópia por qualquer usuário que possa visualizá-la. Os resultados podem ser visualizados pela interface do ambiente e pode ser feito o download de um arquivo contendo o conjunto de dados resultante da consulta visando facilitar a utilizaçāo desses dados em outra ferramenta para sua análisc.

A implementação das consultas na basc de dados está baseada na classe Selection que implementa o processamento da string correspondente à consulta e faz a seleção das regras e dos valores das medidas na base de dados do ambiente. Neste processamento, é gerada uma nova consulta adequada a ser executada no Repositório de Regras e Medidas, de forma que retorne os resultados esperados pelo usuário. Conforme a arquitetura do ambiente, a 
classe de seleção de regras é utilizada pela interface do ambiente para edição das consultas. podendo ser utilizada também em scripts PERL escritos pelos usuários.

As consultas a serem realizadas na base de dados foram projetas de forma semelhante às consultas SQI, scndo expressöes na forma:

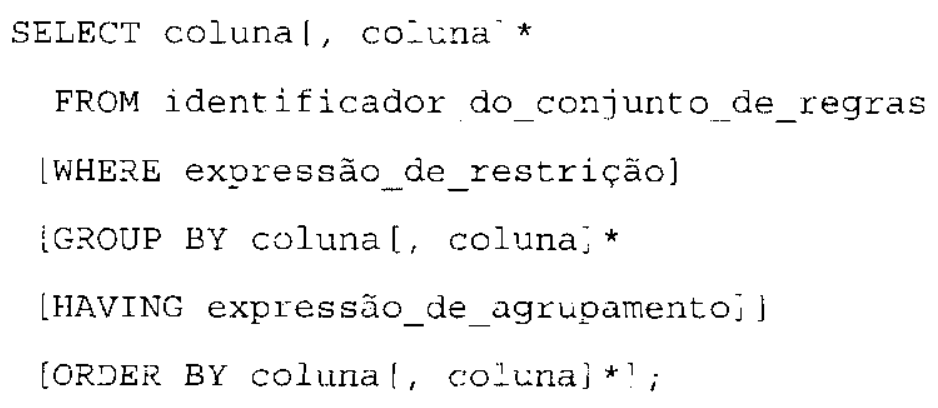

Na cláusula SELECT devem ser especificadas as colunas a serem apresentadas no resultado da consulta, como em uma consulta $\$$ GL. Dentre as colunas que podem ser utilizadas, cncontram-se o antecedente, o conseqüente, a regra completa e as medidas disponiveis para o conjunto de regras. Na cláusula FROM deve ser especificado o identilicador do conjunto de regras do qual as regras serão selecionadas.

Na cláusula WHERE devem ser especificadas as restrições para a scleção das regras a screm aprescntadas no resultado final. $\Lambda$ ssim, esta cláusula deve apresentar uma cxpressāo booleana, como em uma cláusula WHERE SQL, utilizando na aplicação das restriçōes o antecedente, o conseqüente, a regra completa e as medidas disponiveis para o conjunto de regras selecionado.

Como em uma consulta SQL, o resultado de uma consulta no ambiente pode ser agrupado por alguma coluna. Isto permite ao usuário retornar sumarizaçōes de valores de medidas, como o valor médio, minimo ou máximo de uma determinada medida pcla utilizaçào de comandos SUM, AVG, MAX, MIN e COUNT. Devem ser selecionadas ná cláusula GROUP BY as colunas pelas quais o resultado de uma consulta deve ser agrupado. Ao se utilizar uma cláusula GROUP I3Y, é possivel aplicar restriçòcs sobre o resultado do agrupamento. Por exemplo. ao se utilizar HAVING count(*)>2, c retornado ao usuário somente os valores agrupados nos quais o mumero de registros em cada linha agrupada é maior que dois.

Na cláusula ORDER IBY deve ser especificada a lista de colunas pela qual o resultado deve ser ordenado. O resultado da consulta pode ser ordenado pelo valor de qualquer medida de avaliação. 
Na implementaçāo atual do ambiente. o processamento das consultas nảo é realizado de maneira completa, isto é. não é feita uma análise léxica e sintảtica das consultas escritas pelos usuários. As consultas são processadas visando a geração de uma nova consulta a ser executada na base de dados do ambiente equivalente à fornecida pelo usuário.

Alguns exemplos de consultas realizadas no Ambiente RulEE podem ser encontradas no estudo de caso apresentado no Capítulo 6.

\subsection{Medidas Disponiveis}

Na implementação atual do Ambiente RulEE, algumas medidas estão disponiveis para utilização nas consultas. Para os conjuntos de regras de classificação, regressāo e associação estão disponiveis para utilização os valores da tabela de contingência, que são obtidos nos arquivos de descriçāo dos conjuntos de regras, não sendo, portanto, calculados no ambiente. Os valores da tabela de contingência podem ser acessados utilizando os identilicadores $f b h, f n b h, f b n h, f n b n h, n, f b, f n b, f h, f n h$ referenciando os valores da matriz fhh. $f_{b h}, f_{b,}, f_{\overline{b h}}, n, f_{b}, f_{\bar{b}}, f_{h}, f_{\bar{h}}$, respectivamente.

E importante destacar que os valores da tabela de contingència de cada regra de um conjunto de regras de regressão são obtidos segundo métodos definidos por Pugliesi, Dosualdo, \& Rezende (2003), conforme foi destacado na Seção 4.2.3.

Todas as outras medidas disponibilizadas no ambiente sāo calculadas a partir dos valores da tabela de contingência. Dentre as medidas disponibilizadas estão as definidas pelas Equaçōes 3.5 a 3.22, apresentadas no Capítulo 3. Estas medidas podem ser acessadas no ambiente através do uso dos identificadores equivalentes aos nomes das medidas definidas em suas respectivas equacōes.

Atualmente. todas as medidas disponiveis no Ambiente RulEE sāo medidas objetivas. Trabalhos futuros referentes ao ambiente poderāo estar relacionados com a disponibilizacāo de medidas subjetivas.

\subsection{Considerações Finais}

Este capitulo abordou a implementação do Ambiente RulEE, que se apresenta como uma instanciação de um Ambiente para Exploração de Regras proposto no Capitulo 4. Como pode-se observar, o Ambiente RuLE apresenta algumas características importantes para facilitar a análise de regras de associação, regressão é classificação, como a disponibilidade de diversas medidas de avaliaçāo e a possibilidade de se aplicar restriçōes às medidas para seleçāo e ordenação das regras. 
Neste capítulo, primeiramente, foi apresentada a arquitetura geral do Ambiente RulEE. detalhando seus principais módulos e repositórios. Foram então apresentados alguns elementos do ambiente, como sua base de dados, a biblioteca de classes e sua interface. Também foram abordados alguns tópicos sobre como sāo obtidos os valores das medidas, a sintaxe das consultas no Repositório de Regras e Medidas e sobre quais medidas estão disponiveis para utilização pelos usuários. Mais detalhes sobre a implementação do Ambiente RulEE pode ser encontrada em (Paula \& Rezende 2003)

No próximo capitulo é apresentado um estudo de caso utilizando dados financeiros em que são utilizadas as consultas do ambiente para mostrar algumas características importantes para a análise de regras. No próximo capitulo, a utilização de consultas pode ser melhor compreendida pelos exemplos utilizados. 


\section{Capítulo 6}

\section{Estudo de Caso}

\subsection{Considerações Iniciais}

O projeto do Ambiente RulEE visa facilitar a exploração dos resultados obtidos no processo de Mineração de Dados. Com objetivo de apresentar algumas das funcionalidades deste ambiente, foi desenvolvido um estudo de caso no qual foi utilizado um conjunto de dados financeiros disponibilizado para o Discovery Challenge, realizado como parte do PKDD'99 (European Conference on Principles and Practice of Knowledge Discovery in Dalabases) ${ }^{1}$.

Deve-se ressaltar que o objetivo principal deste estudo nāo é atingir todas as metas propostos pelo Discovery Challenge, mas a utilização de dados desse domínio para mostrar algumas funcionalidades do Ambiente RulEE na análise e disponibilização das regras descobertas. exemplificar a utilizaçāo das sintaxes padrāo para dados e regras de classificaçāo e a utilizaçāo dos scripts do Ambiente Discover para conversāo das regras.

Para exemplificar a utilizaçāo do Ambiente RulEE, é apresentado, na Seção 6.2, todo o processo de Extraçāo de Conhecimento e, na Seçāo 6.3, a disponibilização dos resultados utilizando o RulEE.

\subsection{A Extração de Regras em Dados Financeiros}

Como mostrado na Figura 2.1, o processo de Mineração de Dados é composto pelas elapas de Conhecimento do Dominio e Identificaçāo do Problema. Pré Processamento, Extração de Padrōes e Pós-Processamento. Para uma melhor compreensão do dominio, do conjunto de dados e das regras cncontradas. nesta seção é descrita a execução destas elapas com os dados do domínio especificado.

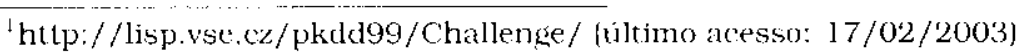




\subsubsection{Conhecimento do Dominio e Identificação do Problema}

Os dados disponibilizados para o Discovery Challenge foram fornecidos por alguma entidarte financeira e o objeto principal da análise desses dados é encontrar novos conhecimentos visando melhorar a qualidade dos serviços oferecidos pela entidade aos seus clientes. Os gerentes desta entidade querem determinar quais as caracteristicas dos clientes bons, a quem desejam oferecer serviços adicionais, e as características dos clientes ruins, os quais devem ser observados com cautela para evitar futuras perdas.

A base de dados fornecida é constituída de um conjunto de tabelas contendo infor maçōes sobre contas. Dentre essas informaçoes encontram-se dados sobre empréstimos, pagamentos, transaçōes, cartões de crédito. cliente e informaçōes sobre a regiāo onde o cliente reside. Na Figura 6.1 pode ser observado o diagrama físico da base de dados fornecida, sendo apresentadas as colunas e as chaves de cada tabela. Na Tabela 6.1, pode ser encontrada uma pequena descrição de cada tabela da base de dados, assim como o nümero de registros existentes em cada uma

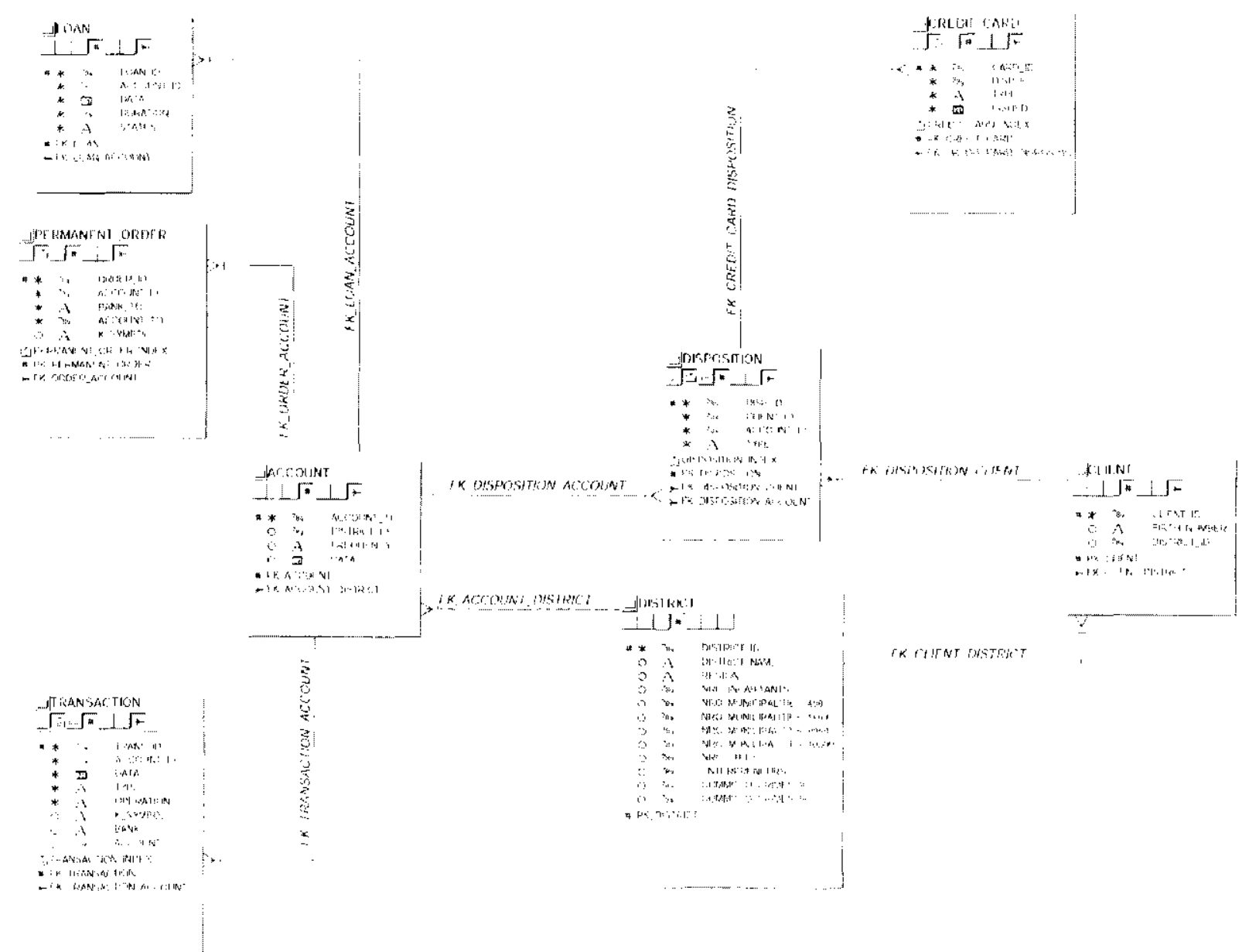

Figura 6.1: Diagrama da Base de Dados Financeira 


\begin{tabular}{|c|c|c|}
\hline $\begin{array}{l}\text { Nome da Tabe- } \\
\text { la }\end{array}$ & $\begin{array}{ll}\text { Número } & \text { de } \\
\text { Registros na } \\
\text { Tabela }\end{array}$ & Descrição \\
\hline account & $4 . \overline{500}$ & Contém caracteristicas estáticas de cada conta. \\
\hline loan & $6 \longdiv { 8 2 }$ & $\begin{array}{l}\text { Cada registro representa um empréstimo relacionado } \\
\text { a uma determinada conta. }\end{array}$ \\
\hline permanent_order & 6.471 & $\begin{array}{l}\text { Os registros apresentam características das ordens de } \\
\text { pagamentos. }\end{array}$ \\
\hline transaction & 1.056 .320 & $\begin{array}{l}\text { Cada registro representa uma transação de uma de- } \\
\text { terminada conta. }\end{array}$ \\
\hline credit_card & 892 & Contém os cartōes de creditos relacionados às contas. \\
\hline disposition & 5.369 & $\begin{array}{l}\text { Os registros apresentam os direitos de cada cliente pa- } \\
\text { ra operar sua conta. }\end{array}$ \\
\hline district & $7 \overline{7}$ & $\begin{array}{l}\text { Cada registro apresenta informacoues demograficas das } \\
\text { regiōes em que os clientes residem. }\end{array}$ \\
\hline client & 5.369 & Apresenta as caracteristicas dos clientes. \\
\hline
\end{tabular}

Tabela 6.1: Descriçāo das Tabelas da Base de Dados Financeira

Cada conta de cliente existente na base de dados possui caracteristicas estáticas, correspondentes às colunas da tabela account. como por exemplo sua data de criação. e características dinâmicas, como pagamentos debitados ou creditados e saldos. correspondentes aos registros das tabelas permanent_order e transaction. A tabela clieni descreve caracteristicas dos clientes que podem manipular as contas. Cada cliente pode possuir muitas contas e uma conta pode ser manipulada por vários clientes. A listagem dos clientes e suas respectivas contas estão presentes na tabela disposition. As tabelas loan (empréstimo) e credit_card (cartāo de credito) armazenam informaçōes referentes a serviços que o banco pode oferecer a seus clientes.

Existem várias abordagens ou objetivos específicos para se realizar a análise dos dados. Por exemplo, pode-se realizar uma análise descritiva, visando identificar relaçōes não triviais ou não previstas, ou realizar uma anảlise preditiva, ao analisar os clientes que possuem ou não cartōes de crédito, visando identificar possiveis novos clientes para oferecer o serviço. Neste estudo de caso. o objetivo da análise dos dados foi verificar os cmprestimos oferecidos pelo banco visando identificar as caracteristicas dos clientes para os quais futuros pedidos de empréstimos poderāo ser aceitos e caracteristicas dos clientes que apresentaram problemas no pagamento de algum empréstimo passado e, portanto, o pedido de um novo empréstimo deve ser analisado com mais cautela.

Com um conhecimento inicial sobre o problema e a especificaçāo do objetivo da análise dos dados, pode-se iniciar o Pré-processamento 


\subsubsection{Pré-Processamento}

Os dados desse domínio foram fornecidos em formato texto juntamente com a descriçāo do modelo apresentado na Figura 6.1. Para facilitar seu Pré-processamento. foram criadas as tabclas especificadas na seção anterior em uma base de dados MySql.

Para que seja possivel a utilizaça dos algoritmos de Aprendizado de Máquina, é necessário que os dados estejam em um formato atributo-valor, conforme definido na Seçāo 2.2.2. Desta maneira. foi neccssária a junção dos dados fornecidos em uma única tabela. No Pré-processamento, as seguintes atividades foram realizadas:

Junção das Tabelas $\Lambda$ definição utilizada para categorizar cada cliente como bom ou ruim foi realizada utilizando os dados existentes na coluna status da tabela loan. Nesta definição. um cliente é considerado bom se elc nunca teve problemas com o paganıento dos empréstimos, sendo considerado ruim caso contrário. Assim, para a extraçāo de padrōes foram utilizados somente os dados dos clientes que, em algum momento, obtiveram crédito. ou seja, foi realizada a junçāo das tabelas utilizando somente os dados de clientes e contas que apresentam algum registro na tabela loan.

Os atributos das tabelas correspondentes aos conjuntos de dados gerados pelas jun çôes foram nomeados utilizando o seguinte padrão: nome da tabela original_nome do atributo original. Por exemplo, os dados do atributo account frequency nas tabelas geradas correspondem aos dados do atributo frequency da tabela account.

Transformação de Valores de Atributos Visando facilitar a compreensão dos dados e dos resultados da execução dos algoritmos, alguns atributos tiveram seus valores transformados, conforme a descrição fornecida juntamente com os dados e apresentado na Tabela 6.2

Criação de Novos Atributos No Pré-processámento, novos atributos foram criados com base nos dados originais

Conforme especificado na ctapa de Conhecimento do Dominio e Identificação do Problema, o objetivo da análise dos dados é prever sc um cliente poderá apresentar problemas no pagamento de um empréstimo, foi necessária a criação da coluna loan_predict como sendo o atributo meta do conjunto de dados. O atributo loan_predict teve seu valor definido como segue: loan_predict $=$ GOOD se loan_status $=A$ (contrato finalizado sem problemas de pagamento) ou loan_status $=C$ (contrato nāo finalizado $e$ pagamento em dia) e loan $p$ predict $=B A D$ se loan_status $=B$ (contrato finalizado e em- 


\begin{tabular}{|c|c|c|}
\hline Atributo & Valores Originais & Novos Valores \\
\hline account frequency & $\begin{array}{l}\text { POPLATEK MESICNE } \\
\text { POPLATEK TYDNE } \\
\text { POPLATEK PO OBRATU }\end{array}$ & $\begin{array}{l}\text { monthly } \\
\text { weekly } \\
\text { after transaction }\end{array}$ \\
\hline permanent_order_ksymbol & $\begin{array}{l}\text { POJISTNE } \\
\text { SIPO } \\
\text { LEASING } \\
\text { UVER }\end{array}$ & $\begin{array}{l}\text { insurrance } \\
\text { household } \\
\text { leasing } \\
\text { loan }\end{array}$ \\
\hline transaction_type & $\begin{array}{l}\text { PRIJEM } \\
\text { VYDAJ }\end{array}$ & $\begin{array}{l}\text { credit } \\
\text { withdrawal }\end{array}$ \\
\hline transaction_operation & $\begin{array}{l}\text { VYBER KARTOU } \\
\text { VKLAD } \\
\text { PREVOD Z UCTU } \\
\text { VYBER } \\
\text { PREVOD NA UCET }\end{array}$ & $\begin{array}{l}\text { credit card withdrawal } \\
\text { credit in cash } \\
\text { collection from another bank } \\
\text { withdrawal in cash } \\
\text { remitance to another bank }\end{array}$ \\
\hline transaction $k$ symbol & $\begin{array}{l}\text { POIISINE } \\
\text { SLUZBY } \\
\text { UROK } \\
\text { SANKC. UROK } \\
\text { SIPO } \\
\text { DUCHOD } \\
\text { UVER }\end{array}$ & $\begin{array}{l}\text { insurrance payment } \\
\text { payment for statement } \\
\text { interest credited } \\
\text { interest if negative balance } \\
\text { household } \\
\text { old-age pension } \\
\text { loan payment }\end{array}$ \\
\hline
\end{tabular}

Tabela 6.2: Transformação de Valores de Atributos da Base de Dados Financeira préstimo não pago corretamente) ou loan_status $=D$ (contrato não finalizado e cliente em débito).

Além do atributo meta loan_predict. foram também criados os atributos definidos na Tabela 6.3 .

\begin{tabular}{|c|c|}
\hline Atributo & Descriçāo \\
\hline client age & $\begin{array}{l}\text { Idade do cliente em meses. Valor calculado a partir da } \\
\text { coluna client birth number. cujo valor determina a data } \\
\text { de nascimento e o sexo do cliente. }\end{array}$ \\
\hline client sex & $\begin{array}{l}\text { Sexo do cliente. Valor tambem obtido a partir cla coluna } \\
\text { client_birth_number. }\end{array}$ \\
\hline account_months_before_loan & $\begin{array}{l}\text { Número de meses entre a criação da conta do cliente e } \\
\text { a obtenção do empréstimo. }\end{array}$ \\
\hline credit_card_months_before_loan & $\begin{array}{l}\text { Númcro de meses entre a obtençào de um cartāo de } \\
\text { crédito e a obtençāo do emprestimo. }\end{array}$ \\
\hline transaction_months_before loan & $\begin{array}{l}\text { Numero de meses entre a transaçào e a obtenção do } \\
\text { empréstimo. }\end{array}$ \\
\hline
\end{tabular}

Tabela 6.3: Novos Atributos da Base de Dados Financeira

Geração dos Arquivos de Dados na Sintaxe Padrão No final do Pré-processamento dos dados, eles foram convertidos para a sintaxe padrào do Ambiente Discover. Para 
ambos os conjuntos de exemplos criados. foram gerados arquivos de treinamento e de teste.

Após os dados terem sido preparados e formatados na sintaxe padrāo. a próxima ctapa do processo de Mineração de Dados pode ser iniciada.

\subsubsection{Extração de Padrões}

De acordo com o objetivo definido. este estudo de caso trata de um problema de classificaçāo. Assim, para a extraçāo de padroes foi utilizado o algoritmo de Aprendizado de Máquina C4.5, sendo necessäria a conversāo dos conjuntos de dados para o formato de cntrada do algoritmo C4.5 utilizando os scripts de conversāo disponiveis no Discover.

Neste estudo de caso foram utilizados dois conjuntos de dados. Em um primeiro instante, foi gerado o conjunto de dados Financial_Data_l. Nesse primeiro conjunto, foram utilizados os dados de todas as tabelas da base de dados na geraçào da tabela no formato atributo-valor. Após executada a junção, a tabela correspondente aos dados Financial_Data_l apresentou um total de 161.314 registros com 33 atributos. Para permitir uma execução mais rápida do algoritmo $\mathrm{C} 4.5$, foi criada uma amostra desse conjunto, contendo 48.382 registros, aproximadamente $30 \%$ dos dados originais. $\Lambda$ pós a divisāo do conjunto Financial_Dala_l, o arquivo de dados de treinamento ficou com 32.114 exemplos c 16.268 exemplos foram utilizados para teste. A árvore de decisāo induzida a partir desses dados apresentou um total de 105 regras e uma taxa de erro estimada de $0.5 \%$.

Ao verificar a árvore de decisão induzida, observou-se que não foram utilizados os atributos da tabela transaction para realizar a classificação. Assim. em uma segunda ileração do processo, foi gerado o segundo conjunto de dados (Financial_Data_2) no qual não foi utilizada a tabela transaction na junção dos dados para a formação da tabela no formato atributo valor

No segundo conjunto, foram utilizadas as tabelas account, loan, permanent_order, cre dit_card. disposition, district e client para a geraçāo da tabela no formato atributo-valor. Estc conjunto de dados apresentou um total de 1.841 exemplos, sendo que 1.212 foram usados para treinamento e 629 para teste. Para este conjunto de dados. foram utilizados os mesmos atributos do conjunto Financial_Data_1. excluindo somente os atributos referentes à tabela transaction. A árvore de decisāo induzida extraída de Financial_Data_2 apresentou um total de 28 regras e uma taxa de erro estimada de $7.1 \%$. 
Após a Extraçāo de Padrōes, as árvores de decisão foram processadas e inseridas no Ambiente RuLEE para uma análise mais detalhada dos resultados, na etapa de Pós-processamento.

\subsubsection{Pós-Processamento}

No Pós processamento das ârvores de decisāo, foran utilizados os scripts do Discover para sua conversão cm conjuntos de regras na sintaxe padrão de classificaçào (Prati. Baranauskas, \& Monard 2001 b). Posteriormente, foram utilizados os scripts para cálculo dos valores da tabela de contingencia para cada regra a partir dos conjuntos de dados de testes (Prati, Baranauskas, \& Monard 2001a). Desta maneira, os conjuntos de regras extraidos a partir de dois conjuntos de dados puderam ser explorados no Ambiente RulEE. Na seçāo seguinte é apresentada a utilizaçāo do ambiente para a análise e disponibilização das regras encontradas no processo.

\subsection{Exploração das Regras Utilizando o RulEE}

Como citado anteriormente. o Ambiente RulEE foi desenvolvido com objetivo de auxiliar a análise c disponibilização de regras, atividade pertencente à etapa de Pós-processamento do processo de Mineração de Dados. O ámbiente possibilita a execução dessa análise de mancira bastante flexivel através da utilização de suas funcionalidades em scripts de Pós-processamento desenvolvidos por especialistas do processo de Mineração de Dados. Por outro lado, essa exploraçāo das regras pode ser realizada mais facilmente utilizando a interface definida para o ambiente. Este tipo de interaçăo é voltada a usuários näo especialistas. Estes dois tipos de interaçào são apresentados nas seçôes seguintes.

\subsubsection{Utilização do Ambiente por Scripts}

Nesta seçāo, é exemplificada a utilizaçào do Ambiente RulEE, pelas classes do Módulo de Gerenciamento, para executar as seguintes atividades: criaçāo de uma sessāo. inserçāo do conjunto de regras extraido do conjunto de dados Financial_Data_1 no RulEE e execuçào de uma consulta.

Primeiramente, para que o usuário possa utilizar as classes em scripts, cle deve possuir senha para login no servidor em que o Ambiente RulEE está instalado, alèm de direito de acesso às classes e à base de dados.

Para permitir a utilizaçāo do ambiente por scriptś é necessária a criação de uma sessão. Esta criação pode ser realizada através do script apresentado na Figura 6.2. O identificador 
da sessão criada deve ser armazenado para os acessos seguintes ao ambiente. Ao executar o script para criação de sessōes, a saida obtida è semelhante à apresentada na Figura 6.3.

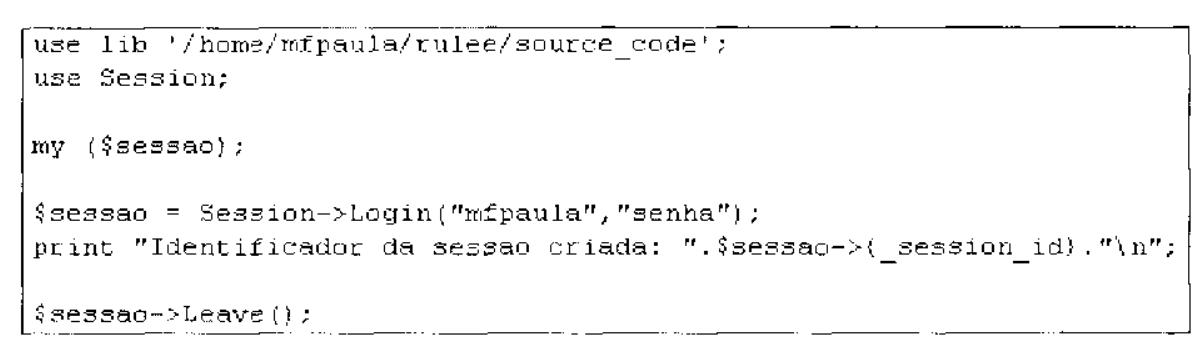

Figura 6.2: Exemplo de Script para Criaçāo de Sessōes no Ambiente RulEE

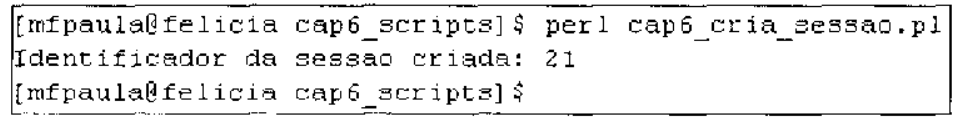

Figura 6.3: Execuçāo do Script de Exemplo para Criação de Sessōes

Um conjunto de regras pode entāo ser inserido no ambiente por um script semelhante ao exemplo apresentado na Figura 6.4. O resultado da execução desse script pode ser observado na Figura 6.5, em que é fornecido o identificador do conjunto de regras referente à arvore extraída a partir dos dados Financial_data_1. Estc identificador deve ser utilizado para a realização das consultas referentes a este conjunto de regras.

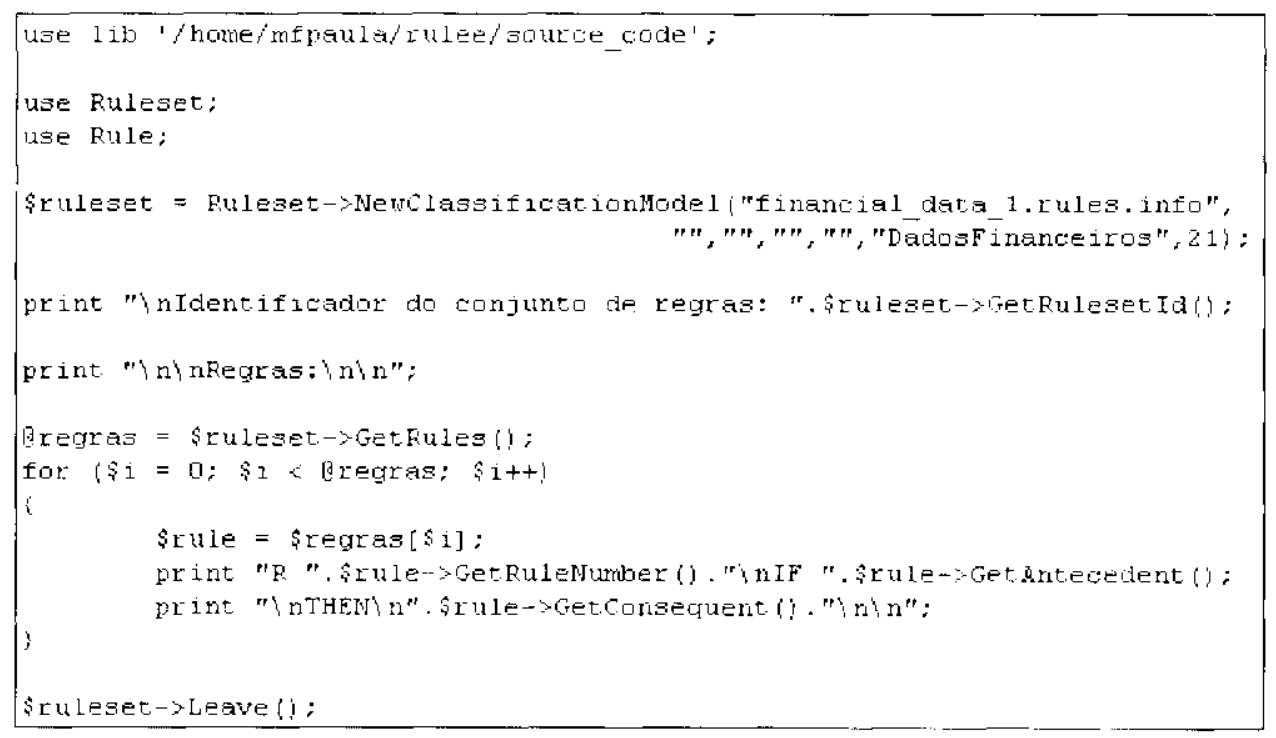

Figura 6.4: Exemplo de Script para Inserção do Conjunto de Regras Extraîdo de Financial_Data_l

Para exemplificar a utilização da classe para execuçāo de consultas. é utilizado o script apresentado na Figura 6.6 que retorna ao usuário os valores da tabela de contingência das 


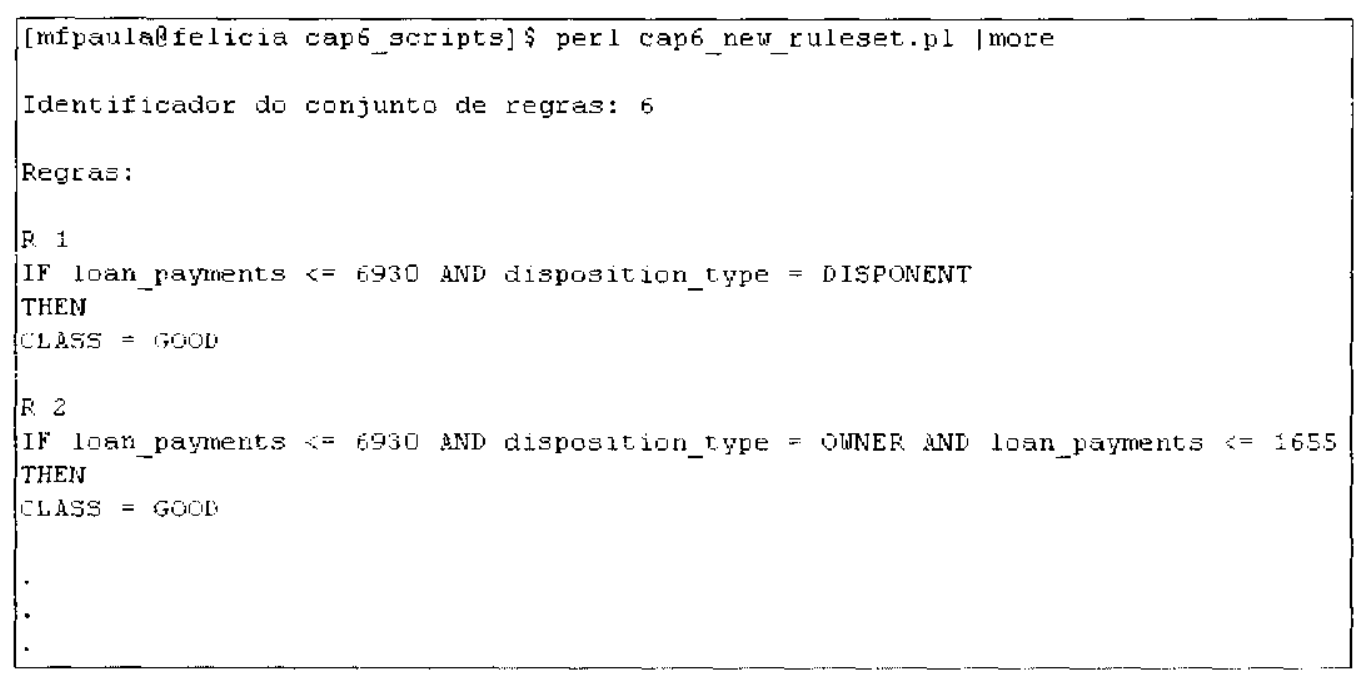

Figura 6.5: Resultado da Execução do Script de Exemplo para Inserção do Conjunto de Regras

regras do conjunto de regras inserido anteriormente. Pela execução de tal script, obtém-se o resultado apresentado na Figura 6.7 .

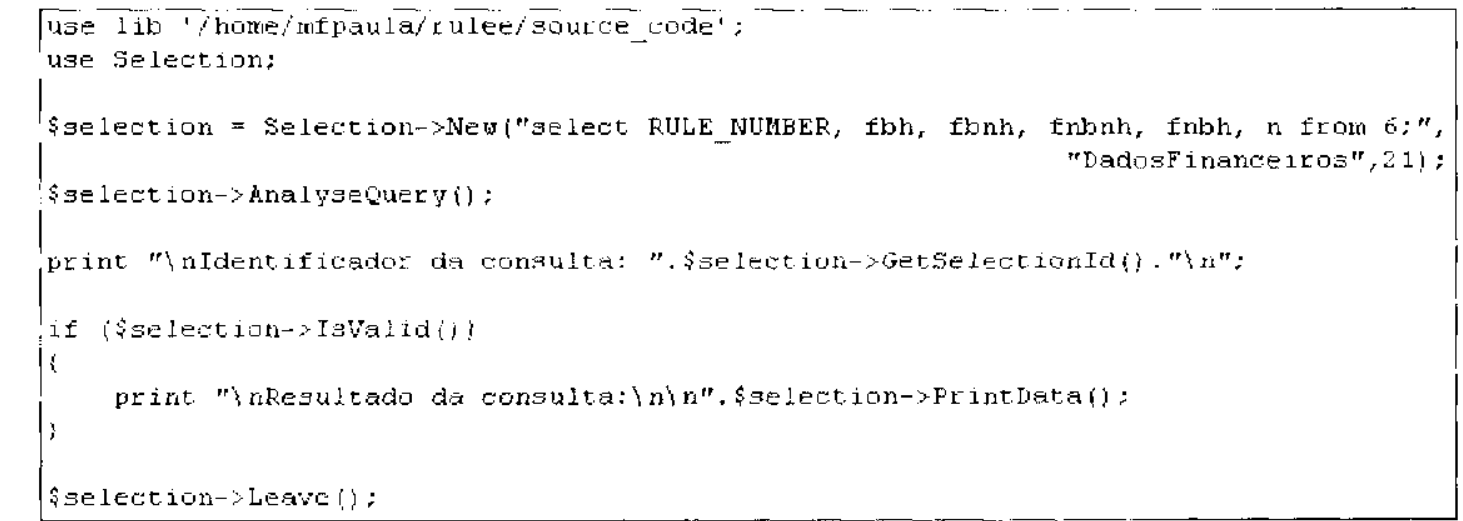

Figura 6.6: Exemplo de Script para Execução de Consulta

Deve-se ressaltar que a construção desses scripts pode ser realizada pelos usuários com conhecimento da biblioteca de classes e da base de dados do Ambiente RulEE. Uma descrição completa de todas as classes e métodos existentes na biblioteca de classes e das tabelas e atributos existentes na base de dados encontra-se em (Paula \& Rezende 2003).

Na próxima seção é apresentada a utilização da interface do ambiente na análise das regras descobertas neste estudo de caso. Para isto, serão apresentadas algumas consultas realizadas. 


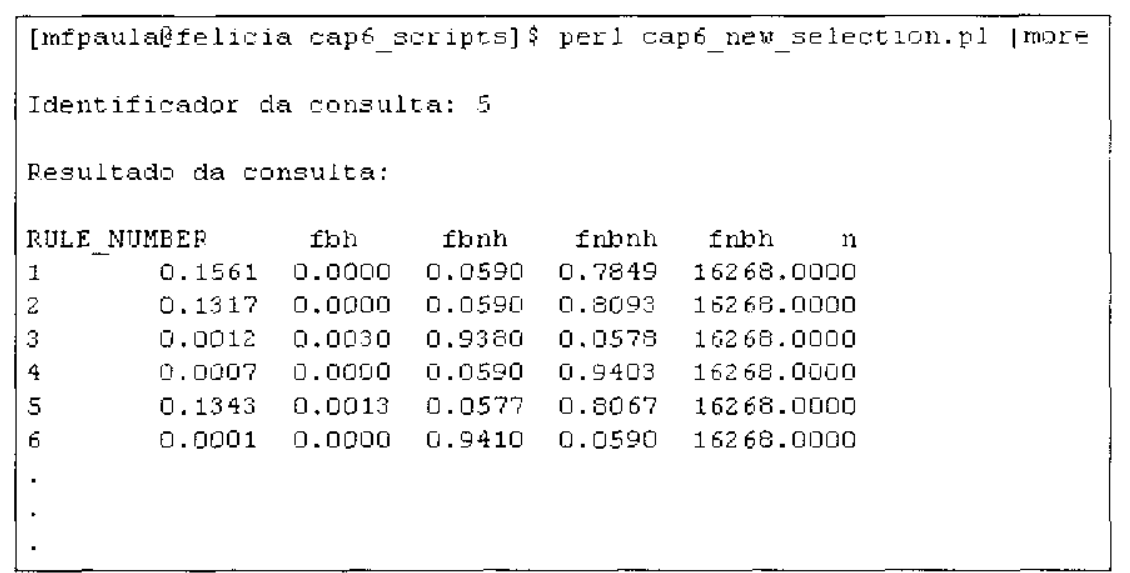

Figura 6.7: Resultado do Script de Exemplo para Execuçāo de Consulta

\subsubsection{Utilização do Ambiente pela interface}

Para exemplificar a utilização do Ambiente RulEE pela interface. foi inserido o conjunto de regras cxtraido a partir do conjunto de dados Financial_Data_2 já que o número de regras extraídas deste conjunto de dados foi menor.

Para a inscrção de um conjunto de regras de classificação no ambiente através da interface, após estar conectado no mesmo deve-se clicar no link Novo Conjunto de Regras nos links rcferentcs a classificaçāo. Na Figura 6.8 é mostrada a inserçāo do conjunto de regras extraidas a partir de Financial_Data_2. Após inserido, o conjunto de regras é apresentado ao usuário, o qual deve verificar o identificador do conjunto para permitir futuros acessos.

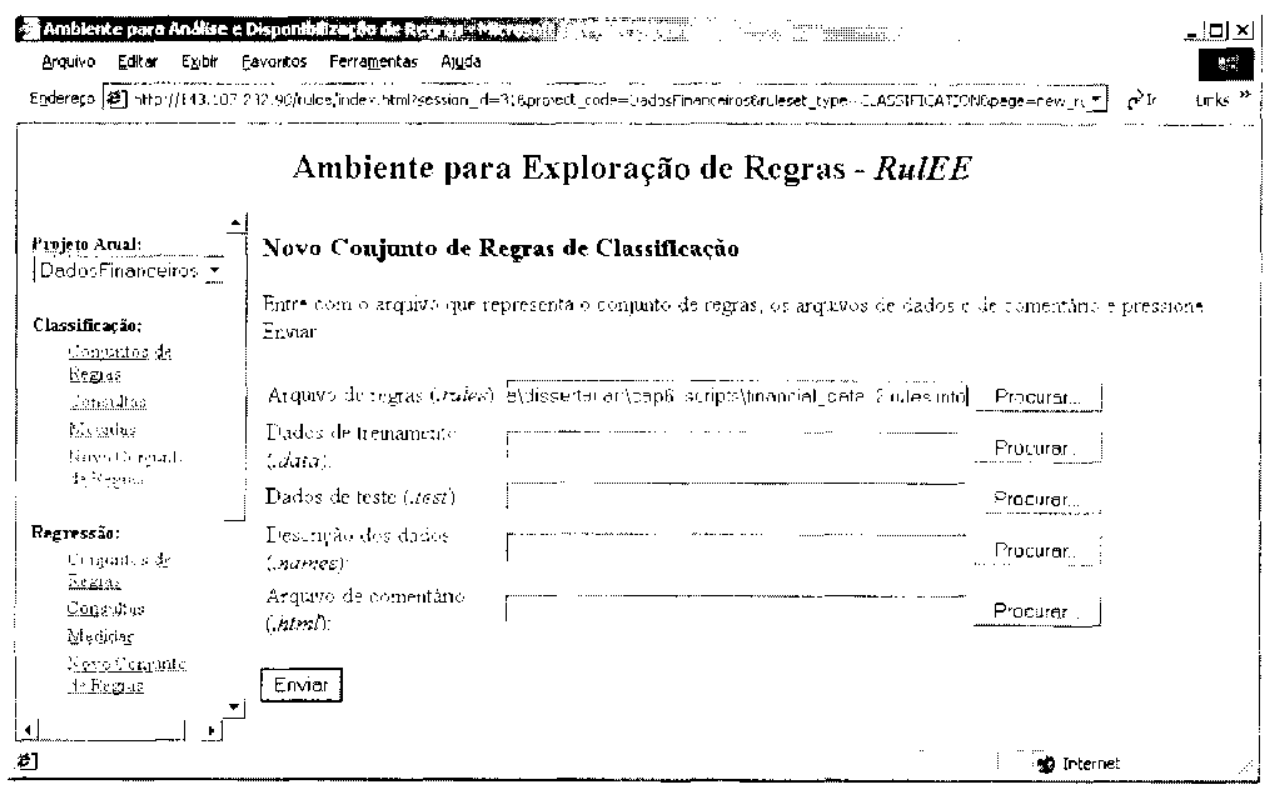

Figura 6.8: Tela para Inserçāo do Conjunto de Regras Extraído de Financial_Data_2 
Pode-se observar nesta seçāo que a interface descnvolvida é bastante simples, uma vez que o foco principal deste trabalho foi a proposta e modelagem do Ambiente RulEE: Outro aspecto importante é que todas os valores das medidas utilizadas nesta seção são calculados automaticamente pelo ambiente, conforme apresentado na Seção 5.3 .

A seguir sāo apresentadas algumas consultas para ilustrar a utilização das mesmas na exploração das regras descobertas. Nas consultas realizadas, é feita uma análise quantitativa baseada nos valores das medidas. O resultado de algumas consultas é apresentado pela interface do ambiente, enquanto que para outras consultas é apresentada somente a conclusão obtida ou a interpretação do resultado, por nāo ser necessária a apresentaçào de todas as telas. Para cada consulta, são apresentados seu objetivo ou descrição do resultado e a consulta rcalizada.

A consultas realizadas foram as seguintes:

1. Verificaçào das características dos cliente bons e ruins. Consulta realizada:

SELECT rile_number, rule_antecedent, rule_consequent FROM 7 ORDER BY rule_consequent, rule_number;

Resultado pode ser visualizado na Figura 6.9. Primeiramente sāo apresentadas as regras que classificam os clientes como ruins e posteriormente as que classificam os clientes como bons.

2. Dezoito regras classificam os cliente como GOOD e dez regras classificam os clientes como $B \Lambda D$. Consulta realizada:

SELECT rule_consequent, count (*) EROM 7 group by ruie_consequent;

Resultado apresentado na Figura 6.10.

3. As regras apresentam uma precisāo bastante alta. Consulta realizada:

SELECT RULE NUMBER, aCC FROM 7 ORDER BY aCC desc, rule number asc;

Parte do resultado desta consulta pode ser observado na Figura 6. 11.

4. Dezessete das vinte e oito regras (aproximadamente 60\%) apresentam precisào maior que 0,95 . Consulta realizada:

SELECT count (*) FROM 6 WHERE aCC > 0.95 ; 


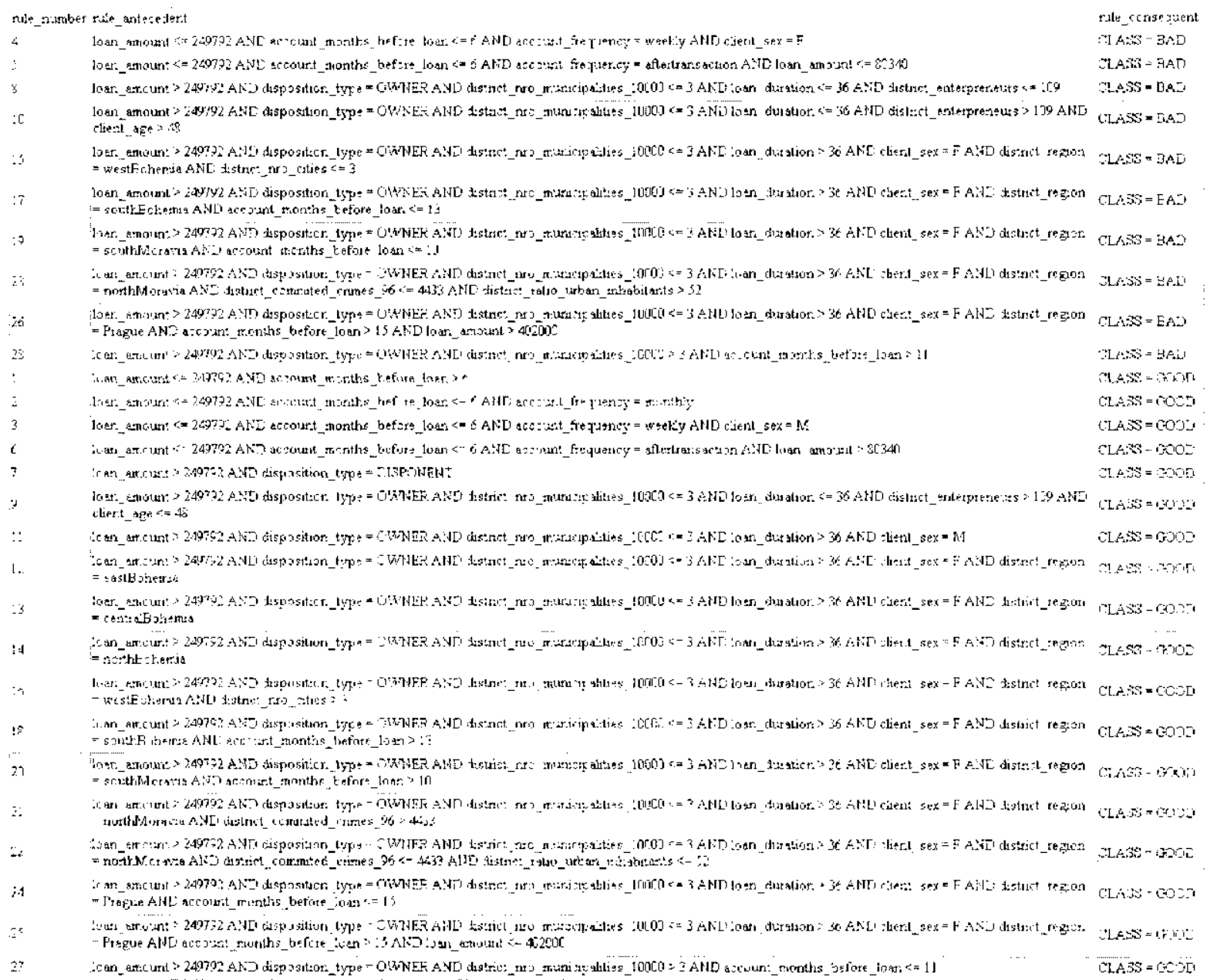

Figura 6.9: Regras que Classificam os Clientes como $B A D$ ou $G O O D$

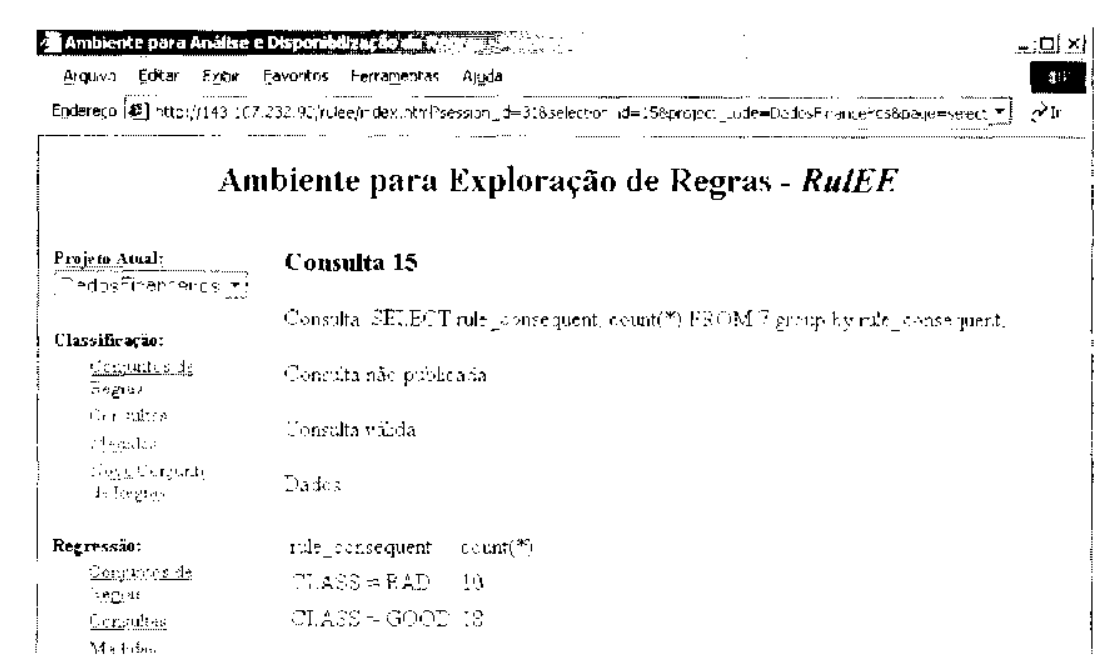

Figura 6.10: Quantidade de Regras que Classificam como BAD c GOOD

5. Pela verificaçāo da precisāo rclativa, observa-se que as regras que classificam os clientes como $B A D$ apresentam. em geral, uma precisāo relativa alta. As regras que 
classificam os clientes como GOOD apresentam, em geral, uma precisão relativa baixa. Consulta realizada:

SELFCT RLIJ NUMEER, racC, ruie consegient FROM 7 ORDER BY racc desC; Resultado apresentado parcialmente na Figura 6.12.

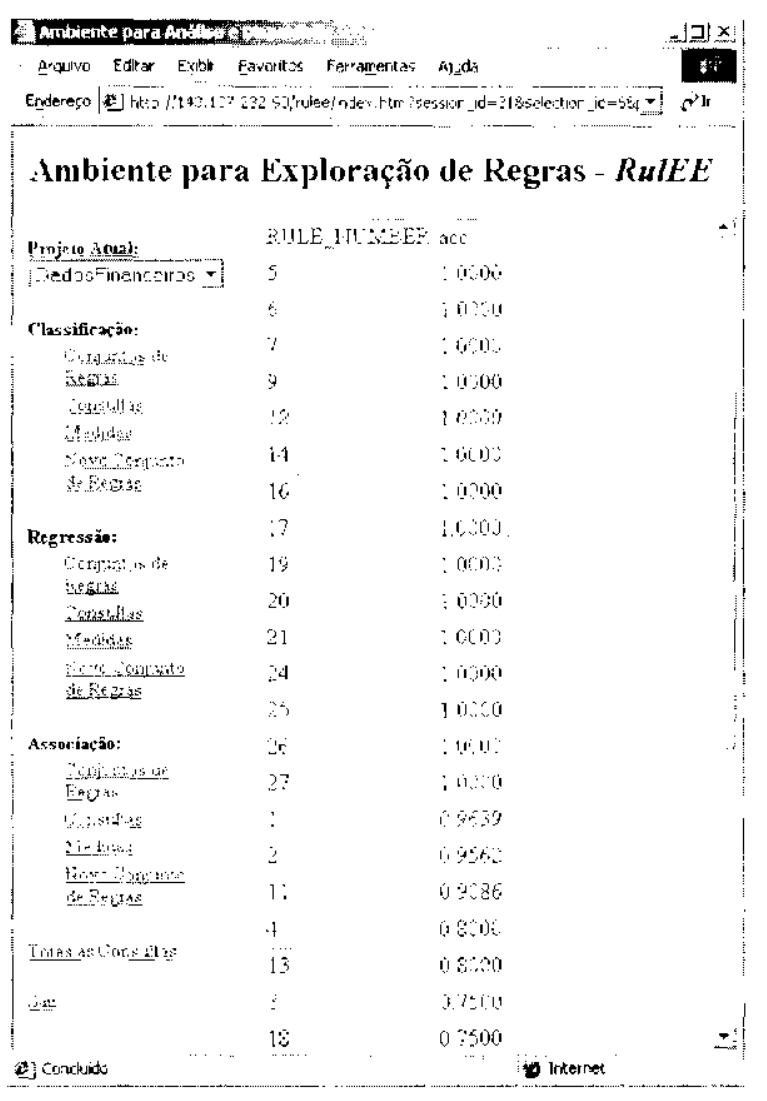

Figura 6.11: Precisão das Regras

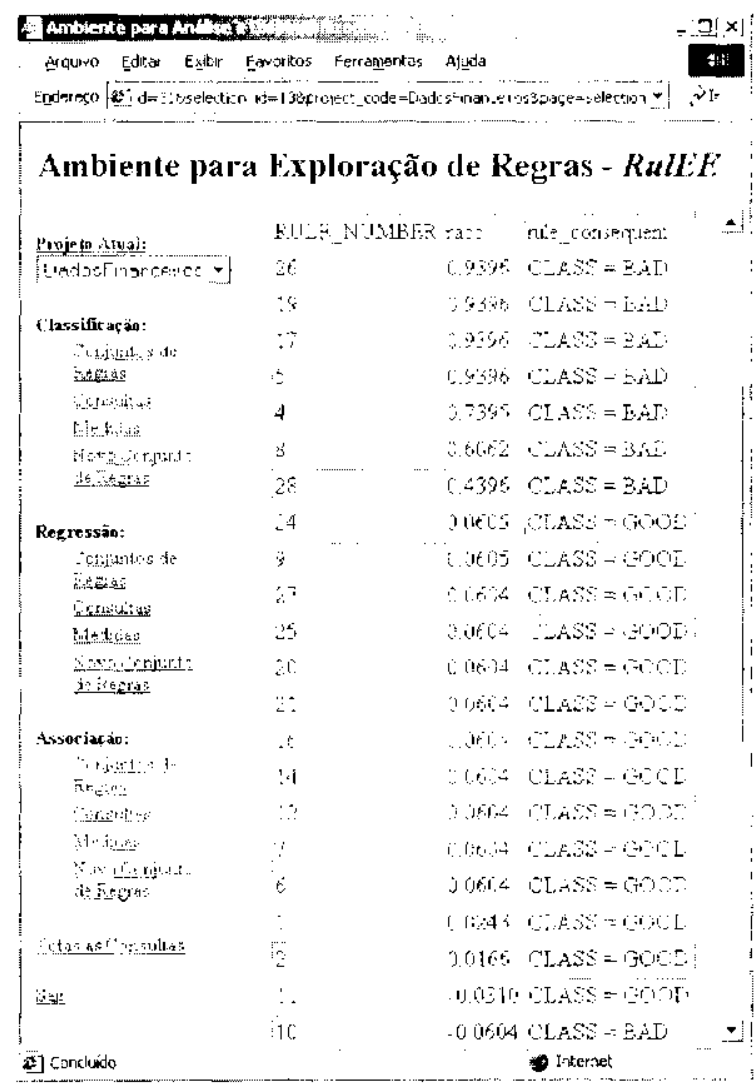

Figura 6. 12: Precisão Relativa

6. A precisăo relativa média das regras que classificam os clientes como BAD é 0.792 . A precisão relativa média das regras que classificam os clientes como GOOI) é 0. (0)íl. Neste resultado, foram consideradas somente as regras que apresentam precisāo relativa maior que zero. Consulta realizada:

SELECT avg(racc), rule consequent FROM 7 where racc $>0$

group by ruze_consequent: 
7. Poucas regras cobrem uma grande quantidade de exemplos. As quatro regras com maior cobertura (aproximadamente $14 \%$ do total) cobrem aproximadamente $90 \%$ dos exemplos. Consulta realizada:

SELECT sum(COV), count(*) FROM 7 WHERE COV > 0.02;

O resultado desta consulta pode ser observado na Figura 6.13.

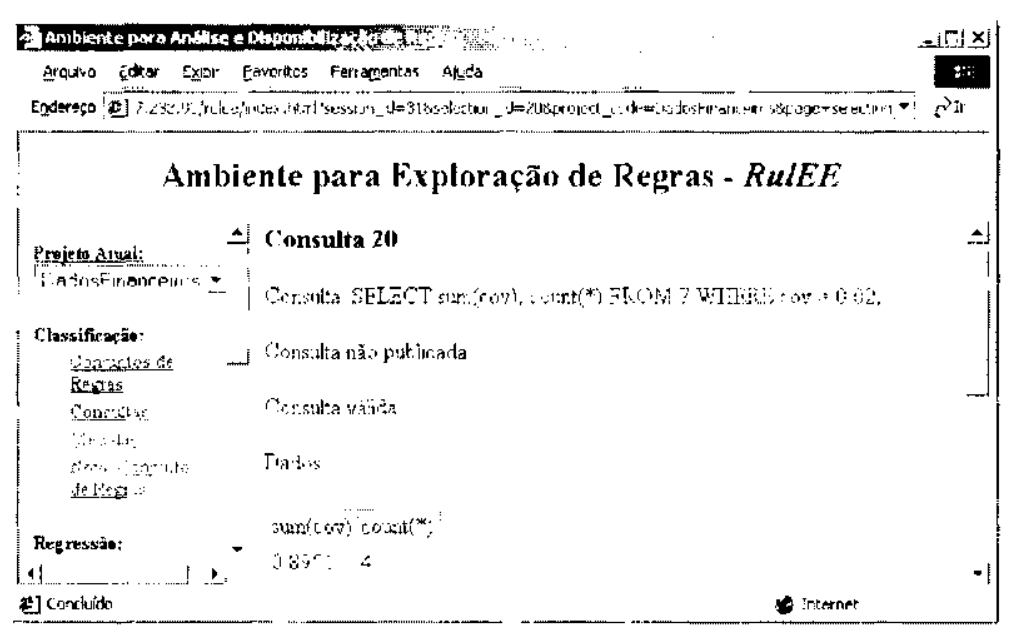

Figura 6.13: Soma da Cobertura das 4 Regras com Maior Cobertura

8. O numero de exemplos classificados incorretamente é trinta c um. Consulta realizada SELECT $\operatorname{sum}\left(\operatorname{COV}^{\star} \mathrm{n}^{\star}\right.$ err $)$ FROM 7

9. As dez regras que classificam os clientes como $B A D$ cobrem $3 \%$ dos registros. As dezoito regras que classificam os clicnte como GOOD cobrem 97\% dos registros. Consulta Realizada:

SELECT rule consequent, slim(cov), count (*) FROM 7 group by ruie_consequent;

10. As regras selccionadas utilizando a medida Novidade sāo oblidas utilizando a seguinte consulta:

SELECT RULE NUMBER, IIOV FROM 7 ORDER BY nOV desC;

P'arte do resultado desta consulta pode ser observado na Figura 6.14. 
11. $\Lambda$ s regras selecionadas utilizando a medida Especificidade sāo obtidas utilizando a seguinte consulta:

SELECT RJLE_NUMBER, SPEC FROM 7 ORDER BY spec desc;

Resultado apresentado parcialmente na Figura 6.15.

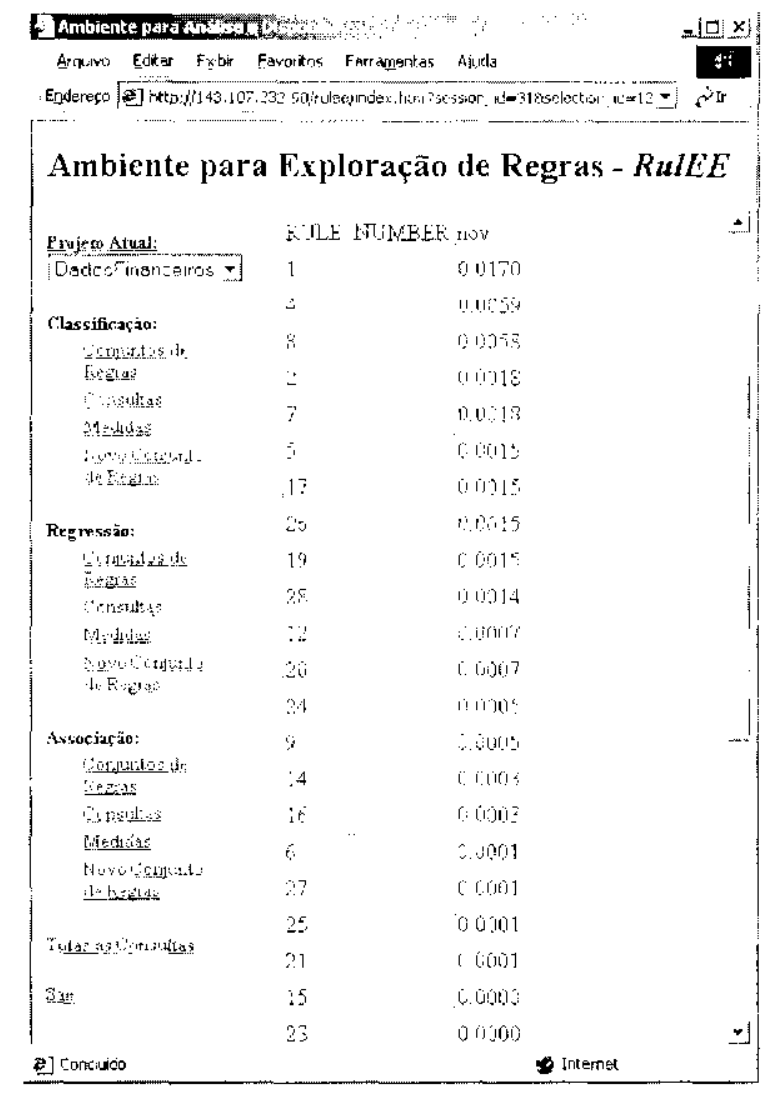

Figura 6.14: Valor da Medida Novidade para as Regras

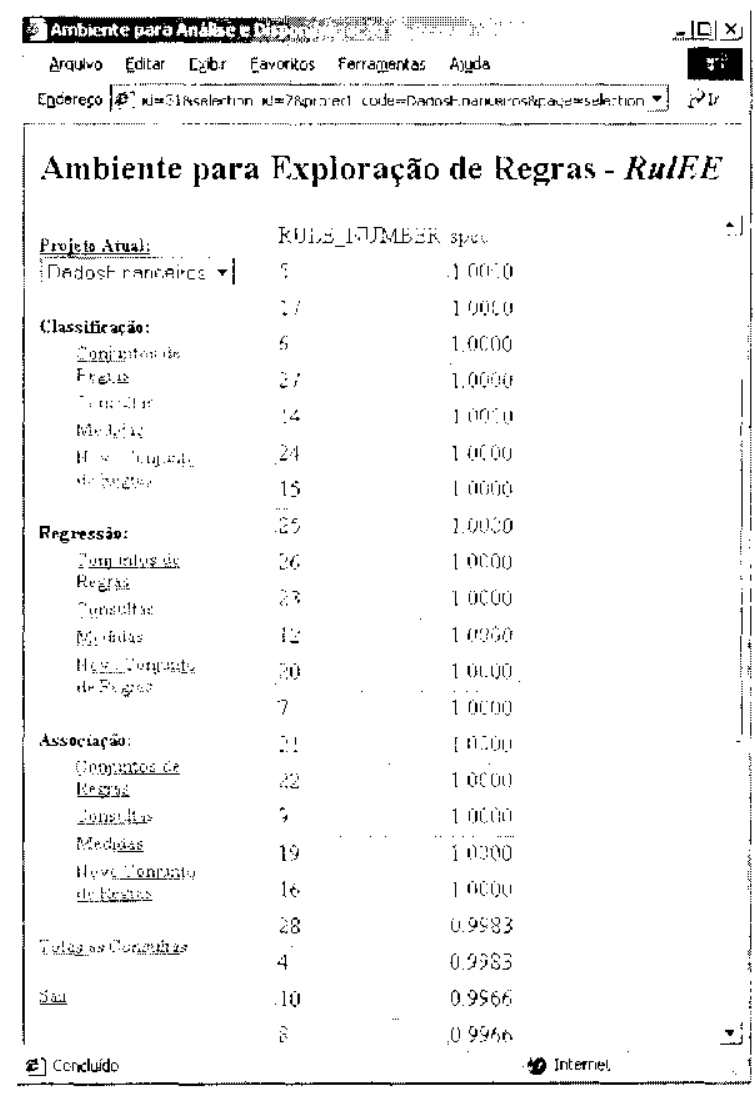

Figura 6.15: Valor da Medida Especificidade para as Regras

Essas 11 consultas foram apresentadas para exemplificar alguns tipos de análises que podem ser realizadas com o apoio do Ambiente RulEE.

\subsection{Considerações Finais}

Após a implementacão do Ambiente RulEE, foi realizado um estudo de caso, apresentado neste capitulo, com objetivo de verificar a utilizaçāo deste ambiente inserido no contexto de um processo completo de Mineração de Dados. Desta maneira, foram apresentadas todas as etapas realizadas para a obtenção das regras, como deve-se proceder para a utilização dessas regras no ambiente e alguns exemplos de análises das mesmas. 
O estudo de caso foi realizado no contexto de dados financeiros e o objetivo do processo de mineração foi encontrar regras que determinam se os clientes são bons, aos quais servicos adicionais devem ser oferecidos, ou ruins, que devem ser observados com mais cautela ao se oferecer serviços. Deve-se destacar. entretanto, que o objetivo principal deste capítulo foi mostrar algumas das funcionalidades do ambiente para exploraçāo de regras.

Pode-se observar neste capítulo que a análise dos conjuntos de regras pode ser bastante facilitada pela utilizaçāo do Ambiente RulEE. Algumas características do ambiente que auxiliam na análise de regras estão a possibilidade da utilização de diversas medidas de forma conjunta, utilização de medidas para ordenação e seleção de regras além do acesso facilitado aos conjuntos de regras e aos valores das medidas por meio da interface WWW que viabiliza a disponibilização das regras. 


\section{Capítulo 7}

\section{Conclusões e Trabalhos Futuros}

Com o desenvolvimento da tecnologia de Mineraçāo de Dados e sua utilizaçāo para solucionar problemas reais em processos de tomada de decisão, observou-se que a extração de padrōes nāo é a ctapa final dessc processo, tendo o P'ós-processamento do conhecimento um papel fundamental no sucesso do mesmo. A utilização efetiva do conhecimento descoberto $\mathrm{cm}$ um processo de apoio à tomada de decisāo depcnde de fatores como a possibilidade do usuário compreender esse conhecimento, conseguir identificar o conjunto de regras mais interessantes, entre outros. Assim, a avaliação dos conjuntos de regras quanto a precisào, compreensibilidade, utilidade e interessabilidade, por exemplo, é de extrema relevância no auxilio ao usuário final para viabilizar a utilização do conhecimento descoberto. Nesse sentido, muitos trabalhos relacionados ao processo de Mineraçāo de Lados têm sido desenvolvidos para avaliação do conhecimento descoberto.

Visando auxiliar os usuários na análise e utilização desses conjuntos de regras, foi proposto neste trabalho um Ambiente para Exploração de Regras que trata aspectos referentes à avaliação de conjuntos de regras de classificação, regressāo e associação. Nesse sentido, a principal contribuiçāo desta dissertação é o projeto e desenvolvimento de um Ambiente para Exploração de Regras denominado RulEE (Rule Exploration Environment).

O Ambiente RulEE apresenta uma arquitetura aberta para disponibilizaçāo de conjuntos de regras e valores de diversas medidas de avaliaçāo. Este ambiente auxilia os usuários finais e especialistas do dominio na análise. avaliação e identificação de regras interessantes através da visualização dos conjuntos de regras e da realização de análises pela utilização de medidas. A interação com os usuảrios é realizada por interface baseada ná WWW, visando facilitar o acesso aos conjuntos de regras. O ambiente apóia também os 
usuários analistas do processo de Mineração de Dados na criaçāo ou armazenamento de novas medidas em uma estrutura integrada, facilitando sua utilizaçāo conjunta.

O RulEE foi desenvolvido visando a criaçāo de um ambiente que apresente um Repositório de Regras no qual, após sua extraçāo, as regras são armazenadas e disponibilizadas para acesso pelos usuários do proccsso de Mineração de Dados. Alèm das regras, sāo armazenadas diversas medidas de avaliaçào para auxiliar o usuário na análise das mesmas. Identifica-se então o elemento principal do ambiente. o Repositório de Regras e Medidas.

O Repositório de Regras e Medidas armazena as regras em uma sintaxe padrāo e permite que, associada a cada regra, sejam armazenadas as medidas de avaliaçāo utilizadas para sua análise. Para cada regra é armazenada sua tabela de contingència. calculada utilizando scripts disponiveis no Ambiente Discover (Prati, Baranauskas, \& Monard 2001b: Prati, Baranauskas, \& Monard 200la; Pugliesi, Dosualdo, \& Rezende 2003; Melanda \& Rezende 2003). A partir desses valores, sāo calculadas no Ambiente RulEE as medidas Precisão, Erro, Confiança Negativa, Sensitividade, Especificidade, Cobertura, Suporte, Novidade, Satisfaçāo, Precisāo Relativa, Confiança Negativa Relativa, Sensitividade Relativa, Especificidade Relativa, P’recisāo Relativa Ponderada, Conflança Negativa Relativa Ponderada, Sensitividade Relativa Ponderada e Especificidade Relativa Ponderada, apresentadas no framework (Lavrac, Flach. \& Zupan 1999), e a medida $R I$ (Rule-Interest), proposta $\mathrm{cm}$ (Piatetsky-Shapiro 1991).

E importante destacar que o Repositório de Regras e Medidas do RulEE foi modclado de maneira que o ambiente seja independente das medidas de avaliação. O RulEE possui implementado o conjunto de medidas apresentadas anteriormente. mas os pesquisadores do processo podem acrescentar novas medidas pelo uso de medidas derivadas ou pela execução de procedimentos de Pós-processamento independentes do ambiente. Isto pode ser feito sem necessidade de alteração de código fonte, e qualquer nova medida pode ser utilizada de forma conjunta com as pré-existentes.

Neste trabalho foram identificados alguns requisitos importantes para um Ambiente para Exploração de Regras. Dentre eles, o Ambiente RuIEE viabiliza a Interatividade e Iteratividade na disponibilização dos conjuntos de regras e apresenta um conjunto de medidas de avaliação que pode ser utilizado de forma integrada na seleçāo e ordenação das regras. $O$ acesso aos conjuntos de regras é realizado pela WWW visando a utilizaçāo de alguns benefícios obtidos pela utilizaçào deste tipo de interface, como a independència de plataforma, facilidade de uso e especialmente a acessibilidade. Também como requisito implementado 
está a possibilidade dos usuários compartilharem suas análises no ambiente, assim como comentários, idéias e sugestōes.

Com a implementação do Ambiente RulEE, uma base de dados valiosa referente a conjuntos de regras e valores de medidas tornou-se disponivel. Somando-se outros tipos do dados fornecidos pelos usuários, tem-se um conjunto de dados em que pesquisas referentes ao processo de análise de regras podem ser feitas.

No LABIC vêm sendo desenvolvidos diversos trabalhos relacionados à avaliaçāo de conhecimento. A fim de integrar esses trabalhos, bem como os relativos a outras etapas do processo de Mineração de Dados, está sendo desenvolvido o Ambiente Discover. No Discover foram desenvolvidas sintaxes padrào para representaçāo de dados, regras de classificação, regressão e associação, assim como scripts para manipulação desses dados e conjuntos de regras. O Ambiente RulEE utiliza esses trabalhos permitindo que a saida de uma grande variedade de algoritmos utilizados em Mineraçāo de Dados possa ser disponibilizada, além de se apresentar como uma interface para a disponibilizaçāo do conhecimento descoberto.

Visando mostrar algumas das funcionalidades existentes no Ambiente RulEE, foi realizado um estudo de caso utilizando uma basc de dados financeira. Nesse estudo de caso foi realizada uma análise qualitativa das regras descobertas por meio de consultas no Repositório de Regras e Medidas. Pela realizaçāo dessas consultas, observou-se que a análise dos conjuntos de regras pode ser bastante facilitada. Entretanto, para que resultados satisfatórios sejam obtidos quanto ao objetivo final da análise dos dados do estudo de caso. seria necessária a participação dos especialistas do dominio e usuários finais do processo de Mineração de Dados em uma análise qualitativa dos conjuntos de regras, que não foi possivel devido a nāo disponibilidade dos mesmos.

A seguir, são apresentadas algumas propostas de trabalhos futuros que complementam o desenvolvimento relatado nesta dissertação e podem trazer novas contribuições para o processo de Extração de Conhecimento de Bases de Dados:

- Como qualquer ferramenta cujo objetivo è sua utilizaçāo por usuários nāo especialistas en computação ou Mineração de Dados, é extremamente importante para a aceitação da mesma que esta apresente uma interface intuitiva e de fácil utilização. Entretanto, a interface do Ambiente RulEE foi desenvolvida visando a disponibilizaçāo dos resultados do ambiente, ou seja, o foco principal nào foi sua usabilidade. Dessa maneira, diversos aspectos deven ser trabalhados nesta interface, dentre eles: 
- Desenvolvimento voltado a facilitar a navegaçāo e a identificaçāo das informaçōes. ou seja, considerando aspectos relativos à usabilidade da interface;

- Guanto à visualização dos conjuntos de regras pela interface, è interessante que no ambiente existissem várias maneiras para a visualizaçào das regras. Por exemplo, poderia haver alguma ferramenta para apresentação não textual, na qual o usuário pudesse interagir com o conjunto de regras. Tendo disponivel várias possibilidades para visualização, os usuários poderiam utilizar a que julgarem mais conveniente;

- Realizaçāo de uma análise dos erros que podem ocorrer durante a execução dos scripts referentes ao Ambiente RulEE. visando apresentar alguma descriçāo mais detalhada do erro e, assim, auxiliar os usuários na compreensāo do mesmo:

- Na implementação atual, a integração do Ambiente RulEE com o Discover é realizada através da utilização de conjuntos de regras representados nas sintaxes padrão e utilização de scripts de conversão de dados e regras, implementado para o Ambiente Discover. É interessante permitir que exista uma integração desses ambientes através de suas interfaces de forma que os conjuntos de regras extraidos pelo Discover pudessem ser disponibilizados no Ambiente RulEE de forma transparente:

- Um outro requisito importante de um ambiente cujo objetivo é auxiliar os usuários na análise de conjuntos de regras é que este viabilize a utilizaçāo de medidas subjetivas para avaliação de regras. Esta funcionalidade não está completamente implementada no ambiente. Nesse sentido, é de extrema importancia para o ambiente o desenvolvimento de trabalhos visando a utilização de medidas subjetivas;

- Um outro ponto a ser melhorado no Ambiente RulEE é o processamento das consultas. Na implementação atual, as consultas inseridas pelos usuários são mapeadas em novas consultas adequadas a serem executadas no Repositório de Regras e Medidas. sem a existência de um parsing completo das consultas inseridas pelos usuários. Um problema encontrado nesta abordagem ć quc não existe uma verificação de erros desenvolvida especificamente para o tratamento das consultas fornecidas pelos usuảrios, dificultando sua identificação e correção pclos usuários;

- Ao se utilizar grandes conjuntos de regras, o Ambiente RulEE apresentou problemas de desempenho. Por exemplo, o ambiente apresenta tempos de resposta elevados ao sc acessar conjuntos com mais de 2.000 regras. Devido ao grande número de regras 
normalmente extraídas pelos algoritmos de regras de associação, este problema deve ser solucionado. 


\section{Referências Bibliográficas}

Baranauskas, J. A. (2001). Extraçāo Automática de Conhecimento por Múltiplos Indutores. Tese de Doutorado. Instituto de Ciências Matemáticas e de Computaçāo, São Carlos, SP Brasil.

Baranauskas, J. A. \& G. E. A. P. A. Batista (2000). O projeto Discover: Idéias iniciais (comunicaçāo pessoal)

Baranauskas, J. A. \& M. C. Monard (2000). Reviewing some machine learning concepts and methods. Relatório Técnico 102, Instituto de Ciências Matemáticas e de Computação, São Carlos, SP - Brasil.

Batista, G. E. A. P. A. (2001). Sintaxe padrão do arquivo de exemplos do projeto discover. http://www.icmc.sc.usp.br $/ \sim$ gbatista/Discover/SintaxePadraoFinal.htm (último acesso: $21 / 01 / 2003)$

Batista, G. E. A. P. A., A. C. P. L. Carvalho, \& M. C. Monard (2000). Applying one-sided selection to unbalanced datasets. In Proceedings of the Mexican Congress on Artificial Inteligence MICAI, Lecture Notes in Artificial Inteligence, pp. 315-325.

Becker, B., R. Kohavi, \& D. Sommerfield (2002). Visualizing the simple bayesian classifier. In U. Fayyad, G. G. Grinstein, \& A. Wierse (Eds.), Information Visualization in Data Mining and Knowledge Discovery, pp. 237-249. Morgan Kaufmann Publishers.

Breiman, L. (2000). Some infinity theory for predictor ensembles. Relatório Técnico 577 , University of California, Berkeley.

Breiman. L., J. H. Friedman, R. A. Olshen, \& C. J. Stone (1984). Classification and Regression Trees. Pacific Groves, CA: Wadsworth.

Dietterich, T. G. (2000). Ensemble methods in machine learning. In J. Kittler and F. Roli, editors, Multiple Classier Systems, Lecture Notes in Computer Science, Volume 1857, pp. $1-15$ 
Fayyad. U. (1996). Data mining and knowledge discovery: Making sense out of data. IEEE Expert-Intelligent Systems \& Their Applications 11, 20-25.

Fayyad, U., D. I Iaussler, \& P. Stolors (1996). Mining scientific data. Communications of the ACM 39(11), 51-57.

Fayyad. U., G. Piatetsky-Shapiro, \& P. Smyth (1996). The KDD process for extracting useful knowledge from volumes of data. Communications of the ACM 39(1 1), 27-34.

Fertig, C. S., A. A. Freitas, L. V. R. Arruda, \& C. Kaestner (1999). A fuzzy beam-search rule induction algorithm. In Proceedings of the Third European Conference (PKDD-99) Lecture Notes in Artificial Intelligence 1704, pp. 341-347.

Félix. L. C. M. (1998). Data mining no processo de extração de conhecimento de bases de dados. Dissertação de Mestrado, Instituto de Ciências Matemáticas e de Computação, São Carlos, SP - Brasil.

Félix, L. C. M., S. O. Rezcnde, C. Y. Doi, M. F. Paula, \& M. J. Romanato (1998). MLC ' : Biblioteca de aprendizado de máquina em $\mathrm{C}^{++}$. Relatório Técnico 72 . Instituto de Ciências Matemáticas e de Computaçāo, São Carlos, SP - Brasil.

Félix, L. C. M., S. O. Rezende, M. C. Monard, \& C. W. Caulkins (2000). Transforming a regression problem into a classification problem using hybrid discretization. Computación y Sistemas 4, 44-52.

Foster, M. \& A. G. Gec (2002). The data visualization environment. In U. Fayyad, G. G. Grinstein, \& A. Wierse (Eds.), Information Visualization in Data Mining and Knowledge Discovery, pp. 87-93. Morgan Kaufmann Publishers

Freitas, A. A. (1998a). A multi-criteria approach for the evaluation of rule interestingness. In Proceedings of the International Conference on Data Mining, pp. 7-20.

Freitas, A. A. (1998b). On objective measures of rule surprisingness. In Proceedings of the 2nd European Conference on the Principles of Data Mining and Knowledge Discovery (PKDD-98), Volume 1510, pp. 1-9.

Freitas, A. A. \& S. H. Lavington (1998). Mining Very Large Databases With Parallel Processing. Kluwer Academic Publishers. 
Geromini, M. R. (2002). Projeto c desenvolvimento da interface gráfica do sistema discover. Exame de Qualificaçāo de Mestrado. Instituto de Ciências Matemáticas e de Computaçāo. São Carlos, SP - Brasil.

Glymour, C., D. Madigan, D. Pregibon, \& P. Smyth (1997). Statistical themes and lessons for data mining. Data Mining and Knowledge Discovery 1, $11 \cdots 28$.

Grinstein. G. G. \& M. O. Ward (2002). Introduction to data visualization. In U. Fayyad, G. G. Grinstein. \& A. Wierse (Eds.), Information Visualization in Data Mining and Knowledge Discovery. pp. 21-45. Morgan Kaufmann Publishers.

Kearns, M. J. \& U. V. Vazirani (1994). An introduction to computational learning theory. Ellis Horwood.

Keim, D. A. (2001). Visual exploration of large data sets. Communications of the ACM 44(8). $38-44$.

Klemettinen, M., H. Mannila, P. Ronkainen, H. Toivonen, \& A. I. Verkamo (1994). Finding interesting rules from large sets of discovered association rules. In Proceedings of the Third International Conference on Information and Knowledge Management, pp. $401-407$.

Klemettinen, M., II. Mannila, \& H. Toivonen (1996). Interactive exploration of discovered knowledge: A methodology for interaction, and usability studies. Relatório Técnico C1996-3, University of Helsinki. Finland.

Klemettinen, M.. H. Mannila, \& H. Toivonen (1997). A data mining methodology and its application to semi-automatic knowledge acquisition. In DEXA Workshop, pp. 670-677.

Kohavi. R., D. Sommerfield, \& J. Dougherty (1997). Data mining using MLC ${ }^{++}$: A machine learning library in $\mathrm{C}^{++}$. International Journal on Artificial Intelligence Tools 6(4), 537-566.

Lavrac, N, P. Flach, \& B. Zupan (1999). Rulc evaluatin measures: A unifying view. Lecture Notes in Artificial Inteligence 1634, 174-185

Lee, H. D. (2000). Selcção c construção de features relevantes para o aprendizado de máquina. Dissertação de Mestrado, Instituto de Ciências Matemáticas e de Computação. São Carlos, SP - Brasil.

Liu, B. \& W. Isu (1996). Post-analysis of learned rules. AAAI 1, 828-834 
Iiu, B., W. Hsu, S. Chen, \& Y. Ma (2000). Analyzing the subjective interestingness of association rules. IEEE Intelligent Systems \& their Applications 15(5), 47-55.

Liu, B., W. IIsu, \& Y. Ma (1999). Pruning and summarizing the discovered associations. In Proceedings of the International Conference on Knowledge Discovery and Data Mining (KDD-99), pp. 125-134.

Liu, B., W. Hsu, \& Y. Ma (2001). Identifying non-actionable association rules. In Procee dings of the International Conference in Knowledge Discover and Data Mining (KDD-OI), pp. $329-334$

Liu, B., W. Hsu, Y. Ma, \& S. Chen (1999). Mining interesting knowledge using DM-II. In Proceedings of the International Conference on Knowledge Discovery and Data Mining (KDD-99), pp. 430-434.

Liu, B., W. Hsu, L. Mun, \& H. Lee (1996). Finding interesting patterns using user expectations. Relatório Técnico TRA7/96, National University of Singapore.

Lyman, I'. \& II. R. Varian (2000). How much information? http://www.sims.berkeley.edu/research/projects/how-much-info/index.html (ültimo acesso: $12 / 02 / 2003)$.

Ma, Y., B. Liu. \& C. K. Wong (2000). Web for data mining: Organizing and interpreting the discovered rules using the web. SIGKDD Explorations 2(1), 16-23.

Melanda. E. A. \& S. O. Rezende (2003). Pós-processamento de regras de associação. Relatório Técnico em preparaçāo, Instituto de Ciências Matemáticas e de Compulaçāo. Sāo Carlos. SP - Brasil.

Monard, M. C., C. W. Caulkins, J. A. Baranauskas. R. B. T. Oliveira, \& S. O. Rezende (1999). Data preparation, reduction and prediction in the context of data mining, Relatorio Técnico 81. Instituto de Ciências Matemáticas e de Computaçāo. Sào Carlos, SP - Brasil.

Motroni, S. \& H. Vanderberg (2000). Mineset 3.0 enterprise edition interface guide. Silicon Graphics Inc. http://techpubs.sgi.com/library/manuals/4000/007-4005-001/pdf/0074005-001.pdf (ültimo acesso: 21/01/2003).

Padmanabhan, B. \& A. Tuzhilin (2000). Small is beautiful: Discovering the mininmal set of unexpected patterns. In Proceedings of the International Conference in Knowledge Discover and Data Mining (KDD-0O), pp. 54-63. 
Paula, M. F. \& S. O. Rezende (2003). Ambiente para exploraçào de regras RulEE. Relatório Técnico em preparaçāo. Instituto de Ciências Matemáticas c de Computaçāo, São Carlos, SP - Brasil.

Pazzani. M., S. Mani, \& W. Shankle (1997). Comprehensible knowledge discovery in databases. In Proceedings of the Nineteenth Armual Conference of the Cognitive Science Society. Lawrence Erlbaum, pp. 596-601.

Pazzani, M. J. (2000). Knowledge discovery from data? IEEE Intelligent Systems 15(2), $10-13$

Piatetsky-Shapiro. G. (1991). Discovery, analysis and presentation of strong rules. In Knowledge Discovery in Dalabases, pp. 229-248.

Piatetsky-Shapiro, G. \& C. J. Mathcus (1994). The interestingness of deviations. In Proceedings of the International Conference on Knowledge Discovery and Data Mining (KDL)-94), pp. $23-36$.

Prati, R. C., J. A. Baranauskas, \& M. C. Monard (2001a). Extraçāo de informaçōes padro nizadas para a avaliação de regras induzidas por algoritmos de aprendizado de máquina simbólico. Relatório Técnico 145, Instituto de Ciências Matemáticas e de Computaçāo, Sāo Carlos, SP - Brasil.

Prati. R. C.. J. A. Baranauskas, \& M. C. Monard (200 lb). Uma proposta de unificação da linguagem de representaçào de conceitos de algoritmos de aprendizado de máquina simbólicos. Relatório Técnico 137, Instituto de Ciências Matemáticas e de Computação. Sào Carlos. SP Brasil.

Pugliesi, J. B., D. G. Dosualdo, \& S. O. Rezende (2003). Pós-processamento de regras de regressāo. Relatório Técnico em preparação, Instituto de Ciências Matemáticas e de Computação, São Carlos, SP - Brasil.

Rezende. S. O.. J. B. Pugliesi, E. A. Melanda, \& M. F. Paula (2003). Mineração de dados. In S. O. Rezende (Ed.), Sistemas Inteligentes: Fundamentos e Aplicaçōes, pp. 307-335. Manole.

Rocha, C. (1999). Redes baysianas para extração de conhecimento de bases de dados considerando a incorporação de conhecimento de fundo e tratamento de dados incompletos. Dissertação de Mestrado, Instituto de Ciências Matemáticas e de Computação, São Carlos, SP - Brasil. 
Silberschatz. A. \& A. Tuzhilin (1995). On subjective measures of interestingness in knowledge discovery. Proceedings of the First International Conference on Knowledge Discovery and Data Mining 1, 275-281.

Silberschatz, A. \& A. Tuzhilin (1996). What makes patterns interesting in knowledge discovery patterns. IEEE Transactions on Knowledge and Data Engineering 8(6). 970-974.

Tamayo, P., J. Berlin, N. Dayanand, G. Drescher, D. R. Mani, \& C. Wang (1997). Darwin: A scalable integrated system for data mining. Thinking Machines Corporation. http://otn.oracle.com/products/datamining/pdf/darwin_arch.pdf (último acesso: $21 / 01 / 2003)$.

Thearling. K. B. Becker, D. DeCoste, W. D. Mawby. M. Pilote, \& D. Sommerficld (2002). Visualizing data mining models. In U. Fayyad, G. G. Grinstein. \& A. Wierse (Eds.), Information Visualization in Data Mining and Knowledge Discovery. pp. 205-222. Morgan Kaufmann Publishers.

Thuraisingham, B. (1999). Data Mining: Technologies, Techniques. Tools. and Trends. CRC Press.

Tsur, D., J. D. Ullman, S. Abitcboul, C. Clifton, R. Motwani, S. Nestorov, \& R. A. (1998). Query flocks: $\Lambda$ generalization of association rule mining. In Proceedings of the ACM SIGMOD Conference, pp. 1-12.

Weiss, S. M. \& N. Indurkhya (1998). Predictive Data Mining: A Practical Guide. Morgan Kaufmann Publishers, Inc., San Francisco, CA.

Witten, I. H. \& E. Frank (1999). Data Mining: Practical Machine Learning Tools and Techniques with Java Implementations. Morgan Kaufmann Publishers.

Zuffo, J. A. (2002). A Sociedade e a Economia no Novo Milênio - Os empregos e as empresas no turbulento alvorecer do século XXI. Manole. 